\title{
A Review of Optical Nondestructive Visual and Near-Infrared Methods for Food Quality and Safety
}

\author{
Jarmo T. Alander, ${ }^{1}$ Vladimir Bochko, ${ }^{1}$ Birgitta Martinkauppi, ${ }^{1}$ \\ Sirinnapa Saranwong, ${ }^{2}$ and Timo Mantere ${ }^{1}$ \\ ${ }^{1}$ Department of Electrical and Energy Engineering, University of Vaasa, 65101 Vaasa, Finland \\ ${ }^{2}$ Bruker Optics KK, 1-4-1 Shinkawa, Chuo-ku, Tokyo 104-0033, Japan \\ Correspondence should be addressed to Jarmo T. Alander; jal@uwasa.fi
}

Received 3 October 2012; Revised 24 December 2012; Accepted 31 January 2013

Academic Editor: Jaan Laane

Copyright (C) 2013 Jarmo T. Alander et al. This is an open access article distributed under the Creative Commons Attribution License, which permits unrestricted use, distribution, and reproduction in any medium, provided the original work is properly cited.

\begin{abstract}
This paper is a review of optical methods for online nondestructive food quality monitoring. The key spectral areas are the visual and near-infrared wavelengths. We have collected the information of over 260 papers published mainly during the last 20 years. Many of them use an analysis method called chemometrics which is shortly described in the paper. The main goal of this paper is to provide a general view of work done according to different FAO food classes. Hopefully using optical VIS/NIR spectroscopy gives an idea of how to better meet market and consumer needs for high-quality food stuff.
\end{abstract}

\section{Introduction}

Consumers are the driving force in the food market. They have become more health conscious, demanding and willing to pay for the "good quality." The consumers' trust for food industry has been diminished due to food scandals thus making it important to improve the safety monitoring.

The "quality" and "safety" have different meanings and aspects which depend on the food class, target market, criteria, and application. In some sense, the safety is part of the quality but here we separate these two because we like to emphasize the difference between how a human perceive the food and how we can evaluate threats of health. Some unsafe food cannot be detected by manual inspection. The food quality and safety evaluation has become more important and the need for more comprehensive assessment for all food batches is adequate.

Even though a lot of research and development work has been done on food safety and quality, more needs to be done to find economic ways of monitoring food safety. In this paper, our purpose is to go through the subject according to Food and Agriculture Organizations of the
United Nations (FAO) categories (http://www.fao.org/) and publications related to quality and safety. These two factors can be evaluated in many different methods and techniques.

The traditional methods are sensory evaluation, chemical analysis, and microbiological analysis. A more recent approach in technical sense is optical techniques, especially the multispectral methods in visual and near-infrared wavelengths. The optical methods can be used for nondestructive, fast, real-time, online monitoring of all samples (Huang et al. [1]). Table 1 gives a general comparison of these four approaches.

The sensory evaluation is the oldest method and still used every day. The evaluation is done by both consumers and professional food observers. It is relatively fast but hardly suitable for a large amount of samples due to many reasons like observer's fatiguing. The reliability varies with food item group and by person. The results are typically very subjective, depending on many non-food-related factors, and difficult to evaluate quantitatively.

The chemical analysis is an objective technique which often provides reliable results if the monitored batch is represented well by the samples measured. It has some 
TABLE 1: Comparison of method properties.

\begin{tabular}{lcc}
\hline Method & Subjective/objective & Sample/all \\
\hline Sensory & Subjective & All \\
Chemical & Objective & Sample \\
Microbiological & Objective & Sample \\
NIR & Objective & All \\
\hline
\end{tabular}

limitations-the processes may not work correctly due to some substances, the need of accurate and correct calibrations, the need of complex multiphased processing, and the need of experts for the analysis. It might not be suitable if the distribution of the substance content is nonuniform. It cannot provide a point measurement of the sample, only an average over the whole sample. Since the sample is destroyed, chemical analysis cannot be used for monitoring all food units. In addition, the price of the analysis per measurement may be quite high and it produces toxic waste; thus, the number of samples for monitoring must be limited due to economic and ecological reasons. It is generally not very well suited for fast, online product management.

The microbiological analysis is usually applied to detect biological organism like fungi or bacteria but not so much for identifying other content. It gives often objective and reliable results provided that, for example, the culture do grow, the growth is detectable, or the sample is not contaminated by some other sources. The analysis is typically slow and more tedious and expensive than the previous two methods. The microbiological analysis is suitable only for low speed, offline monitoring using a representative sample set of the batch. The main problem is that it allows defective products to be manufactured even though the cheapest solution might be to immediately stop processing and clean up the manufacturing unit.

To overcome the disadvantages and limitations of the previous methods, new economic, fast, and environment friendly techniques are sought after. As a result, optical multispectral measurements and imaging have recently become more and more popular in food measurements because they lend themselves easily to online monitoring of all samples even without touching the samples. The price of the measurement instruments has also decreased so they provide a viable option for the traditional methods. However, analysis of spectral measurements is often not easy and requires expertise. The mathematical and statistical models created might not be general and need to be adjusted to new conditions and products. Nowadays, a typical optical system employs ultraviolet (fluorescence) and visible wavelengths (VIS), near-infrared (NIR) or infrared (IR) areas or a combinations of them. The near-infrared spectrum is especially interesting since it is related to overtones and combinations of such chemical bonds as $\mathrm{C}-\mathrm{H}, \mathrm{O}-\mathrm{H}$, and $\mathrm{N}-\mathrm{H}$ which have influence on many properties of food.

1.1. History. Food and agriculture have been subjects for near-infrared (NIR) applications from the beginning of NIR measurement history. The earliest work which involved nondestructive moisture content determination of grain and seeds is published in [2] of the United State Department of Agriculture (USDA). Later, the success of NIR spectroscopy is marked by the establishment of wheat protein analysis throughout Canada by Phil Williams of the Canadian Grain Commission in 1975 [3]. In this area of application, at first, NIR was restricted to quality evaluation of low-moisture products such as cereal grains including wheat, corn, and soybean due to interference of water absorption in the long-wavelength region, especially in the combination area of 1900-2500 nm. In the latter stages of NIR applications, the development of silicon sensors allowed acquisition in the short-wavelength region of 700-1100 nm, leading to the analysis of thicker and higher-moisture samples such as fruit, fish, meat, and intact kernels. The use of the short-wavelength region allows nondestructive measurement of relatively thick samples since the electromagnetic wave in this region has better penetration because the absorption of water in this third overtone band becomes weak.

According to Osborne [4], the major limitation of using NIR spectroscopy for food analysis is its dependence on less precise reference methods. Since the chemical information of sample is analyzed from the changes in spectra, in most food samples NIR spectroscopy needs calibration against a reference method with the ingredient of interest.

Other optical methods have been studied for food quality lately by many researchers, for example, Farkas and Dalmadi [5], Kaffka [6], and Huang et al. [7]. The optical methods could alleviate these problems although they are not so accurate. Another advantage of optics is that it can be imaging and thus characterizing the sample better. A popular spectral area for food research has been near-infrared (NIR) in which many publications can be found like Huang et al. [7], Pallav et al. [8], Ozaki et al. [9], and Osborne [4].

Berrueta et al. [10] have recently made a review of supervised pattern recognition methods in food analysis. Reid et al. [11] have made a review of different food authentication methods including NIRS. Cen and $\mathrm{He}$ [12] give a review of NIR reflectance spectroscopy in determination of food quality.

$\mathrm{Du}$ and Sun [13] give a review of machine learning techniques such as neural networks and evolutionary optimization in computer vision for food quality.

\subsection{Optical NIR Measurements for Food}

1.2.1. NIR Measurement Modes. There are four standard measurement modes for the acquisition of NIR spectra from a sample: transmission, reflection, transflection, and interaction (interactance). Illustrations of these are shown in Figure 1. The selection of measurement mode depends on many factors like sample type or installment location. Generally, the design and implementation of measurement system and the selection of measurement mode require at least some expertise.

In the transmission measurement mode (Figure 1(a)), incident light propagates through the sample and is measured as it exits the sample at a point directly opposite to the light 


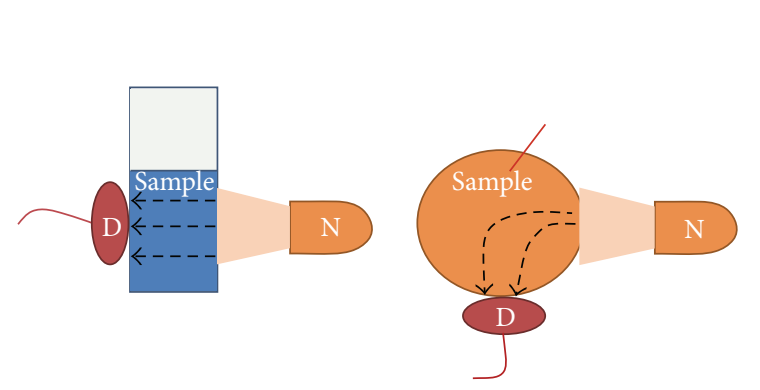

(a) Transmission

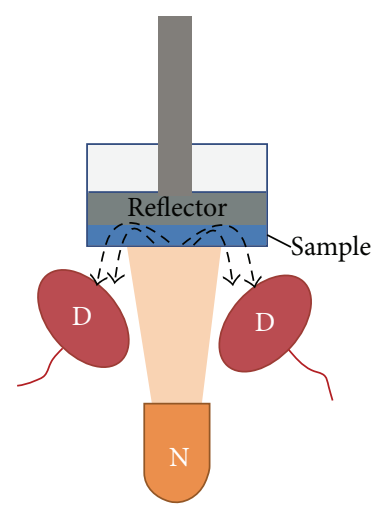

(c) Transflection

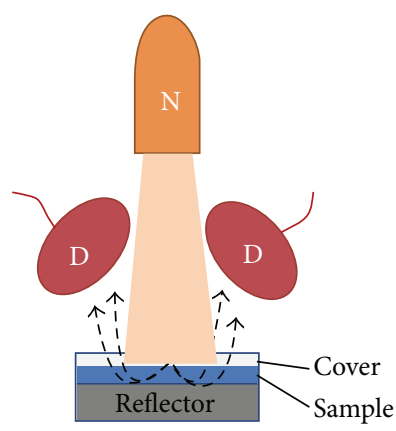

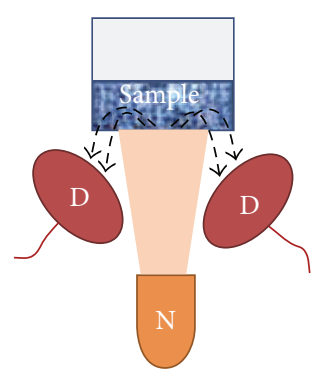

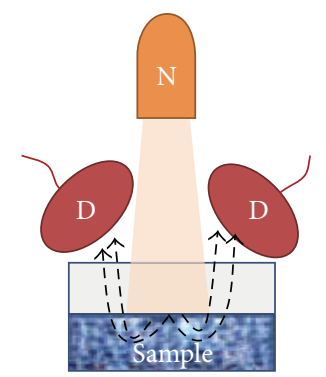

(b) Reflection

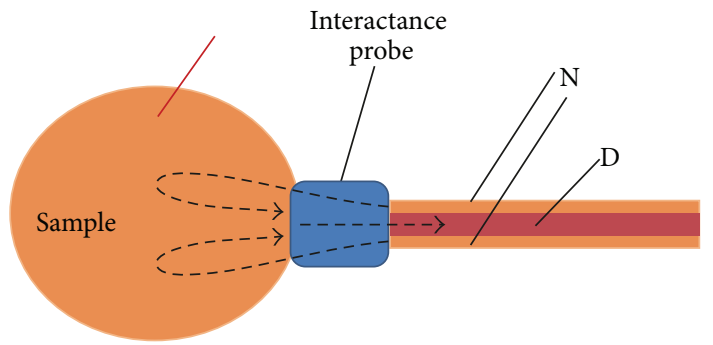

(d) Interaction

FIGURE 1: Sample presentation for near-infrared (NIR) spectroscopy. N: NIR light source, D: detector.

source. Occasionally, in the case of transmission for solid samples, the detector is placed at an angle of 90 degrees to the source.

For the reflection mode (Figure 1(b)), the light source and the detector are placed on the same side of sample. To avoid surface reflection, detectors are usually placed at an angle of 45 degrees to the sample plane. In some cases, an integrating sphere is used to concentrate light reflected from the sample before it reaches the detector by capturing and integrating light from various directions.

Transflection (Figure 1(c)) is the combination of transmission and reflection modes. The sample is positioned as if for reflection mode measurement, but a reflector is situated opposite to the light source on the far side of the sample, reflecting light that is transmitted through the sample back through the sample again to the detector. The samples, generally in liquid form, are placed in a holder of $0.1-0.3 \mathrm{~mm}$ width along the direction of light propagation. Therefore, the physical path length of transflection mode is double the sample thickness. Transflection is often used to reduce path length as the thinnest cuvette (standard sample holder for transmission measurements) is generally $1.0 \mathrm{~mm}$ thick. In some cases, transflection is employed for NIR instruments without transmission capability.

The fourth configuration, the interactance mode (Figure 1(d)), is also a combination of transmission and reflection but for solid samples. In this mode, the sample is illuminated by a fiber-optic cable(s) in direct contact with the sample surface or the sample holder. Light propagates inside the sample and interacts with the interior through reflection, transmission, and/or absorption. Fibre bundles that are placed on the same side as the source subsequently return the light that propagates inside the sample to the detector. The direct contact between the fibre bundles (for both the source and the detector) and the sample eliminates the effect of surface reflection and maximizes the penetration depth.

1.2.2. Types of Food Samples. From the product viewpoint, NIR applications in food and agriculture could be classified into three groups by the state of the sample: (i) liquid samples, (ii) ground and relatively small solid samples, and (iii) relatively large samples that require nondestructive or noninvasive measurement.

A benefit in working with samples from the first group (liquid samples) is the handling of optical path length. In the case of a clear liquid such as soy sauce, filtrated fruit juice, or vegetable oil, samples can be contained in a quartz cuvette, a disposable glass vial, or a transflectance sample holder, all of which would provide a relatively high consistency of optical path length due to the low scattering characteristics of the samples. The measurements used are transmission or transflection. The sample thickness can be adjusted based on the absorptivity of major composition(s) and the constituent of interest.

Figure 2 shows NIR spectra in the long-wavelength region of water and oil acquired in various physical path lengths. According to the figure, if the sample analyzed is water-rich and the constituent of interest has absorption 


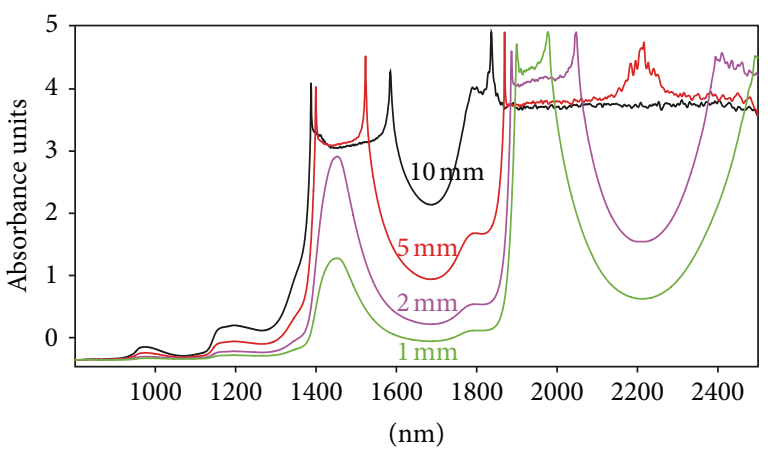

(a) Water measured at 1,2,5, and $10 \mathrm{~mm}$ path length

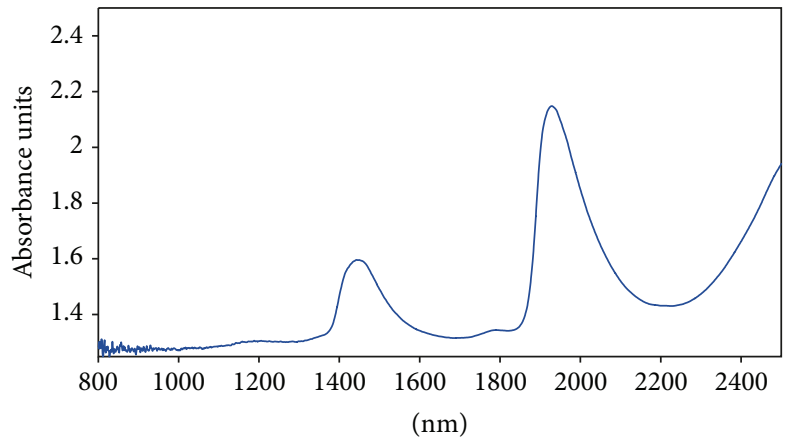

(b) Water measured at $0.2 \mathrm{~mm}$ path length

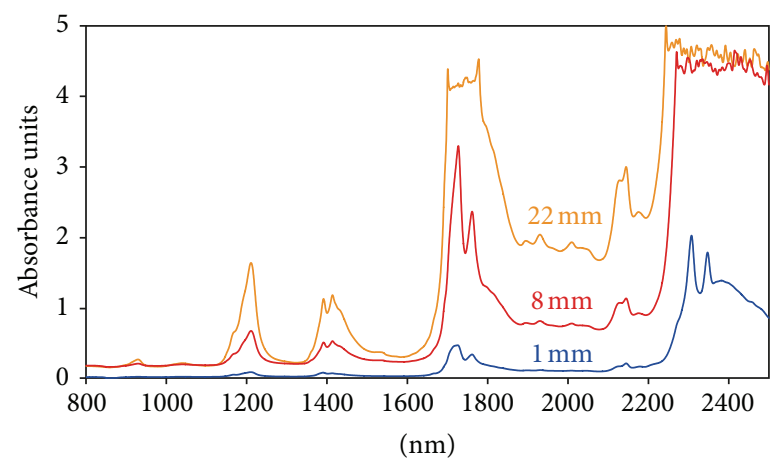

(c) Vegetable oil measured at 1,8 , and $22 \mathrm{~mm}$ path length

FIGURE 2: NIR spectra of water and oil measured at different path lengths. (a) Water spectra when the path length is 1, 2, 5, or 10 mm. (b) Water spectra when the path length is $0.2 \mathrm{~mm}$. (c) Vegetable oil spectra when the path length is 1,8 , or $22 \mathrm{~mm}$. The shape and level of measured spectra depend on the path length.

bands overlapped with water absorption, the appropriate physical path length would be $0.2 \mathrm{~mm}$ for the combination region measurement $(1800-2100 \mathrm{~nm}), 1.0 \mathrm{~mm}$ for the first overtone region ( $1400-1500 \mathrm{~nm}$ ), and $10 \mathrm{~mm}$ for the second overtone region $(900-1000 \mathrm{~nm})$. However, as a forementioned, the decision for optical path length is also dependent on the molar absorptivity, that is, the ability of a particular substance to absorb light at a given wavelength, and the concentration of that constituent of interest. In many cases, the constituent of interest has absorption bands on the shoulder of water bands such as in the region of $2100-$ $2300 \mathrm{~nm}$. In such cases, sample cells with longer physical path length, say $1 \mathrm{~mm}$, could be more appropriate than the $0.2 \mathrm{~mm}$ sample cell due to lower absorptivity of substances in this region.

On the other hand, if the sample is oil-based, sample cells with significant longer path length could be used due to the lower absorptivity of oil compared to water. In the case where the constituent of interest has very low absorptivity and/or concentration, for example, acid value or peroxide value in fresh vegetable oil, increasing physical path length to obtain adequate information is necessary.

However, one should keep in mind that the analysis of clear samples typically differs from that of the analysis of scattering samples. When colloids or suspensions are analyzed, the scattering characteristics of the samples are stronger, and thus the optical path length, that is, the actual distance that NIR wave travels, is much longer than that of clear samples. Due to this, the path length would have to be reduced. Figure 3 shows the NIR spectra of homogenized milk (colloid) and vegetable-mix juice (suspension) using a $4 \mathrm{~mm}$ path length. In this case, milk has a stronger absorption due to its composition and the scattering characteristics of the constituent small fat globules. Vegetable-mix juice has less absorbance compared to milk but stronger than that of water at $5 \mathrm{~mm}$ path length (for water, see Figure 2). This is due to the scattering characteristics of the constituent suspended particles.

1.2.3. Some Important Considerations for Measurements. Another point to be aware of for liquid samples with water as a major constituent is the importance of temperature control. It is well documented [14-17] that water absorption bands in the NIR region shift in both peak position and amplitude according to sample temperature, as the number of hydrogen bonds in the water molecules is temperature dependent. Increasing temperature results in a higher percentage of water molecules with fewer hydrogen bonds due to the higher kinetic energy. Therefore, in many cases, temperature control is necessary to perform precise NIR measurements. Since many oil-based samples are in solid or opaque form at room temperature, temperature control is required not mainly to maintain spectral consistency but to increase sample transparency. 


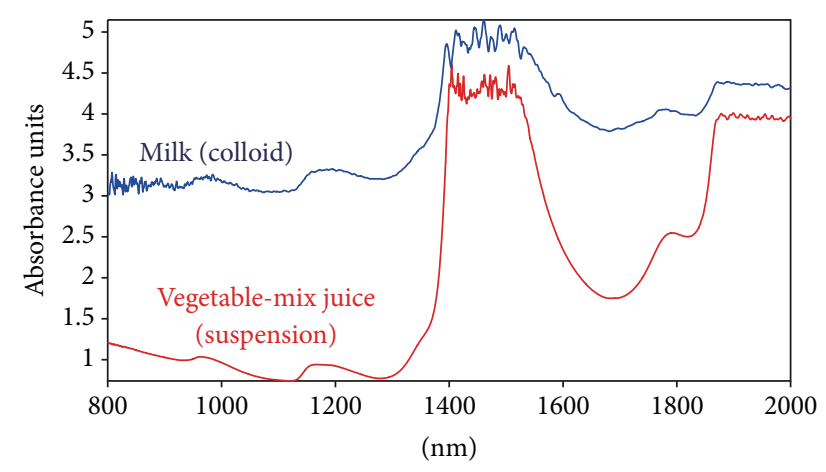

FIGURE 3: NIR of milk (colloid) and vegetable-mix juice (suspension) measured with $4 \mathrm{~mm}$ physical path length. Note: the preamplifier gain used for milk was stronger than that of vegetablemix juice due to very weak transmitted light.

For ground or small-particle samples, NIR spectra are usually acquired in reflection mode due to strong scattering characteristics. Such samples are generally placed in sample holders with quartz or glass windows. Quartz is more expensive but has lower $\mathrm{OH}$ absorption compared to glass resulting in better precision in some constituents, especially those with $\mathrm{OH}$ functional groups. However, in the case where the absorption of the constituent of interest occurs at different wavelength region than the $\mathrm{OH}$ absorption in glass and there is enough concentration of those constituents, it is possible to use glass-window sample holder or glass Petri dish. For many food manufacturers, the use of glass or quartz is prohibited and plastic such as a polystyrene dish is used as a sample holder. In that case, the absorption band of the constituent would fall within the absorption bands for polystyrene, especially in the combination region beyond $2000 \mathrm{~nm}$. If the absorption bands of the constituent can be precisely measured in the shorter-wavelength region by arranging an adequate path length and detector, the use of plastic dish would be applicable. For samples with a relatively coarse particle size, there is the possibility that light could pass through the space between samples and be lost. One way to reduce this problem is to place a reflector on the back side of the sample cell. During the measurement, spinning the sample cell will increase the acquisition area, thus reducing error due to sample nonuniformity especially in relatively coarse or large-particle samples. Examples of samples belonging to this group include ground and intact cereal grains, cereal meals such as soy bean meals or corn gluten meals, crushed processed foods/snacks, and powder milk or drink.

Finally, we consider samples that require nondestructive measurement. Samples in this group include meat, fish, intact fruit, and intact nut kernels. For the most part, these samples are sold intact and the constituent of interest is not evenly distributed between the surface and the sample core. To obtain information from deep inside the sample, two modes of measurement are used for this group: the interaction mode and the transmission mode. As mentioned earlier, most of the applications in this group use silicon detectors that allow spectral acquisition in the short-wavelength region of 700$1100 \mathrm{~nm}$. The measurement parameters could be moisture and sugar contents for intact fruit and fat, protein, and moisture content in meat and kernels, as well as detection of various internal disorders or pest in agricultural products.

To employ NIR spectroscopy for routine quality control, it is not enough to develop calibration equations. A system developer needs to consider various factors affecting calibration results including instrument status (source strength, detector responses, and wavelength selection mechanism), atmospheric effects (temperature and humidity), and physical conditions (dust, vibration, and stray light) as well as transferability of the equations developed between various instrument in the same period of time and the transferability to the newer version of instrument and software upon the end of instrument life span.

1.3. Chemometrics. Optical measurement results connected with chemical analysis and statistics are called chemometrics. Chemometrics has become an established technique for handling chemical data. Good reviews of chemometrics are provided by Geladi and Grahn [18], and Workman and Springsteen [19], and Koljonen et al. [20], which present a review of genetic algorithm optimization in chemometry. The next text is a short introduction for the subject, and for a deeper insight, the previous reviews are recommended.

The first step of chemometrics is to collect the data. This includes sample selection, measurements, and chemical analysis. The measurement geometry, measurement conditions, number of samples, and ingredients need to be very carefully designed and determined. The samples need to be representative of the food batches because interpolation or generalization of the model most probably does not work. The samples are first subjected to optical measurement and after that chemical analysis. One should also notice that the chemical analysis might sometimes provide unreliable results. Sometimes even the samples may change during time. The data should be divided into a training and test sets.

After the measurements, the equations to transform optical data to chemical data should be set up. Since many functions and equations are available, it might be useful to test a couple of them to select the best results. After the selection, the equations need to be solved and coefficients to be determined with the training set. A typical approach for modeling is regression. The training of the model can be understood as a "calibration." The optical methods are calibrated to produce the amount of a given substance or substances.

The training data should be subjected to detection of residuals, outliers, and nonlinearity. The outliers should be excluded and nonlinearity corrected if present. Otherwise the results might be distorted. Typically the number of wavelengths from the optical measurements needs to be reduced due to their high amount and interdependence. Many techniques are available for wavelength reduction (e.g., splines or Savitzky-Golay filtering).

Maybe the most often used regression models are multiple linear regression (MLR) or "ordinary" least squares 
(LS), ridge regression (RR), principal component regression (PCR), and partial least squares (PLS). The general equation for the regression is

$$
\begin{aligned}
y & =b_{0}+b_{1} x_{1}+b_{2} x_{2}+\cdots+b_{k} x_{k}+f \\
& =b_{0}+\sum_{i=1}^{k} b_{i} x_{i}+f=b_{0}+f+B X
\end{aligned}
$$

where $y$ is the response (from chemical analysis), $x_{k}$ are the predictors (from optical measurements, $k$ pieces), $b_{k}$ are the regression coefficient to be determined, $b_{0}$ is the offset and a constant factor, and $f$ is the residual. If $X$ and $y$ are meancentered, then $b_{0}=0$.

The solution for regression coefficient for the LS is

$$
b=\left(X^{T} X\right)^{-1} X^{T} y
$$

where $T$ means transpose of the matrix. The LS may not work since the inverse might not exist or may be unstable. It is also notoriously sensitive to noise. The results should be also diagnosed using the following method: coefficient of determination and root mean squared error of calibration. RR:

A better solution for problems related to inversion can be

$$
b=\left(X^{T} X+r I\right)^{-1} X^{T} y
$$

where $I$ is an identity matrix and $r$ is a ridge constant. The ridge constant should be as small as possible. However, there is no established method for the selection of the ridge constant or diagnostic of results.

PCR also provides an easy inversion of matrices. It requires applying the principal component analysis (PCA) to reduce dimensions of $X$ and to obtain the eigenvectors. The eigenvectors are orthogonal. The PCA also reduces the noise present in $X$. The equation for regression can be formulated as

$$
y=V d+f, \quad d=\left(V^{T} V\right)^{-1} V^{T} y,
$$

where $V$ is the principal components and $d$ contains coefficients. The number of components needs to be determined by testing and checking.

Assume that $y$ matrix consists of several measurements of $y$. PLS decomposes both $y$ and $X$ matrices. It also removes noise in both of these matrices. Its formulae are

$$
\begin{aligned}
& y=U Q^{T}+F, \\
& X=T P^{T}+E,
\end{aligned}
$$

where $T$ and $U$ are projections (principal components) of $X$ and $y$ on eigenvectors and $P$ and $Q$ are eigenvectors of $X$ and $y$. The projections are obtained by decomposing the corresponding matrix. Error terms are marked as $E$ and $F$.

Both PLS and PCR calculate one component at a time using regression between $t$ and $u$. Then a residual is calculated and the calculation of the next component is based on this residual.
The obtained results for equations need to be evaluated by using the test set. The predicted values are calculated using test values from the optical measurement set and parameters obtained from the training phase. The difference between actual and predicted values in the test set can be evaluated using the root mean squared error of prediction and the coefficient of determination.

The visualization gives a good view of how the model is working. This could be done, for example, by plotting root mean squared error of calibration, root mean squared error of prediction, calculated loading plot, residual versus sample, and residual versus predicted test value.

\subsection{Food Quality and Safety}

1.4.1. Safety Factors. We consider here food safety to factors which may cause danger to health either directly or indirectly.

(1) Foreign Bodies. A foreign body can be anything unwanted in a food product. It can be from the raw material for the product or external material added indeliberately; for example, the raw material can contain bones which are shattered to sharp bone fraction pieces during the manufacturing process. The product may be littered with machine parts due machine blistering or residues from other sources like pieces of plastic.

(2) Incorrect, Contaminated, or Phony Ingredients in Product. Incorrect food ingredients refer here to any material which should not be in the food. They can be residues from previous production like peanut remnants or accidently added wrong material. The food can be contaminated from external sources like manure or too much pesticide. The phony ingredients are deliberately added to generate more income from consumers or manufacturers. The phony items can be rip-offs like cheap wine sold as a more expensive version or even very dangerous ones like melanin milk.

(3) Spoilage. The spoilage is considered in this paper as a decomposition of the food. It is often a byproduct of the activity of harmful bioagents like fungi or bacteria. Other causes are wrong handling, like overheating, freezing or wrong harvesting time, wrong environment, like too hot environment or environment that has gases like ethene which mature fruits too fast, or age.

(4) Bioagents: Fungi, Yeast, and Molds; Microbes, Bacteria, and Viruses. Fungi, yeast, or molds can be used in the production of certain food, but usually they are serious quality problems. This paper concentrates on articles on harmful effects of the bioorganisms like food poisoning or infections. The detection of smaller bioorganisms like bacteria or viruses is usually very hard due to their small size.

1.4.2. Quality Factors. Food quality consists of several factors. The validity or importance of a factor depends on the food group and on the evaluator. For example, the fat content is irrelevant for apples but very relevant for meat. The factors for this paper are appearance and taste.

(1) Appearance. The appearance of food is related to the visual experience of the product. It is affected by the perceived colors 
and textures as well as personal preferences and opinions. The environment in which the food is presented has its own effect. Since the color perceived depends on the prevailing illumination, for example, there are already available special lamps to emphasize the color of meat. Good texture can be achieved with proper processing.

(2) Taste. Taste is composed of several ingredients and is affected greatly by smell and also appearance. In this paper, we limit the taste to the actual food ingredients or state-like amount of sugar or acidity.

Smell. The smell can be used to separate bad food from good food. It is also essential to make food more delicious.

Juiciness. One attribute especially for fruit is juiciness. It is related to the water content and distribution of fruits.

Noise. Consumers often expect certain noise when eating food like cereals.

Freshness. Freshness is important especially for fish and other sea products.

Authentication. Some food products have been falsified. An example of this kind of products is wine. Spectral methods can be used to separate authentic wine from nonauthentic wine. The NIR spectra is used for food authentication by Sun [21].

Essential Ingredients. Food can contain many elements which have positive effects on health. These elements include, for example, flavonoids and vitamins in plants flavonoids and vitamins or omega- 6 fatty acid in fish. It is generally thought that the higher the amount obtained from food the better the effect on health. Ingredients can be correlated using chemometrics.

Unwanted Ingredients. Food contains also ingredients which consumers want to avoid for real or imaginary reasons. These ingredients can be preservatives which can in fact make the food safer. Other harmful ingredients include excessive amount of fat or salt.

Unwanted Objects. Although food can be perfectly safe and edible, it can still contain unwanted objects. This kind of objects can range from machine parts to stones and insect parts.

In their book, Workman and Weyer [22] explain theoretical backgrounds on how different qualities can be analyzed and found from NIR spectra; these qualities include alkanes and cycloalkanes, methylene groups, alkenes and alkynes, aromatic compounds, hydroxyls, water, carbonyls, amines and amides, carbohydrates, amino acids, peptides, and proteins.

High Quality. Affordable price consistently.

Chemometric Models. None known.

1.5. Optimization. Optimization with NIR spectroscopy is mostly connected with the selection of optimal wavelengths that correlate best with the object of interest. Usually we want to use as few wavelengths as possible, since the less the data needs to be analyzed the faster it is. However, we need to be sure that the selected wavelengths are adequate for reliable results.
A special type of genetic algorithms is called genetic programming (GP). It uses genetic algorithms to find a function or a program to solve a given problem. GP has been demonstrated to find solutions to problems that have been found by the most skilled engineers as patents and other inventions [23]. Another view of GP is to say that it is symbolic regression, that is, a method to find a function that best satisfies the given constraints. Yet another usage of GP is to find rules to explain data. GP is an extremely flexible method to solve computational intelligence problems. The main drawback of GP is its slow processing which prevents its usage in most online applications. However, in the systems design or similar phase, GP can be a nice tool to find good solutions automatically after the proper fitness function is implemented.

While spectroscopy produces huge amounts of raw data, there is a strong need to automatically process this data to compress it and to find the features that are relevant or correlate to those that are looked for. Norris and Williams [24] used wavelength selection so that they selected 12 wavelengths that produced the closest prediction with the required constituent in wheat measurements, particle size, and protein content. Goodacre and Kell [25] have demonstrated spectroscopical imaging GP applications related directly or indirectly to food quality. More specifically the application was to find the algebraic formula of the wavelengths that give the best discrimination between the bacterial samples examined. More generally the authors claim that GP is one potential tool to decrypt metabolomic data for biomedical applications.

With several materials, the VIS/NIR reflectance works best if the wavelengths used are optimized between 400 and $1800 \mathrm{~nm}$ [26]. This was also true with wholegrain measurement, where they found wavelengths between 1100 and $1400 \mathrm{~nm}$ giving the highest correlations with most of the constituents of interest with wholegrain measurements. However, the protein content was best determined from the 1700 to $2500 \mathrm{~nm}$ wavelength band.

1.5.1. Illustrative Example of Tomato Classification. The spectral methods lend themselves very well to fruit quality inspection. In this example, the transmittance spectra of tomatoes were measured using a spectrophotometer (Ocean optics). The spectra were further handled: they were smoothed to reduce noise and then downsampled by splines. An example of tomato spectra is shown in Figure 4. The transmittance is measured from $400 \mathrm{~nm}$ to $1000 \mathrm{~nm}$. The spectra differ in both visible and NIR areas. The difference is caused by the ripening process.

The spectral data itself contains a lot of information, part of which is in some cases irrelevant or redundant. The dimensionality of data can therefore be reduced. Here the locally linear embedding was used for this purpose in a nonlinear manner. The visualization of results can be seen in Figure 5, in which the feature space is spanned by the first two embedded components.

The kernel Fisher discriminant (KFD) was used to classify tomatoes into good and bad ones. As shown in Figure 5, the tomatoes are classified $100 \%$ correctly into these two groups. 


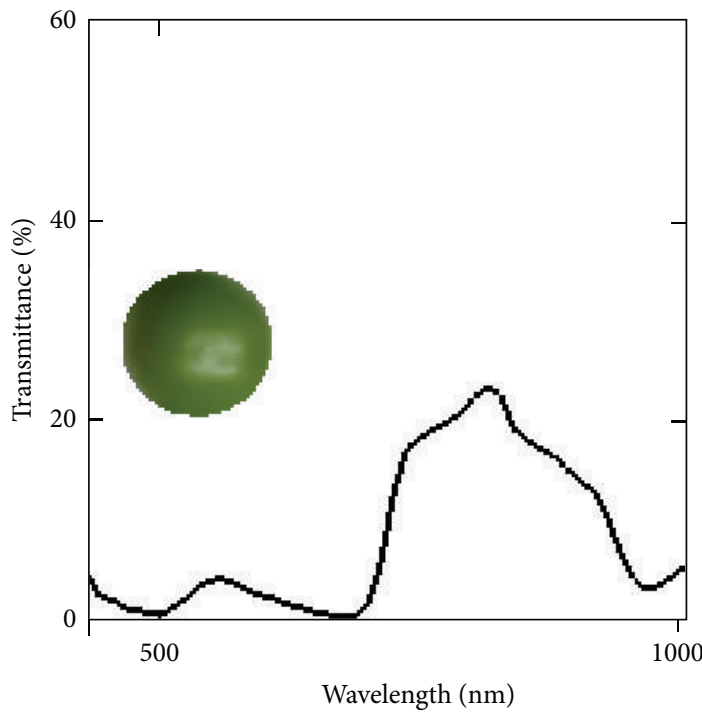

(a)

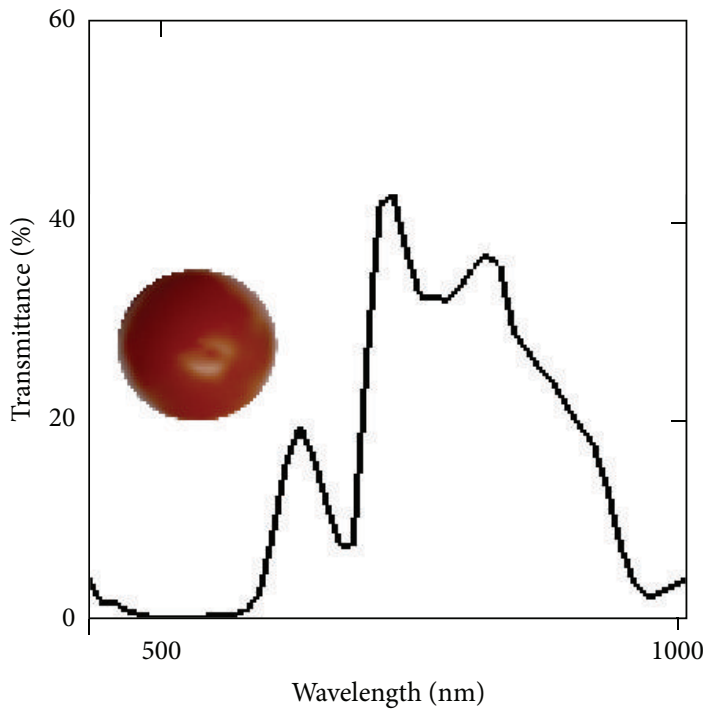

(c)

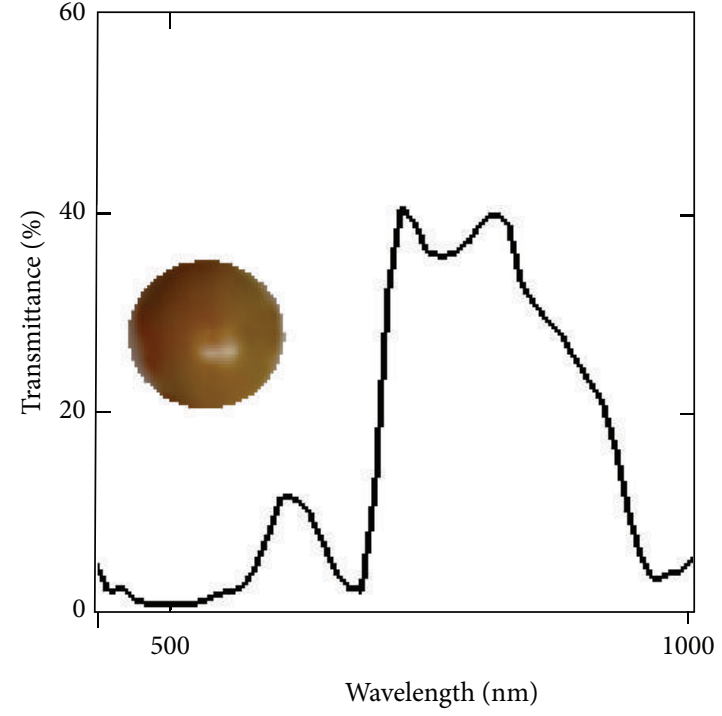

(b)

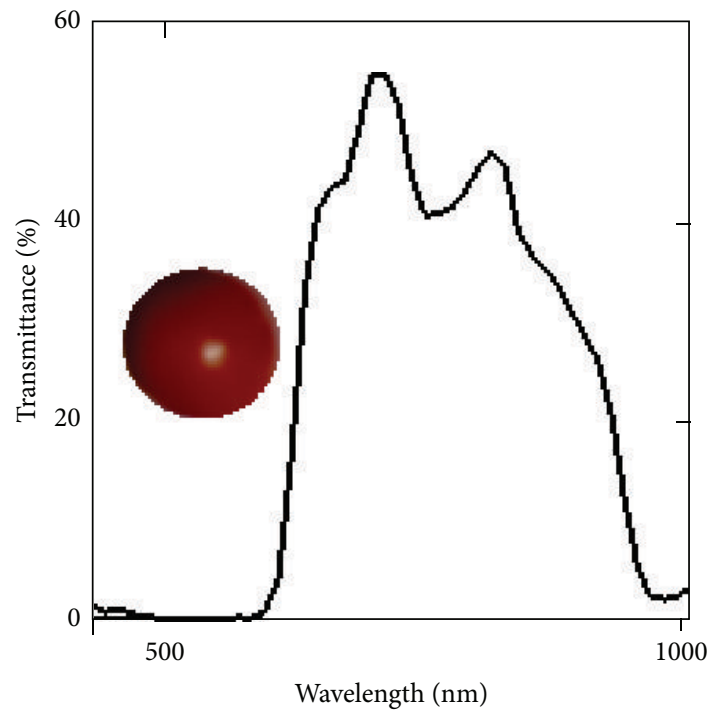

(d)

Figure 4: Transmittance spectra for different tomatoes of the same cultivar from $400 \mathrm{~nm}$ to $1000 \mathrm{~nm}$. (a) A raw tomato, (b) a partially raw tomato, (c) an acceptably ripe tomato, and (d) a ripe tomato.

The red-colored tomatoes are ripe while the yellow and green are raw. The boundary between the groups is visualized with red curve (Figure 5).

\section{Review of Hyperspectral/Multispectral Methods for Different Food Groups}

This paper follows the FAO classification in grouping food which divides the food and animal feed into five classes:

(i) class A-primary food commodities of plant origin,

(ii) class B - primary food commodities of animal origin,

(iii) class $\mathrm{C}$-primary animal feed commodities,

(iv) class $\mathrm{D}$ - processed foods of plant origin, (v) class $\mathrm{E}-$ processed foods of animal origin.

Each of these classes has subclasses. Class A consists of five subclasses: fruits, vegetables, grasses, nuts and seeds, and herbs and spices. Class B has the following classes: mammalian products, poultry products, aquatic animal products, amphibians and reptilians, and invertebrate animals. Class $\mathrm{C}$ has only one class, primary feed commodities of plant origin. Subclasses, which belong to class D, are secondary food commodities of plant origin, derived products of plant origin, manufactured foods (single ingredient) of plant origin, and manufactured foods (multi-ingredient) of plant origin. Class $\mathrm{E}$ is made of the following subclasses: secondary food commodities of animal origin, derived edible products of animal origin, manufactured food (single ingredient) of 


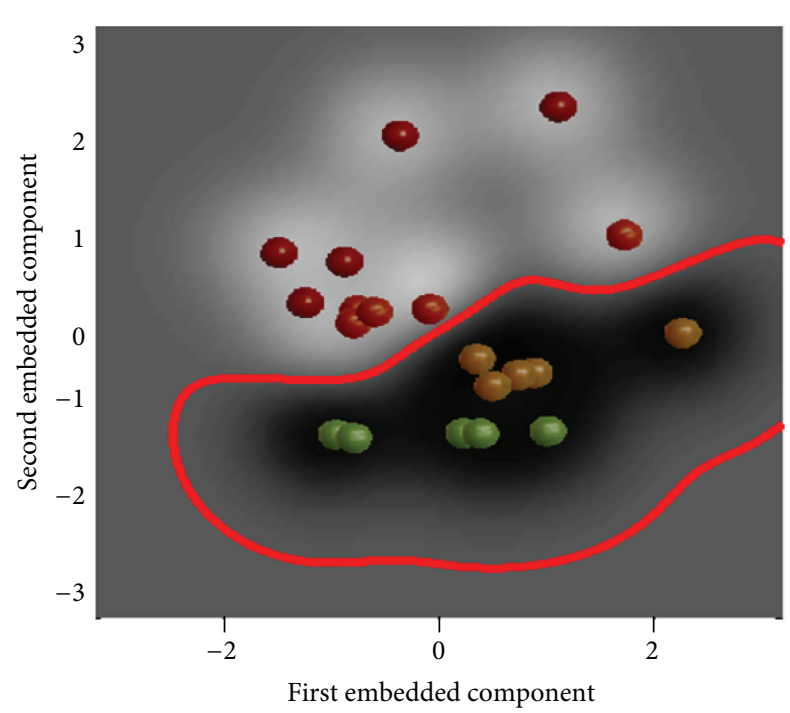

FIGURE 5: The feature space is spanned by the first two components. The red curve indicates the boundary between good and bad tomatoes. The good tomatoes are outside the red curve.

animal origin, and manufactured food (multi-ingredient) of animal origin.

More detailed reviews of the selected papers for each of the classes can be found at the Appendices A (for class A), B (for class B), C (for class D), and D (for class E). The papers in class $\mathrm{C}$ are not considered in this paper.

\subsection{Class A-Primary Food Commodities of Plant Origin.} Class A has five groups: fruits, vegetables, grasses, nuts and seeds, and herbs and spices.

The fruit group consists of 6 subgroups: citrus, pome and stone fruits, berries and other small fruits, and assorted tropical and subtropical fruits with edible or inedible peels. Optical and spectroscopic methods [27] and near-infrared spectroscopy [28] present a review of promising methods for fruit quality.

Vegetables include bulb vegetables, cabbage (Brassica (cole or cabbage) vegetables, Head cabbages, Flowerhead cabbages), fruiting vegetables either cucurbits or other than cucurbits, leafy vegetables (including Brassica leafy vegetables), legume vegetables, pulses, root and tuber vegetables. Mushrooms and fungi belong also to this group. Reviews of vegetable quality have been made by Butz et al. [27] and Nicolaï et al. [28].

The grasses have two groups: cereal grains and grasses used for sugar or syrup production. The nuts and seeds' group consists of tree nuts, oilseed, and seed for beverages, and sweets. The herbs and spices' group consists of herbs and spices as the name indicates.

Table 2 provides a short description for each of the subgroups of class A. We list parameters which have successfully been evaluated for the group and methods applied.

2.2. Class B-Primary Food Commodities of Animal Origin. Class $B$ consists of the following groups: mammalian products, poultry products, aquatic animals, amphibians and reptilians, and invertebrate animals. Examples of publications can be found at Table 3 .

Mammalian products consist of nonmarine meat, mammalian fats, edible offals, and milks. It seems that NIR technologies are more acceptable, for example, to the AOAC (Association of Official Agricultural Chemists).

The poultry can be studied by other optical techniques than just reflectance or transmittance. Autofluorescence has been suggested for food by Andersen et al. [29] and for poultry by Wold and Mielnik [30].

FAO includes in aquatic animals fish (freshwater, marine and diadromous, i.e., migrating between fresh and saltwater), fish roe and milt, fish offals, marine mammals, and crustaceans. Seafood and its products are an important source of nutrition [31]. Their special challenge is the changes in properties from the moment of catch or harvest due to metabolic processes, microbiological processes, and microbiological fauna change. This change is described as a function of spoilage and freshness parameters.

The invertebrate animals' group consists of molluscs (including cephalopods) and other invertebrate animals.

2.3. Class D-Processed Foods of Plant Origin. Class D has four groups: secondary food commodities of plant origin, derived products of plant origin, manufactured foods (single ingredient) of plant origin, and manufactured foods (multiingredient) of plant origin.

Secondary food commodities of plant origin are dried fruits, vegetables and herbs, secondary food commodities of plant origin, and miscellaneous secondary food commodities of plant origin.

Derived products of plants for human consumption include cereal grain milling fractions, teas, vegetable oils: crude, edible, or refined, origin including miscellaneous derived edible products of plant origin, and fruit juices.

Manufactured foods (single ingredient) of the plant origin group naturally consist of fruits, vegetables, or miscellaneous manufactured single-ingredient foods from plants. Manufactured foods (multi-ingredient) of the plant origin group are all manufactured, multi-ingredient cereal products. Table 4 shows examples of published works in this area.

2.4. Class E-Processed Foods of Animal Origin. Class E has the following subgroups: secondary food commodities of animal origin, derived edible products of animal origin, manufactured food (single-ingredient) of animal origin, and manufactured food (multi-ingredient) of animal origin.

Secondary food commodities of animal origin consist of dried meat and fish products and secondary milk products. We include here also products using dried meat and fish. An example of this is ham.

Derived edible products of the animal origin group include processed crustaceans and animals, milk, and derived fats. Manufactured food (single ingredient) of the animal origin group is the manufactured milk products using only single ingredient. 
TABLE 2: Different food groups, their parameters and methods applied for class A.

\begin{tabular}{|c|c|c|}
\hline Food group/appendix & Examples of parameters evaluated and one of related research articles & Methods applied \\
\hline \multirow{17}{*}{ Fruit/A.1 } & Quality & \multirow{17}{*}{$\begin{array}{l}\text { MLR, PCR, PLS, PCA } \\
\text { Genetic algorithms for } \\
\text { wavelength and calibration } \\
\text { model selection }\end{array}$} \\
\hline & Taste (Mehinagic et al. [46]) & \\
\hline & Content & \\
\hline & (i) Sugar (Walsh et al. [47]) & \\
\hline & (ii) Soluble solid (Carlini et al. [48]) & \\
\hline & (iii) acid content (León et al. [51]) & \\
\hline & (iv) water/moisture (Blakey et al. [50]) & \\
\hline & (v) titratable acidity and ph (Ying and Liu [56]) & \\
\hline & (vi) vitamin C and polyphenol (Pissard et al. [57]) & \\
\hline & Translucency (Terdwongworakul et al. [53]) & \\
\hline & Internal quality (Magwaza et al. [54]) & \\
\hline & Maturity (Tanaka and Kojima [58]) & \\
\hline & Defects (Blasco et al. [262]) & \\
\hline & Safety & \\
\hline & Internal insect detection (Xing et al. [60]) & \\
\hline & Fecal and other contaminations (Kim et al. [61] and Mehl et al. [263]) & \\
\hline & Storage (Veraverbeke et al. [63]) & \\
\hline \multirow{18}{*}{ Vegetables/A.2 } & Quality & \multirow{18}{*}{$\begin{array}{l}\text { Texture metrics, wavelength } \\
\text { selection, PLS, MLR, PCA }\end{array}$} \\
\hline & Appearance (Flores Rojas [65] and Gowen et al. [84]) & \\
\hline & Content & \\
\hline & (i) Cyst nematode (Fernández Pierna et al. [64]) & \\
\hline & (ii) Sugar (Tsuta et al. [67]) & \\
\hline & (iii) Soluble solid content, lycopene, $\beta$-carotene, & \\
\hline & and carotenoid (Pedro and Ferreira [68]) & \\
\hline & (Iv) Protein (Liu et al. [69]) & \\
\hline & (v) Phytic acid (Delwiche et al. [73]) & \\
\hline & (vi) Dry matter (Van Dijk et al. [70]) & \\
\hline & (vii) Protein (Pazdernik et al. [75]) & \\
\hline & (viii) Freshness (Esquerre et al. [81]) & \\
\hline & (ix) Moisture (Lamb and Hurburgh Jr. [78]) & \\
\hline & Structural characteristics (Siska and Hurburgh Jr. [83]) & \\
\hline & Damage (Esquerre et al. [81]) & \\
\hline & Safety & \\
\hline & Incorrect ingredients (Roggo et al. [72]) & \\
\hline & Bioagents (Pearson and Wicklow [85] ) & \\
\hline \multirow{15}{*}{ Grasses/A.3 } & Quality & \multirow{15}{*}{ PLS, MLR, PCA } \\
\hline & Content & \\
\hline & (i) Moisture, gluten, alveograph parameters, and protein (Miralbés [90]) & \\
\hline & (ii) Scab, vomitoxin, and ergosterol (Dowell et al. [89]) & \\
\hline & (iii) Rutin and D-chiro-inositol (Yang and Ren [91]) & \\
\hline & (iv) Carotenoids (Brenna and Berardo [92]) & \\
\hline & (v) Phenolics and antioxidant capacity (Zhang et al. [94]) & \\
\hline & $\begin{array}{l}\text { (vi) Neutral acid detergent fibers and acid detergent lignin (Stubbs et al. } \\
\text { [95]) }\end{array}$ & \\
\hline & (vii) Nitrogen and protein (Wiley et al. [96]) & \\
\hline & structural characteristics & \\
\hline & (i) Softness/hardness (Manley et al. [98]) & \\
\hline & (ii) Density (Siska and Hurburgh Jr. [83]) & \\
\hline & Taste (Kawamura et al. [99]) & \\
\hline & Safety & \\
\hline & many impurities like plastics or faeces (Fernández Pierna et al. [64]) & \\
\hline
\end{tabular}


TABLE 2: Continued.

\begin{tabular}{|c|c|c|}
\hline Food group/appendix & Examples of parameters evaluated and one of related research articles & Methods applied \\
\hline \multirow{9}{*}{ Nuts and seeds/A.4 } & Quality & \multirow{9}{*}{ PLS } \\
\hline & Content & \\
\hline & (i) Moisture, fat, stearic acid, and oleic acids (Davrieux et al. [100]) & \\
\hline & (ii) Sinigrin, gluconapin, and glucosinolate (Font et al. [101]) & \\
\hline & (iii) Lipids, water, protein, and chlorophyll (Font et al. [102]) & \\
\hline & (iv) Oil and fatty acid content (Kim et al. [103]) & \\
\hline & (v) Starch (Hacisalihoglu et al. [104]) & \\
\hline & (vi) Amino acids (Wang et al. [105]) & \\
\hline & Authentication (Downey et al. [107]) & \\
\hline \multirow{8}{*}{ Herbs and spices/A.5 } & Quality: & \multirow{8}{*}{ PLS } \\
\hline & Content & \\
\hline & (i) Kava pyrones (Gautz et al. [110]) & \\
\hline & (ii) Moisture, volatile content, and coloring strength (Zalacain et al. [111] & \\
\hline & (iii) Curcuminoids (Tanaka et al. [112]) & \\
\hline & (iv) Ginsenosides (Ren and Chen [113]) & \\
\hline & (v) Lignans (Kwan et al. [114]) & \\
\hline & Origin (Zalacain et al. [111]) & \\
\hline
\end{tabular}

Manufactured milk products using multi-ingredient belong to manufactured food (single ingredient) of the animal origin group. Here we consider dairy products like cheese or yogurts. Some publications has been listed in Table 5.

2.5. Other Foods Not Included in FAO Criteria. Some foods are not included in FAO classification although they are commonly used. For example, honey is not included. There is no clear category for processed foods like hamburgers or sausages. Some of the research done for these foods is introduced here.

2.5.1. Authentication. There have been cases in which the ingredients of manufactured food have been replaced by a cheaper version. For example, beef hamburger can be adulterated with mutton, pork, skim milk powder, or wheat flour. Ding and $\mathrm{Xu}$ [32] used near-infrared for detecting and evaluating the adulteration level in the adulterated hamburgers with $5-25 \%$ phony ingredients. The accuracy increases as a function of adulteration rate since there were more ingredients to be detected. The highest detection rate was $92.7 \%$.

ElMasry et al. [33] have applied hyperspectral imaging (Imspector N17E, Specim, Spectral Imaging Ltd., Oulu, Finland) in the region $900-1700 \mathrm{~nm}$ for predicting colour, $\mathrm{pH}$, and tenderness of fresh beef. With more improvement in terms of speed and processing, their approach has potential for nondestructive quality measurements.

Liao et al. [34] have used VIS/NIR reflectance spectroscopy for the online assessment of the $\mathrm{pH}$ value in fresh pork. Their result show that VIS/NIR spectroscopy can be used for the online prediction of $\mathrm{pH}$ and that wavelength selection can provide a cost-effective calibration model. For wavelength selection, they compared variable importance in projection (VIP), uninformative varible elimination (UVE), genetic algorithms, and success project algorithm (SPA).

Collell et al. [35] have used NIR reflectance spectroscopy to predict moisture, water activity, and salt content on the surface of dry-cured ham during the process. Their results show that the proposed method could be used in the drycuring process of ham. However, the optical properties of the meat surface seem to strongly affect the measured spectra.

Authenticity and origin are also important issues for honey especially when it is claimed to be collected by bees from certain flowers. One example is avocado honey. Dvash et al. [36] applied near-infrared reflectance spectroscopy to obtain the concentration of specific sugar (perseitol) for this honey.

Downey and Kelly [37] studied sulfited strawberry and raspberry purées which have been adulterated with cooked apples $(10-75 \% \mathrm{w} / \mathrm{w})$. They applied VIS and NIR transreflectance measurement on $0.1 \mathrm{~mm}$ thick samples. The best wavelength bands were $400-1098 \mathrm{~nm}$ with $75 \%$ correct classification rate for strawberry and 750-1098 nm with 95\% rate for raspberry. PLS regression was used for the prediction of apple content with $400-1880 \mathrm{~nm}$ range for raspberry and with 1100-1880 $\mathrm{nm}$ range for strawberry. They concluded that apple adulteration can be detected if its content exceeds $25 \%$ for raspberry and $20 \%$ for strawberry purées.

Fügel et al. [38] made a review about authenticity control of fruit purées, fruit preparations, and jams.

2.5.2. Content. Qiu et al. [39] applied near-infrared transmittance to quantify the chemical content of honey. They found that $1 \mathrm{~mm}$ optical path length was the best for this purpose. Modified partial least squares were applied for the determination of content except for moisture. Moisture was determined using just partial least squares. The models were successful for fructose, glucose, sucrose, and maltose 
TABLE 3: Class B groups.

\begin{tabular}{|c|c|c|}
\hline Food group/appendix & Examples of parameters evaluated and one of related research articles & Methods applied \\
\hline \multirow{24}{*}{ Mammalian products/B.1 } & Quality & \multirow{24}{*}{$\begin{array}{l}\text { Color, geometrical features, } \\
\text { texture } \\
\text { Multivariate data analysis, ratios, } \\
\text { MLR, PCA, PLS }\end{array}$} \\
\hline & Taste (Byrne et al. [120]) & \\
\hline & Color (Van den Oord and Wesdorp [124]) & \\
\hline & Diet (Prieto et al. [130]) & \\
\hline & Content & \\
\hline & (i) $\mathrm{pH}$ (Andrés et al. [128]) & \\
\hline & (ii) Moisture (Chan et al. [135]) & \\
\hline & (iii) Fat (Sierra et al. [136]) & \\
\hline & (iv) Iron (Hong and Yasumoto [139]) & \\
\hline & (v) Protein and dry content (Prieto et al. [140]) & \\
\hline & Maturity (Prieto et al. [154]) & \\
\hline & Shear force (Yancey et al. [155]) & \\
\hline & Tenderness (Shackelford et al. [126]) & \\
\hline & Texture (Byrne et al. [[120]) & \\
\hline & Sensory characteristics (Prieto et al. [159]) & \\
\hline & Structural properties (Shackelford et al. [126]) & \\
\hline & Drip loss (Geesink et al. [160]) & \\
\hline & $\begin{array}{l}\text { Authentication (Dian et al. [168] and Arvanitoyannis and } \\
\text { Houwelingen-Koukaliaroglou [264]) }\end{array}$ & \\
\hline & Freshness (Downey and Beauchêne [173]) & \\
\hline & Safety & \\
\hline & Spoilage (Horváth et al. [116]) & \\
\hline & Contamination (Windham et al. [118]) & \\
\hline & Bioagents (Ellis et al. [117]) & \\
\hline & Adulteration of milk (Sato et al. [181]) & \\
\hline \multirow{8}{*}{ Poultry products/B.2 } & Quality & \multirow{8}{*}{$\begin{array}{l}\text { Wavelength selection } \\
\text { PLS } \\
\text { Correlation }\end{array}$} \\
\hline & Content (fat, protein, iron) & \\
\hline & Authenticity/origin (Hong and Yasumoto [139]) & \\
\hline & Storage and handling (Liu et al. [192]) & \\
\hline & Safety & \\
\hline & Safety in general (Chen et al. [182]) & \\
\hline & Fecal contamination (Park et al. [188]) & \\
\hline & Spoilage (Lin et al. [190]) & \\
\hline \multirow{14}{*}{ Aquatic animal products/B.3 } & Quality & \multirow{14}{*}{$\begin{array}{l}\text { Wavelength } \\
\text { PCA, linear discriminant analysis } \\
\text { PLS }\end{array}$} \\
\hline & Temperature & \\
\hline & Appearance (olsen [195]) & \\
\hline & Identification/authentication (Cozzolino et al. [197]) & \\
\hline & Freshness (Uddin et al. [198]) & \\
\hline & Content & \\
\hline & (i) Water, fat, and protein (Gjerde and Martens [204]) & \\
\hline & (ii) Free fatty acids (Zhang and Lee [203]) & \\
\hline & (iii) Salt and moisture (Huang et al. [7]) & \\
\hline & (iv) Crude lipid (Mathias et al. [209]) & \\
\hline & Defects like bruises (Lin et al. [211]) & \\
\hline & Safety & \\
\hline & Incorrect ingredients (Font et al. [212]) & \\
\hline & Spoilage (Lin et al. [202]) & \\
\hline \multirow{3}{*}{$\begin{array}{l}\text { Invertebrate animals and } \\
\text { spices/B.5 }\end{array}$} & Quality & \multirow{3}{*}{ PLC, PCA } \\
\hline & Authenticity (Gayo and Hale [213]) & \\
\hline & Content (Brown [215]) & \\
\hline
\end{tabular}


TABLE 4: Class D food groups, their parameters, and methods applied.

\begin{tabular}{|c|c|c|}
\hline Food group/appendix & $\begin{array}{l}\text { Examples of parameters evaluated and one of related research } \\
\text { articles }\end{array}$ & Methods applied \\
\hline \multirow{6}{*}{$\begin{array}{l}\text { Secondary food commodities of } \\
\text { plant origin/D.1 }\end{array}$} & Content & \multirow{6}{*}{$\begin{array}{l}\text { Wavelength selection } \\
\text { PLS } \\
\text { PCA }\end{array}$} \\
\hline & (i) Starch, sugar, nitrogen, and ash (Lebot et al. [216]) & \\
\hline & (ii) Hollow heart (Dacal-Nieto et al. [217]) & \\
\hline & (iii) Bioactive components (Jourbert et al. [218]) & \\
\hline & (iv) Glucan and protein (Bellato et al. [219]) & \\
\hline & Adulteration (Laasonen et al. [224]) & \\
\hline \multirow{6}{*}{$\begin{array}{l}\text { Derived products of plant } \\
\text { origin/D. } 2\end{array}$} & Content & \multirow{6}{*}{$\begin{array}{l}\text { Multivariate calibration } \\
\text { PLS, MLR }\end{array}$} \\
\hline & (i) Dry extract and sugars (Li et al. [225]) & \\
\hline & (ii) Acids (Chen et al. [226]) & \\
\hline & (iii) Alcohol (González-Sáiz et al. [227]) & \\
\hline & (iv) Soluble solids and $\mathrm{pH}$ (Liu and He [229]) & \\
\hline & (v) Oils (Ng et al. [230]) & \\
\hline \multirow{7}{*}{$\begin{array}{l}\text { Manufactured foods (single } \\
\text { ingredient) of plant origin } \\
\text { aquatic animal products/D.3 }\end{array}$} & Content & \multirow{7}{*}{$\begin{array}{l}\text { Wavelength selection } \\
\text { PLS, LS, PCA }\end{array}$} \\
\hline & (i) Carbohydrate (Chen and Lei [232]) & \\
\hline & (ii) Soluble solids and pH (Liu et al. [238]) & \\
\hline & (iii) Methanol (Dambergs et al. [233]) & \\
\hline & (iv) Acids (Fan et al. [236]) & \\
\hline & Protein-lipid-carbohydrate interactions (Bruun [237]) & \\
\hline & $\begin{array}{l}\text { Authentication (Cozzolino et al. [239]) } \\
\text { Age }\end{array}$ & \\
\hline \multirow{7}{*}{$\begin{array}{l}\text { manufactured foods } \\
\text { (multi-ingredient) of plant } \\
\text { origin/D.4 }\end{array}$} & Content & \multirow{7}{*}{$\begin{array}{l}\text { PLS } \\
\text { Wavelength selection }\end{array}$} \\
\hline & Fat (Vines et al. [243]) & \\
\hline & Moisture (Kays et al. [245]) & \\
\hline & Impurity (Fernández Pierna et al. [64]) & \\
\hline & Total fiber amount (Kays et al. [246]) & \\
\hline & Structural properties (de Alencar Figueiredo et al. [253]) & \\
\hline & Handling and fermentation (Bruun et al. [254]) & \\
\hline
\end{tabular}

TABle 5: Different food groups, their parameters, and methods applied for class E.

\begin{tabular}{lll}
\hline Food group/appendix & $\begin{array}{l}\text { Examples of parameters evaluated and one of related research } \\
\text { articles }\end{array}$ & Methods applied \\
\hline $\begin{array}{l}\text { Secondary food commodities of } \\
\text { animal origin/E.1 }\end{array}$ & Appearance (García-Rey et al. [257]) & Wavelength \\
\hline & $\begin{array}{l}\text { Appearance (Lucas et al. [258]) } \\
\text { Smell and taste (Çelik [259]) }\end{array}$ & $\begin{array}{l}\text { Content (Lucas et al. [258], Arvanitoyannis and Van } \\
\text { Manufactured food (multi-ingredient) } \\
\text { of animal origin/E.5 }\end{array}$ \\
& $\begin{array}{l}\text { Houwelingen-Koukaliaroglou [264]) } \\
\text { pH (Navrátil et al. [260]) } \\
\text { Origin (Cozzi et al. [261]) } \\
\text { Authenticity (Woodcock et al. [265]) }\end{array}$ & \\
\hline
\end{tabular}

content but poor and unreliable for free acid, lactone, and hydroxymethylfurfural.

NIR spectroscopy is applicable also for wholemeals. Fontaine et al. [40] used near-infrared for detecting essential amino acids for different meals. They concluded that the NIRS calibration model was good for evaluating the content of protein-rich feed ingredient for amino acids methionine, cystine, lysine, and threonine, tryptophan with 85-98\% variation explained and was better than crude protein regression. The protein and moisture contents were also evaluated.

Kim et al. [41] used NIR reflectance (400-2498 nm) and partial least-square modeling to detect the total dietary fiber in meals. Meals have different handling alternatives: homogenization, homogenization and drying, and homogenization, 
drying, and defatting. The reference method for total dietary fiber evaluation was AOAC 991.43. The predictions were good. The main advantage over the NIR-based method was faster evaluation. The traditional method takes 4 days.

Zeng et al. [42] developed a NIR transmission system for determining the amount of starch in liquid gravies with low concentration. The best wavelengths were 605, 623, 919,1017 , and $1031 \mathrm{~nm}$ for the regression model. The starch content makes possibility to evaluate the viscosity of liquid gravies.

2.5.3. Authenticity. Sausages can be made with different fats. In some cases, sausages can be identified based on their fat substitutes [43]. The quality of them has been studied, for example, by Gaitán-Jurado et al. [44] and Ortiz-Somovilla et al. [45].

\section{Conclusions}

Nondestructive methods for food quality measurement are warmly welcomed by the food industry. Optical engineering provides a large variety of measurement techniques, some of which, like optical and near-infrared spectroscopy and imaging, have especially high potential for various foodquality-related measurements. And indeed, during the last few decades, it has seen an increasing number of applications, not only in food quality laboratories, but also in factories, and even in farm fields and orchards, where the food quality arises. In this paper, we have shortly described the most prominent application examples in this rapidly growing area of food quality techniques. Unfortunately there are already so many important works in this area that we were able to consider only a small fraction of the total literature existing, which means that too many important contributions had to be omitted from this paper. However, the authors hope that even in its current imperfect state this paper could help those who are trying to find solutions or model approaches to their food quality problems from optics, imaging, and spectroscopy.

\section{Appendices}

\section{A.}

\section{A.1. Class A, Type 01: Fruits}

A.1.1. Taste. Taste is an elemental parameter for fruits. Mehinagic et al. [46] demonstrated promising results in combining taste and spectra for apples.

A.1.2. Content and Factors Related to Content. A popular ingredient sought after for a fruit is sugar, for example, Walsh et al. [47]. Another important content is soluble solid content. Carlini et al. [48] evaluated the soluble solid content using VIS/NIR spectra. They modeled spectra using partial leastsquare regression.

The time-of-flight technique with NIR was applied to detect sugar and acid contents of apples [49]. The modeling used multiple linear regression, principal component regression, and partial least squares. The prediction precision was high and especially superior for acid content.

NIR has been used to predict water content of several different fruits. The water content of avocados was used by Blakey et al. [50] to predict ripening of the fruit. The water content was predicted using PLS (partial least squares) model with 14 factors in the region of $1100-2000 \mathrm{~nm}$.

León et al. [51] studied the intact olive VIS/NIR spectra (400-1700 nm) for evaluation of oil, moisture, oleic acid, and linoleic acid contents. They compared spectra from different female parent trees and harvest year. The partial least-square calibration models were not transferable across year.

Zhang et al. [52] have recently used partial least-square (PLS) calibration model for the measurement of soluble solids content (SSC) of fresh jujube (Ziziphus zizyphus L.). The device used was FieldSpec3 (Analytical Spectral Device, USA). The correlation found was over 0.88 indicating the feasibility of the method for SSC measurement.

Terdwongworakul et al. [53] have used NIR transmittance spectroscopy for the quality assessment of mangosteen fruits. The goal was to develop a method for nondestructive detection of translucency in mangosteen fruit. The water peak absorbance at $955 \mathrm{~nm}$ seems to be an important factor for discriminating translucent and normal fruits.

Magwaza et al. [54] give a recent review of NIRS in external and internal quality analysis of citrus fruits.

Shi et al. [55] have used the genetic algorithm (GA) for wavelength selection for the determination of SSC in Fuji apples. They used NIRS in the range from 1065 to $1625 \mathrm{~nm}$ and were able to reduce the number of wavelengths from 88 to 17 with their GA approach.

Ying and Liu [56] have used FT-NIR spectroscopy for the internal quality assessment of pears. For wavelength selection, they also used genetic algorithms (GAs). The quality factors tested were sugar content (SC), titratable acidity (TA), and $\mathrm{pH}$. Despite the complexity of the spectral data, the GA found calibration models that significantly outperformed those based on full-spectrum analyses.

Pissard et al. [57] suggested the use of NIR spectroscopy and multivariate calibration to determine the levels of vitamin C, total polyphenol, or sugar content. They stated that the prediction performance was very good.

A.1.3. Maturity. Maturity or fruit ripeness affects the quality and taste of the fruit. Tanaka and Kojima [58] studied the growth stages and maturity of Japanese pear fruit using the sugar concentration as an indicator. Pear juice from different maturity stages produced different spectra, the absorption bands of which were related to carbohydrate. Multiple linear regression models were applied to determine the content of sucrose, fructose, sorbitol, and glucose sugars with 3-7 wavelength variables. Sirisomboon et al. [59] used NIR with principal component analysis (PCA) to classify tomatoes. The model provided a prediction for maturity.

A.1.4. Unwanted Objects. Insects cause damage to fruits in many ways. Some of them can grow inside the fruit like in 
tart cherry. Xing et al. [60] have used genetic algorithms to find the optimal wavelengths for detection of internal insect (plum curculio (Coleoptera: Curculionidae)) infestation that in tart cherry. Based on the GA wavelength selection on the reflectance spectra (580-980 nm), three to four wavelength regions were selected. The results were checked using partial least-squared discriminant analysis (PLSDA) and they showed that the wavelengths selected resulted in classification efficiency similar to that of the full spectral range. Different GA runs resulted in somewhat different results, which are typical for the wavelength selection problem.

A.1.5. Contamination. Fruit skin can be contaminated by fecal material which can have pathogens like E. coli. Kim et al. [61] applied multispectral imaging $450-851 \mathrm{~nm}$ to detect fecal with thin and thick layer on apples with different green and red colorations. This was somehow successful for thick patches. Apple coloration caused problems with thin layer. Kim et al. [62] studied also fluorescence spectral information. They identified four optimal bands (450, 530, 685 , and $735 \mathrm{~nm}$ ) for fecal detection and suggested the use of a simple ratio.

A.1.6. Storage. Veraverbeke et al. [63] utilized NIR transmission spectra to solutions of single wax components and extracted apple wax. The wax was collected from apples with different parameters: apple cultivar (Jonagold, Jonagored, and Elshof), picking data (early, commercial, and late), storage time $(0,4$, or 8 months in controlled atmosphere), and shelf life periods $(0,1$, and 2 weeks). They applied canonical discriminant analysis on the first derivative of spectra. The proposed NIR technique could identify cultivar and storage duration but not very well the picking date or shelf life period. It seems that storage time and cultivars are related to differences in the number of aliphatic chains, like alkanes and esters, and the presence of $\alpha$-farnesene.

A.2. Class A, Type 002: Vegetables. Fernández Pierna et al. [64] have used NIR hyperspectral imaging and chemometrics for the detection of cyst nematode (Heterodera schachtii) infected sugar beets. They used a pushbroom system (SWIR XEVA CL 2.5320 TE4 camera from XENICS using an Imspector $\mathrm{N} 25 \mathrm{E}$ spectrograph with a cooled, temperaturestabilised mercury-cadmium-telluride (MCT) detector from Specim Ltd., Oulu, Finland) combined with HyperPro and HyperSee software (BurgerMetrics SIA, Riga, Latvia). The samples were moved with a conveyor belt at $2 \mathrm{~mm} / \mathrm{s}$ speed. The result of the study was that NIR imaging has potential for, for example, plant breeders to select cyst-nematode-resistant traits.

A.2.1. Appearance. The quality of a vegetable is sometimes evaluated by its texture. One of these kinds of vegetables is Asparagus, the texture of which has been evaluated by Flores Rojas [65]. The textural quality parameters considered in their research were maximum shear force and cutting energy. The evaluation was based on results from a scanning monochromator of 400-2500 $\mathrm{nm}$ and a combination of diode array and scanning monochromator of 350-2500 nm.

A.2.2. Content. Sugar concentration is important for many vegetables because it affects their sensory evaluation and storage ability. Sugar content of melon was evaluated and visualized using NIR absorption spectra by the autor in [66]. His paper indicated a strong inverse correlation for a melon between sugar content and specific wavelength $(676 \mathrm{~nm})$ near to the chlorophyll absorption band. The visualization was implemented by taking an image through a filter with band around $676 \mathrm{~nm}$ and converting the pixel values to another unit (absorbance) to assign them with a color. However, there was still a bias caused by melon color. Later, they developed another visualization method using deeper NIR region to prevent bias from melon color [67]. They noticed that the two 2 nd derivative absorbances in $874 \mathrm{~nm}$ and 902 correlated strongly to the sugar content. For this visualization, two bandpass filters were employed.

Pedro and Ferreira [68] applied NIR and multivariate calibration to evaluate soluble solid, lycopene, $\beta$-carotene, and carotenoid contents of tomato. The PLS-1 was used for calibration. Prediction accuracy $r$ values were over 0.99 .

Protein content of edible fungi (Auricularia auricular) was studied by Liu et al. [69] They applied partial leastsquare, multiple linear regression, and least square support vector machine on data and compared performances of different preprocessing including Savitzky-Golay smoothing, standard normal variate, multiplicative scatter correction, first derivative, second derivative, and direct orthogonal signal correction. Wavelength selection was based on successive projections algorithm. Liu et al. [69] concluded that the best full spectrum partial least-square model was obtained using "raw" data whereas optimal successive projection algorithm with multiple linear regression, successive projection algorithm with partial least squares, and successive projection algorithm with least-square support vector machine models were achieved with spectra preprocessed multiplicative scatter correction. The optimal model was produced by successive projection algorithm with least-square support vector machine combination.

For cooked potatoes, dry matter content is important. Van Dijk et al. [70] studied three potato cultivars, cv. Nicola (a firm cooking potato), cv. Irene (a mealy cooking potato), and $\mathrm{cv}$. Bintje (intermediate between firm and mealy cooking potato). They related NIR spectra to dry mater content and sensory perceived texture of steam cooked potatoes. The dry mater content affected most on the texture while the effect of chosen cultivar is minimal. Storage did not have any effect on the relationships.

Dacal-Nieto et al. [71] have used genetic algorithm (GA) for feature selection in potato classification done by the help of computer vision.

Roggo et al. [72] applied NIR for sucrose content with very small sucrose ester of fatty acid (SEF, fresh beet) and got satisfactory results for brix, marc, sugar in molasses, and juice purity but lower accuracy results for glucose, nitrogen, sodium, and potassium. 
Soybean is an important vegetable in many countries. Soybeans have phytic acid which has nutritional and environmental importance. To evaluate the levels of the phytic acid, Delwiche et al. [73] measured its complement, inorganic phosphorus, using diffuse reflectance of near-infrared (1100$2500 \mathrm{~nm})$ for ground meal and transmittance $(600-1900 \mathrm{~nm})$ for single beans. The results were not very good with partial least-square regression but give an indication. Kovalenko et al. [74] developed calibration equations for estimating amino acid composition of whole soybeans from near-infrared spectra. They also concluded that cysteine and tryptophan could not be estimated from spectra while leucine and lysine have a high correlation.

Pazdernik et al. [75] applied near-infrared reflectance spectroscopy to evaluate crude glycinin fraction of soybean protein. They find that the fraction was positively correlated to crude protein concentration and negatively to oil concentration. The high crude protein and fraction content was related to higher growing temperatures while the lower growing temperature produced higher oil concentration. Pazdernik et al. [76] studied also amino and fatty acid compositions. Hollung et al. [77] applied NIR reflectance on soybeans to find samples with a low content of oligosaccharides and nonstarch polysaccharides. They were able to predict that total content of nonstarch polysaccharides could be predicted using partial least-square regression.

The moisture content of whole soybean in the range of 5 to $22 \%$ can be determined with great accuracy using nearinfrared transmittance ( 800 to $1100 \mathrm{~nm}$ ) and difference in absorbance, stepwise multiple linear regression, or partial least-square modeling [78].

The classification based on soybean position can be useful, too. Bennett et al. [79] analyzed field-grown soybean seeds with different nodal positions with NIR. They found that seed protein content varied as a function of place: those from plant basal region have higher oil content and lower protein content while the opposite was true for the apex. Later in [80], they studied the seed quality traits (protein, oil) utilizing NIR to determine percentage of oil and protein. They noticed that early-planted crop has increased the amount of oil (3-8\%) while there was not much change in protein content.

A.2.3. Freshness. Quality of mushroom can decrease if too long time elapsed from harvest. Esquerre et al. [81] used VIS and NIR absorption spectra to detect bruises and evaluate the freshness. The partial least-square model was employed and it was mostly influenced by changes in water matrix and enzymatic browning.

A.2.4. Authentication. Li et al. [82] have recently tested classification methods for the authentication of pure camellia oil NIR spectra. Sample authenticities were confirmed by gas chromatography. The classification methods were unsupervised principal component analysis (PCA), hierarchical cluster analysis (HCA), supervised classification techniques based on discriminant analysis (DA), and radical basis function neural network (RBFNN). The classification rate of all methods reached $98.3 \%$ when smoothing, first derivative, and autoscaling were used. The good performance showed that NIR spectroscopy could be successfully used as a rapid, simple, and nondestructive method to discriminate pure camellia oil.

A.2.5. Structural Characteristics. The physical and chemical properties of soybean and corn are correlated with size and density. However, the change on size and density has no effect in accuracy of determination of soybean protein and oil content. The effect is very small for determining protein, oil, and starch contents for corn [83].

A.2.6. Damage. Vegetables, mushrooms, and fungi can suffer physical damages for too rough handling. VIS/NIR absorption seems to be useful for quantifying bruise damages for mushrooms $[81,84]$.

A.2.7. Incorrect Ingredients. Roggo et al. [72] suggested the use of NIR spectroscopy for decreasing pollution of heavy metals, lead acetate, caused by the legal methods, polarimetric measurement for sucrose content, and wet chemical analysis for quality control.

A.2.8. Bioagents. The detection of fungi from food assumes those the spectra of fungi differ from that of the food itself. This assumption has been shown to be valid, for example, by Pearson and Wicklow [85] who detected the fungi in corn kernels, Gordon et al. [86] for food grain, and Berardo et al. [87] for maize.

Jin et al. [88] have used GAs to find the optimal wavelengths when trying to discriminate aflatoxin-producing Aspergillus flavus (AF13) fungi and non-toxin-producing Aspergillus strains (AF2038, AF283, and AF38). Their hyperspectral image was taken of several strains cultured 7 days on potato dextrose agar using both broad-spectrum UV light source and tungsten halogen bulbs. GA was used to find the most important principal components (PCs) among the first 40 PCs. The selected PCs were given to a support vector machine (SVM) for training for classification between toxigenic and atoxigenic fungi species. The discrimination accuracy varied between the strains and the light source used ranging from $70 \%$ to $95 \%$ pixel-wise.

Berardo et al. [87] applied NIR for the detection and identification of mycotoxigenic fungi and their toxic metabolites. They analyzed the samples for fungi infection, ergosterol, and fumonisin $B_{1}$ content. They concluded that NIR is suitable for monitoring mold contamination and separating the contaminated lots from clean lots.

\section{A.3. Class A, Type 003: Grasses}

A.3.1. Content. Cereal grains have many important ingredients which are searched in many studies. Also moisture is an important parameter. Dowell et al. [89] have applied NIRS for scab, vomitoxin, and ergosterol determination in single-wheat kernels. The results obtained show that the NIRS 
method was able to find all scab-damaged kernels that were identified by official inspectors.

Miralbés [90] measured NIR transmittance 850-1048 nm of whole wheat from different countries and evaluated their moisture, protein, wet gluten, dry gluten, and alveograph parameters (W, P, and $\mathrm{P} / \mathrm{L}$ ) using partial least squares. The alveograph parameters required division of wheat samples into two groups according to their deformation energy values.

Tartary buckwheat has beneficial ingredients, rutin and D-chiro-inositol, against hemorrhagic diseases and insulinresistant diseases. Yang and Ren [91] applied NIR reflectance to evaluate their content. They developed a partial leastsquare method and used the results from HPLC as a reference. A good chemometric correlation existed.

Brenna and Berardo [92] studied maize whose antioxidant compounds like carotenoids are useful against reactive oxygen substances. They combined NIR and HPLC results for determining carotenoid concentration of grinded maize using modified partial least squares.

Rice is another very important food plant. Kawamura et al. [93] used NIR transmittance and PLS for successful evaluation of moisture and protein contents of undried rough rice. However, they found that their method was not applicable to determine amylase content. Zhang et al. [94] suggested use of NIR to predict total phenolics, flavonoid content and antioxidant capacity of dehulled grain of brown rice. The phenolic content, and antioxidant capacity were successfully determined using mPLS and PLS while this failed for flavonoids.

Stubbs et al. [95] measured residue from cultivars of spring wheat (Triticum aestivum L.), winter wheat, and spring barley (Hordeum vulgare) with NIR and made models to estimate neutral detergent fiber (NDF), acid detergent fiber (ADF), acid detergent lignin (ADL), carbon (C), sulfur (S), nitrogen $(\mathrm{N})$, and $\mathrm{C}: \mathrm{N}$. The models were successful for neutral acid detergent fibers and acceptable for acid detergent lignin, for others less successful.

Wiley et al. [96] studied barley mutants. They evaluated grain nitrogen and protein composition. The grains were measured with NIR reflectance spectra, which were resolutionally enhanced by derivative spectroscopy. The advantage of derivative spectroscopy is to allow wavelengths to be identified with clear differences in contribution from the associated chemical bonds. They compare the 4th derivative of wholemeal flour with high and low $N$ containing grains.

A.3.2. Structural Characteristics. Structural characteristics like hardness have effect on quality. For maize, the hardness was evaluated using NIR spectra in [97]. Manley et al. [98] used hyperspectral images of 1000 to $2498 \mathrm{~nm}$ wavelength range to classify yellow maize kernels. They found clusters for different endosperms (vitreous, floury, and 3rd type) which present varying ratios of soft and hard kernels. Cereal composition reveals the properties of inner structure. Siska and Hurburgh Jr. [83] applied NIR transmittance and PLS to obtain corn density which is related to starch and protein.
A.3.3. Taste. Taste from cereal food is affected by the grains themselves. The study of Kawamura et al. [99] indicates that VIS/NIR reflectance could be useful for rough classification of wholegrain milled rice using multiple linear regression (MLR) analysis into three groups: poor, better, and best taste.

A.3.4. Safety. Fernández Pierna et al. [64] applied nearinfrared hyperspectral images for separating impurities from cereal grains. The cereal grains were wheat, spelt, and barley while the contaminants were a variety of different matters (straw, broken grains, grains from other crops, weed seeds, insects, plastic, stones, pieces of wood and paintings, and animal feces) classified into different categories. For each category, a discriminant model was developed. The method was based on PCA and support vector machine.

\section{A.4. Class A, Type 004: Nuts and Seeds}

A.4.1. Content. Nuts of shea tree can be used as a source of nut butter. The moisture, fat, stearic acid, and oleic acid can be determined using NIRS [100].

Front et al. [101] studied the sinigrin, gluconapin, 4hydroxyglucobrassicin, and total glucosinolate of Indian mustard seed. They modeled the NIR spectra with modified partial least-square regression for chemometrics. The coefficients of determination were over 0.8 for all other except for 4-hydroxyglucobrassicin which was only 0.33 . Font et al. [102] measured intact and ground seed of Indian mustard, Ethiopian mustard, and rapeseed and applied modified partial least-square regression to combine near-infrared spectra and acid detergent fiber values. The sample type did not have any significance on the evaluation. According to them, the most important factors for modeling were $\mathrm{C}-\mathrm{H}$ and $\mathrm{O}-\mathrm{H}$ groups of lipids, water, protein, and chlorophyll.

Kwan et al. [103] determined the oil and fatty acid contents of intact perilla seed using NIR reflectance. They concluded that mPLS produced good predictions for oil, oleic acid, and linolenic acid contents whereas the predictions for palmitic, stearic, and linoleic acid were unsuitable for screening purposes.

The content of intact common bean was subjected to NIR reflectance in order to determine seed weight, protein, and starch for 91 genotypes [104]. PLS model was able to predict protein content with high accuracy (SEP) $=1.6 \%$ and reasonable accuracy for weight and starch. Seed color had a correlation to spectra; black seed has very different spectra. Color did not affect model accuracy.

Wang et al. [105] used near-infrared and PLS to study proteins and amino acids in peanuts. They found the results acceptable. Yang and Sun [106] demonstrated that the hardness of licorice seeds can be done with NIR.

A.4.2. Authentication. Downey et al. [107] applied near- and mid-infrared spectra for authentication of lyophilized coffee samples of Arabica and Robusta cultivars. They used factorial discriminant analysis and partial least-square models.

Downey et al. [108] applied VIS and NIR transflectance spectra to detect adulteration of pure extra virgin olive oils. 
The adulteration rates for the olive oil were $1 \%(\mathrm{w} / \mathrm{w})$ and $5 \%(\mathrm{w} / \mathrm{w})$ sunflower oil. The best classification was obtained using 1st derivative of $400-2498 \mathrm{~nm}$ spectra. The adulterant content was predicted with $0.8 \%$ standard error accuracy.

Woodcock et al. [109] studied European olive oil samples to specify their geographical origins with near-infrared transflectance spectroscopy $(1100-2498 \mathrm{~nm})$. The samples were collected from harvests of 2005, 2006, and 2007. The detection rate for Ligurian ones was $92.8 \%$ and non-Ligurian ones $81.5 \%$ when using the first-derivative data pretreatment and discriminant partial least-square regression.

\section{A.5. Class A, Type 005: Herbs and Spices}

A.5.1. Content. The herbs and spices contain many characteristic ingredients, the amount of which is often a concern. Often the goal is to find an alternative method for HPLC. The herbs and spices can come in many forms like leaves, roots, or powders. Chemometrics can be applied to all these forms.

Another example is kava which is an herb with anxiolytic properties caused by active compounds called kavalactones or kava pyrones. As a natural product, the amounts of active compounds vary between specimens. The NIR reflectance and partial least squares can be used to detect these compounds reliablly [110]. The results from the developed method are reproducible and have repeatability comparable to HPLC methods.

NIR reflectance can be used to determine several factors of the chemical composition of saffron according to Zalacain et al. [111]: moisture and volatile content, coloring strength, $E_{1 \mathrm{~cm}}^{1 \%}(250 \mathrm{~nm})$, and $E_{1 \mathrm{~cm}}^{1 \%}(330 \mathrm{~nm})$, established on the ISO 3632 Technical Specification Normative and used to certify saffron quality in the international market. They also analysed five main crocetin glycosides (compounds causing saffron color). The best correlations obtained for trans-crocetin di ( $\beta$-d-gentibiosyl) ester was $R^{2}=0.93$, for trans-crocetin $(\beta$ D-glucosyl)-( $\beta$-D-gentibiosyl) $R^{2}=0.94$, and for picrocrocin (saffron bitterness) $R^{2}=0.92$.

Tanaka et al. [112] quantified curcuminoids (total curcuminoid content, curcumin, demethoxycurcumin, and bisdemethoxycurcumin) of turmeric. They applied 2nd derivative preprocessing and standard normal variate to NIR data and after that partial least-square regression. Characteristic absorption of curcuminoids was detected in approximately $1700 \mathrm{~nm}$ and $2300 \mathrm{~nm}-2320 \mathrm{~nm}$. The results obtained have a high correlation with HPLC.

Many herbs and spices are often milled to powder-like Ginseng. Chemical methods like HPLC are expensive and sometimes they can be replaced by NIR/VIS spectroscopy $400-2500 \mathrm{~nm}$. The authors in [113] studied it for American Ginseng root powder to detect ginsenosides. They found that it is applicable for major ginsenosides, $\mathrm{Rb}_{1}$, Re, and $\mathrm{m}-\mathrm{Rb}$ and total ginsenosides.

Sesame has some antioxidative-activity-related ingredients like lignans (including lipid-soluble lignans sesamin and sesamolin) and water-soluble lignin glycosides (sesaminol triglucoside and sesaminol diglucoside). Kim et al. [114] developed a NIR reflectance method for evaluating the lignin content of intact sesame seeds. The modeling was done using mPLS regression using results from high-performance liquid chromatography analysis as reference values. The results were good ingredients except for sesaminol diglucoside owning to its small amount.

Xin et al. [115] suggested a method to separate raw and processed herbs. They measured the herbs in the NIR area and used support vector machine, random forests, and linear discriminant analysis in analysing and classification. The obtained results were excellent.

A.5.2. Origin. Sometimes the origin is important for consumers. Zalacain et al. [111] suggested the use of near-infrared to determine the origin of saffron (Iran, Greece, and Spain).

\section{B.}

\section{B.1. Class B, Type 06: Mammalian Products}

B.1.1. Spoilage. Meat spoils very easily and thus produces a health risk not to mention unpleasantness. So excluding certain delicacies, the spoilage should be avoided or at least the spoilt meat should be removed before going to consumer. The spoilage for different meats has been studied for pork meat [116] and beef [117]. These papers considered also bacteria and microbiological factors.

B.1.2. Contamination. The fecal material is sometimes found on animal carcasses. Windham et al. [118] suggested the use of four optimal wavelengths: $434,517,565$, and $628 \mathrm{~nm}$. These wavelengths were selected using multivariate data analysis and VIS/NIR reflectance data. Different spectral ratios were tested to find optimal classification. The ratios $565 \mathrm{~nm} / 517 \mathrm{~nm}$ provide $100 \%$ detection rate in carcasses of broilers fed a corn or soybean meal diet. Another ratio, $574 \mathrm{~nm} / 588 \mathrm{~nm}$ was shown to be optimal for a larger variety of diets.

B.1.3. Taste (including Juiciness). One of the earliest references to taste of meat was already published in 1969 [119]. Byrne et al. [120] used NIR reflectance $(750-1098 \mathrm{~nm})$ to examine the taste of heifer cow. The samples from the longissimus dorsi ( $2.5 \mathrm{~cm}$ thick) were taken at 2, 7, and 14 days post mortem. They were vacuum-packaged in plastic bags and stored at $-20^{\circ} \mathrm{C}$.

The results from taste panel and chemical processes for lamb meat were evaluated against NIR reflectance by Andrés et al. [121]. They evaluated a set of 232 muscle samples from Texel and Scottish Blackface lambs. They concluded that absorbance is correlated to juiciness, flavour, abnormal flavor, and overall liking of lamb meat, but the correlation does not provide very clear classification. It was applicable for separating extreme samples.

B.1.4. Appearance. The appearance consists of color, geometrical features, and texture of meat. Texture of meat here is the general surface appearance.

Color of meat depends on water content and concentrations of myoglobin and also the relative proportions of 
myoglobin's different forms, oxymyoglobin, myoglobin, and ferric myoglobin $[122,123]$.

Meat color has been studied for decades and several methods have been suggested. For example, Van den Oord and Wesdorp [124] suggested the use of reflectance differences at 630 and $580 \mathrm{~nm}$. Later, beef color prediction has been studied by Leroy et al. [125] and Shackelford et al. [126]. Shackelford et al. [126] showed that the best color prediction with NIR was obtained in reflectance mode. Leroy et al. [125] studied also beef, longissimus thoracis, and obtained similar results. For pork, color is an especially important parameter for customers which make their buy/not buy partially based on it. Cozzolino et al. [127] applied VIS/NIR for prediction.

Andrés et al. [128] applied VIS/NIR (400-2500 nm) for determining $L^{*} a^{*} b^{*}$ colour parameters. The results for luminosity at 0 and $60 \mathrm{~min}$ had a good predictability.

B.1.5. Diet. The diet affects the composition of beef: their subcutaneous fat and its fatty acid composition [129]. Prieto et al. [130] report that NIR can be used to separate whether or not the beef cows has been fed with flaxseed.

B.1.6. $p H$. $\mathrm{pH}$ is affected by light scattering [131-133] study produced over 0.8 values for coefficient of correlation when using first derivative and multiplicative scatter correction for calibration and validation sets. The obtained precision is good; only $4.27 \%$ of predictions had difference more than 0.2 $\mathrm{pH}$. Andrés et al. [128] predicted $\mathrm{pH}$ of beef with NIR with good accuracy.

B.1.7. Content. Important factors for meat are lean-to-fat ratio, meat percentage, intramuscular fat, marbling, protein, water contents and muscle area. Certain ingredient, or their amount can be used as a guarantee for quality and used as a mark of quality.

Moisture of meat has been evaluated by Liao et al. [133] with coefficient of correlation near 0.8 for validation set using the first derivative and multiplicative scatter correction. Tornberg et al. [134] with no processing showed very poor predictability $(0.21)$ for both VIS $(400-800 \mathrm{~nm})$ and NIR (800-2500). Chan et al. [135] used first derivate and preprocessing of spectra $(400-1700 \mathrm{~nm})$ and obtained results over 0.7 for the validation set.

Liao et al. [133] showed over 0.75 values for the calibration, and the validation sets for protein content. Values around 0.7 were obtained by Chan et al. [135].

The intramuscular fat is important quality factor which has been studied for beef $[130,136,137]$ and pork $[133,137]$. Sierra et al. [136] studied the composition and content of intramuscular fat has been studied by using NIR transmittance 850 to $1050 \mathrm{~nm}$. They evaluated the fatty acid profile for samples of ground beef from the longissimus thoracis of yearling bulls. The study indicates that it is possible with relatively good accuracy to evaluate saturated, branched, and monounsaturated fatty acids. NIR transmittance also provides information about conjugated linoleic acids. Prieto et al. [130] used NIR reflectance 400 to $2498 \mathrm{~nm}$ for determining concentration of polyunsaturated fatty acids and their biohydrogenation products in beef cows which have been fed on special diet (flaxseed).

Studies of intramuscular fat for pork [132-135, 137, 138] have dissimilar results. The best results were from Prevolnik et al. [137] where the coefficient of determination value was over 0.9 . Very poor results were obtained by Tornberg et al. [134] when no preprocessing was used with VIS (400$800 \mathrm{~nm})$ whereas NIR $(800-2500 \mathrm{~nm})$ provided almost twice as good results. The first derivative of spectra with preprocessing provided further improvement [135]. One reason for difference could be different wavelength areas: Tornberg et al. [134] used visible range $400-800 \mathrm{~nm}$, Barlocco et al. [138] used NIR (800-2500 nm), Savenije et al. [132] used VIS/NIR (400-2500 nm), and Liao et al. [133] used VIS/NIR (350$1100 \mathrm{~nm})$. The homogeneity of samples varies [133, 137, 138]; for example, Liao et al. [133] and Savenije et al. [132] used intact pork samples. Minced pork samples were used, for example, in [137, 138]. Liao et al. [133] studied in addition to intramuscular fat protein and water content for pork in 350$1100 \mathrm{~nm}$.

The intramuscular fat and water for lamb meat were predicted at a higher accuracy and they seem to correlate to the sensory parameters [121].

Iron-related substances can also be evaluated from meat. Hong and Yasumoto [139] used NIR diffuse reflectance from 1100 to $2500 \mathrm{~nm}$ to study heme and nonheme iron in raw meats: beef, pork, chicken, rabbit, duck, horse, lamb, and mutton. The second derivate was taken from data and after that multiple regression equations were applied. The result indicates that the multiple correlation coefficients are over 0.9 for both hemes and total iron. Hong and Yasumoto [139] obtained the best results with multiple regression equation at wavelengths where $\mathrm{NH}$ groups in protein molecules and $\mathrm{C}-\mathrm{C}$ and $\mathrm{CH}$ in the porphyrin ring of heme have absorption.

The same NIR wavelength range $(1100-2500 \mathrm{~nm})$ has been tested for evaluating crude protein $(\mathrm{CP})$, myoglobin, collagen, ether extract (EE), gross energy (GE), dry matter (DM), and ash content of oxen meat [140]. Prieto et al. [140] found that myoglobin, collagen, and ash contents could be evaluated with poor predictability. They speculate that this was due to lack of correlation between these parameters and ether extract content. However, ether extract evaluation was successful and important since this parameter is highly related to the organoleptic characteristics (like juiciness, flavor, and texture) in oxen meat samples. Also other parameters like crude protein, dry matter, and gross energy, which have a high correlation with ether extract content, were predicted with an acceptable degree of accuracy.

Pérez-Marín et al. [141] applied NIR for all stages of pigs: the live animal, carcass in slaughterhouse, subcutaneous fat sample with skin, skin-free subcutaneous fat sample, and transverse section. They develop prediction model for the four main fatty acids in Iberian pig fat, obtaining for palmitic acid SECV values of $1.24 \%$ for in vivo analysis and $0.82 \%$ for carcass analysis, for stearic acid $0.67 \%$ and $0.94 \%$, for oleic acid $1.42 \%$ and $1.48 \%$, and for linoleic $0.36 \%$ and $0.55 \%$. The model proved the feasibility of NIR because it accounted for between $60 \%$ and $74 \%$ of the variation of spectra of live animals and between $31 \%$ and $87 \%$ of variation of carcasses. 
For Iberian pigs, also intact fat or adipose tissues are studied [142-144].

Lamb muscles appear to have special absorption bands at $424 \mathrm{~nm}$ and $550 \mathrm{~nm}$. These bands are related to the Soret band and the oxymyoglobin absorption band $[145,146]$. The absorption bands (at $540 \mathrm{~nm}$ and at $580 \mathrm{~nm}$ ) correlate with both myoglobin and oxymyoglobin $[145,147,148]$, but myoglobin has also another absorption band at $555 \mathrm{~nm}$ [145-150] with the absorption band at $574 \mathrm{~nm}$ with oxyhaemoglobin absorption.

According to Murray [151], an absorption band at $762 \mathrm{~nm}$ is caused by the $\mathrm{OH}$ third overtone or according to Swatland [145] and Delpy and Cope [149], an absorption band produced by the oxidation of the myoglobin (deoxymyoglobin). Pigments and other characteristics (intramuscular fat, fattyacids, and moisture) cause most of the spectral information used for the VIS region $(400-700 \mathrm{~nm})$ and the NIR region around $1400-2300 \mathrm{~nm}$.

Similar results are reported by others like Downey et al. [152]; Lomiwes et al. [153] predicted glycogen concentration of prerigor muscle.

B.1.8. Maturity. The age of animal can affect the meat quality since there can be differences in intramuscular fat and water contents. Prieto et al. [154] applied successfully NIR reflectance $1100-2500 \mathrm{~nm}$ to separate adult, over 4 years old castrated steers and young, under 14 months old cattle. The samples were taken from longissimus thoracis muscle.

B.1.9. Shear Force. Shear force value indicates how much force is needed to cut the meat and it is related to tenderness. In fact, Yancey et al. [155] studied the connection between shear force (Warner-Bratzler shear force (WBSF), and Meullenet-Owens razor shear (MORS)) and tenderness (consumer evaluation, also with overall impression) for beef ribeye rolls taken from Select, low Choice, top (upper 2/3) Choice, and Prime quality grade carcasses with visible and near-infrared spectroscopy reflectance. Steaks were cut $2.54 \mathrm{~cm}$ thick and put to aging for 14 or 28 days. The longer aging of samples was related to increased tenderness. The 2nd derivatives of VIS/NIR measurements were found to be capable for predicting tenderness and overall impression than shear force measures.

Many studies for shear force have been made, for example, Byrne et al. [120] 1998, Park et al. [156] Rodbøtten [157] and Venel et al. [158]. Byrne et al. [120] evaluated WarnerBratzler shear force using NIR 750-1098 nm for Heifer cows. They obtained over 0.7 value of correlation coefficient for both groups, for samples taken at 2, 7 and 14 days post mortem, vacuum-packaged in plastic bags and stored at $-20^{\circ} \mathrm{C}$. However, the results seem to vary. Prieto et al. [159] studied beef and cooked pork and suggest significant variation as a function of position. Shackelford et al. [126] applied shear force detection online for beef. The NIR transmission measurement provided better results than reflectance measurements [125]. The ability was limited longissimus thoracis at 2 or 8 days post mortem. Venel et al. [158] suggest using additional features (age, grade, $\mathrm{pH}$, and sex) to improve results.

The results for pork meat have different conclusions. Study of Geesink et al. [160] indicates poor predictability. Liao et al. [133] obtained relatively good prediction for the calibration set but over 2.5 times poorer for the validation set. It has been discussed that the problem is the significant variations at different positions of the samples.

B.1.10. Tenderness. Tenderness of a beef describes the resistance to bite or shear meat and is related to the hardness. It should be noted that the characteristics can correlate to each other, like tenderness of meat that has a positive correlation to flavor and juiciness [161].

Generally the customers prefer beef with low effort needed and thus tenderness is an important factor related to quality. NIR models have predictions rating fair to good for the tenderness of postrigor longissimus muscle in many publications [120, 148, 156, 162], and [157]. Common measurement ranges were $1100-2500 \mathrm{~nm}$ and $750-1100 \mathrm{~nm}$. It seems that absorption increases when the meat becomes tougher. Tenderness predictions for prerigor longissimus muscle were not so good $[134,157]$ which may indicate that the change from before rigor to after rigor and parameters related to it might be critical for tenderness. The applicability of techniques is different: extracted part of a muscle sample [156, 162-164] or a very small area $\left(4 \mathrm{~cm}^{2}\right)$ [120]. Shackelford et al. [165] have extended the technique for exposed longissimus crosssection of ribbed beef. Later, an online detection of tenderness has been tested by Shackelford et al. [126].

B.1.11. Texture of Meat. Byrne et al.'s [120] results showed correlation coefficient values of 0.5 and 0.7 for heifer meat texture by NIR. Texture of lamb meat has been evaluated by Andres et al. [121], but although absorbance does correlate to texture, it was not suitable for classification.

B.1.12. Acceptability. The acceptability of heifer meat seems to be very poorly predicted by NIR according to Byrne et al. [120]. The correlation coefficient values were under 0.5 .

B.1.13. Sensory Characteristics other than Appearance. It would be advantageous to classify the beef based on its quality directly in the abattoir. Prieto et al. [159] applied VIS/NIR fiber optics measurements ( 350 to $1800 \mathrm{~nm}$ ) to very fresh beef muscle to correlate it with lab color, cooking loss, instrumental texture (Volodkevitch, 10-day aged meat; slice shear force, 3 and 14-day aged meat), and sensory characteristics. However, the results indicated that only the sensory characteristics correlation was useful.

B.1.14. Structural Properties. Structural properties are related to functional quality. They can be water holding capacity, isometric tension, muscle fiber shortening, $\mathrm{pH}$, and cooking loss.

Shackelford et al. [126] evaluated NIR for water-holding capacity and cooking loss for beef. The average reflectance showed higher absorbance for samples with highest cooking 
loss with meat 2 days post mortem. The difference between spectra diminished when the meat was 8 days post mortem. The transmission spectra improved the results. The drip loss prediction was not very high. It was best for reflectance at day 8 with a correlation coefficient of 0.54 . Tornberg et al. [134] studied the drip loss for porcine meat using wavelength 802$2500 \mathrm{~nm}$. They obtained a correlation coefficient of 0.64 .

The study of Prieto et al. [159] suggest that VIS/NIR may not be very useful for determining cooking loss. Drip loss and shear force for pork were studied by Geesink et al. [160]. The data (reflectance spectra (1000-2500 nm), water-holding capacity, shear force, ultimate $\mathrm{pH}$, and colour $\left(\mathrm{L}^{*}, \mathrm{a}^{*}, \mathrm{~b}^{*}-\right.$ value) of 96 pork longissimus) were obtained two days post mortem and subjected to stepwise multiple linear regression (SMLR) and partial least-square regression (PLSR). The drip loss was predicted successfully while shear force was not.

B.1.15. Other Subjects. Shackelford et al. [165] studied optimal measurement for NIR and VIS. They recommended for online VIS/NIR studies of longissimus quality traits of ribbed beef carcasses: a high-intensity probe (with a $50 \mathrm{~mm}$ diameter hole in the limiter plate), data acquirement was done with averaging 20 spectra per observation, measurement place longissimus from one side per carcass, and at a standardized bloom time for spectra taking. Offline measurement application to lamb and pork and smaller muscles may require a reduction in the size of the opening in the limiter plate.

Information about sample characteristics, process, and slaughter conditions can be found, for example, in Cozzolino et al. [166], Cozzolino et al. [146], Cozzolino et al. [167], Mitsumoto et al. [148] 1991, Swatland [145], and Cozzolino and Murray [150].

B.1.16. Authentication. Authenticity of meet has several viewpoints. One viewpoint is the origin, another adulteration, and the last one ecological point. The common factor is that consumers should get what they intend to buy, even when the food bought is otherwise acceptable. Some people prefer organic food for their perceived superiority. The composition of meat, flavor, color, and fatty acid composition [168] of cattle and sheep depend heavily on diet.

Dian et al. [168] used VIS 400-700 nm and VIS/NIR 400-2500 nm with laboratory monochromator for separating pasture-fed and concentrate-fed lamb carcasses. They evaluate for this purpose three methods: (1) composition based on carotenoid absorption and perirenal fat reflectance at 450$510 \mathrm{~nm}$, (2) composition based on perirenal fat reflectance at $400-700 \mathrm{~nm}$, and (3) full spectrum of $400-2500 \mathrm{~nm}$. The measured target was especially the perirenal fat because it is always present and can be removed without affecting carcass quality, and it provides better results than subcutaneous caudal fat [169]. The methods assessed the pasturefed lambs by classification rates of $89.1 \%, 90.8 \%$, and $97.5 \%$ and for concentrate-fed lambs by $98.6 \%, 98.6 \%$, and $97.8 \%$, respectively.

Cozzolino and Murray [170] applied VIS/NIR 400$2500 \mathrm{~nm}$ spectra for classifying the meat from beef, lamb, pork, and chicken. The achieved accuracy was over $80 \%$ with PCA and PLS.

Ding and $\mathrm{Xu}$ [171] obtained ideal results while separating beef and kangaroo samples. All kangaroo samples were identified with $100 \%$ accuracy.

B.1.17. Drip Loss/Water Holding Capacity. The water-holding capacity is a major pig meat technological property. Prevolnik et al. [172] used artificial neural network to predict protein drip loss from NIR with error of 2.5-2.6\%.

B.1.18. Meat Freshness. The meat freshness can be thought to be related to its butchery date and possible freezing/thawing. Downey and Beauchêne [173] successfully applied VIS/NIR for separating the fresh meat from frozen/thawed beef using factorial discriminant procedure. Another study to separate frozen and unfrozen beef was done by Thyoldt and Isaksson [174].

B.1.19. Spoilage. Spoilage of beef has been studied by Ellis et al. [117]; Horváth et al. [116] applied NIR spectroscopy to pork meet.

B.1.20. Bioagents. Hobson et al. [175] suggested the use of spectral methods for detecting the metabolic state of microorganisms.

\section{B.1.21. Milks}

General Quality. Milk quality measured using NIR has been suggested by Kawasaki et al. [176]. Al-Qadiri et al. [177] studied the quality with visible (starting at $600 \mathrm{~nm}$ ) and short infrared NI Karoui and De Baerdemaeker [178] give a review of analytical methods including NIRS coupled with chemometric tools for the quality determination and identity of dairy products.

Content. Laporte and Paquin [179] used partial and overall PLS calibration of near-infrared transmission data to evaluate its fat, crude protein, true protein, and casein content. The results indicated that NIR provides reliable results for the evaluation purposes and overall PLS calibration can improve the results.

Šašić and Ozaki [180] subjected raw milk to SW-NIR (800-1100 nm) measurements. They predicted the fat, protein, and lactose contents using PLS regression and band assignment. The correlation of spectra and milk protein was sufficiently high. Fat content prediction needed pretreatment. Prediction of lactose content was limited.

Adulteration. Milks are also subject to adulteration. Some cases of the adulteration can be subtle like adding foreign fat. Sato et al. [181] used NIR analysis to detect these fats.

B.2. Class B, Type 07: Poultry Products. Chicken meat products need to be controlled because of their safety risk and quality. These issues have been considered in many papers such as Chen et al. [182], Chen and Marks [183], Chen and 
Marks [184], Chen et al. [185], McElhinney et al. [186], and Rannou and Downey et al. [187].

Park et al. [188] have recently constructed a prototype multispectral imaging system for online poultry carcass fecal contamination detection. They used a line-scan imaging system using 517, 565, 600, and $802 \mathrm{~nm}$. The longest wavelength was used for removing artifacts caused by cuticle.

B.2.1. Incorrect Ingredients. The poultry meat can be contaminated by many things. One of the most dangerous things is the manure which contains many disease-causing microorganisms.

B.2.2. Content. The poultry meat is evaluated for ash, dry matter (DM), crude protein (CP), and fat content. The meat can be in different formats-like fresh or dried. Freeze dried ostrich meat tenderloin (M. ambiens), big drum ( $M$. iliofibularis), and fan fillet (M. gastrocnemius) were evaluated by Viljoen et al. (2005) using NIR $1100-2500 \mathrm{~nm}$ and PLS 0 . The results were accurate for crude protein and fat, but the prediction of ash and dry matter was not very successful.

Iron-related substances can also be evaluated from meat. Hong and Yasumoto [139] studied heme and nonheme iron in raw meats (e.g., chicken and duck) using NIR diffuse reflectance. They applied multiple regression equations, the second derivative data $(1100$ to $2500 \mathrm{~nm})$ with multiple correlation coefficients over 0.9 for both hemes and total iron. The best MREs were obtained with the NIR data recorded at wavelengths where $\mathrm{NH}$ groups in protein molecules and C-C and $\mathrm{CH}$ in the porphyrin ring of heme give absorption.

B.2.3. Authenticity/Origin. The origin of chicken meat affects its value. Ding et al. [189] applied VIS/NIR (750-1100 nm) to separate broilers from Chinese local chickens using pieces of chicken meat cut.

B.2.4. Spoilage. Lin et al. [190] used chicken as a material for investigating spoilage. Poultry can be spoilt with too much heating. It seems that the intensity of wavelength bands around $445 \mathrm{~nm}$ and $560 \mathrm{~nm}$ decreases with cooking time when using correlation analysis [191]. After this decrease, the intensity begins to vary at 475,520 , and $585 \mathrm{~nm}$.

B.2.5. Storage and Handling. It has been indicated that thawing may swallow the reabsorption of certain fluids like soluble proteins, vitamins, and salts by the meat. However, there is a risk of meat discoloration and lipid oxidation if the time for thawing is too long. Liu et al. [192] studied the effect of chilled and frozen storages (temperature, time) and shear force on chicken breasts using generalized 2D correlation analysis of VIS and NIR spectra. They noticed that the temperature of frozen storage changed intensities at 445 and $560 \mathrm{~nm}$. The NIR spectra decreased. Tender and tough muscles caused difference in NIR spectral intensity. Liu et al. [193] examined the thawing behavior of frozen chicken meat with 2D VIS/NIR correlation.
B.3. Class B, Type 08: Aquatic Animal Products. Visible spectroscopy may sometimes be more useful than NIRS as found by Stormo et al. [194] who used visible spectroscopy for assessing endpoint temperature of heat-treated surimi. Their method shows potential for use in the food processing industry.

B.3.1. Appearance. Blood in fish is sometimes an unwanted characteristic. Olsen [195] and Olsen et al. [196] suggested that it might be possible to develop a method using VIS/NIR to access residual blood in intact cod muscle.

B.3.2. Identification and Authentication. Fishmeal batches can be made from different fish species. Cozzolino et al. [197] used NIR reflectance (1100 nm-2500 nm) and chemometrics to identify and authenticate the patches. They concluded that dummy partial least-square regression achieves 80$82 \%$ correct classification. Linear discriminant analysis based on principal component analysis scored achieved over $80 \%$ correct rate.

B.3.3. Freshness. Fish quality is largely determined by freshness. The freshness parameter can be linked to the time of catch or harvest or freezing. It can refer to instrumental analysis or sensory evaluation.

Uddin et al. [198] suggest using of VIS/NIR spectroscopy to determine whether the fish were frozen-thawed or fresh. Bøknaes et al. [199] used NIR spectroscopy and sensory quality evaluation to rate the freshness of thawed and chilled cod fillets packed in modified atmosphere. They studied the estimation of storage temperature, storage period, and chill storage period for fish. The storage time for cod and salmon was also investigated with VIS/NIR spectra by Nilsen et al. [200]. Several techniques like visible spectroscopy, texture, and image analysis can be combined to improve results [201]. The spoilage of rainbow trout has been studied by Lin et al. [202].

Zhang and Lee [203] used near-infrared for determining free fatty acids content of fish oil and mackerel. Since the change in free fatty acids is related to hypoxanthine, they suggested it to be used as an indicator of freshness. They found that the partial least-square model produced better results than multiple linear regression.

B.3.4. Content. Earliest fish study seems to be by Gjerde and Martens [204], they demonstrated that NIR can be used to predict water, fat, and protein contents in rainbow trout. They used reflectance spectroscopy to minced and freeze-dried samples. Since then, a lot of fish studies have been published and some at-line and online food quality controls. However, the technique is not yet a standard everyday instrumental tool. This might be due to high instrumentation costs and the need of models between spectroscopic reading and quality parameters in order to analyze them [31].

The fat content of fish has and still is under research. It has been applied on different species and different forms of fish: frozen and thawed glazed bigeye tuna [205], albacore [206], frozen skipjack [207, 208], raw and frozen horse mackerel 
[206], frozen and thawed mackerel. Fish are sometimes ranked by their fat using visual inspection which seems to be an inaccurate method [205].

Mathias et al. [209] suggested the use of NIR for protein content analysis of freeze-dried freshwater fish. The standard deviation between results from NIR (mean lipid content) and chemical analysis was 3.7\%. Mathias et al. [209] suggested also the use of NIR for lipid content analysis of freeze-dried freshwater fish. The standard deviation between results from NIR (mean lipid content) and chemical analysis was $10 \%$.

Application of short-wavelength near-infrared spectra (600-1100 nm) can be used to determine the salt and moisture contents of salmon roe [7].

Lee et al. [210] applied diffusive reflectance of shortwavelength near-infrared in the range of 700-1000 for predicting the amount of crude lipid of intact, whole rainbow trout. The best correlation between measured and reference values was obtained from measurements at a midposition between dorsal and adipose fins above the lateral line. The modeling was done using multivariate calibration models, multiple linear regression, and partial least squares.

B.3.5. Defects. Lin et al. [211] used VIS and SW-NIR (600$1100 \mathrm{~nm}$ ) to find bruises in intact, whole Pacific pink salmon. The measurements were done in diffuse reflectance mode and without removing skin or scales. The spectral results were compared against digital images of filleted fish with partial least-square model. The correct classification rate for nonbruised fish spectra was $84 \%$, while for bruised it was $81 \%$.

B.3.6. Incorrect Ingredients. Inorganic arsenic is an unwanted and unhealthy ingredient. Font et al. [212] subjected freezedried samples of red crayfish to inorganic arsenic content analysis. They applied a modified partial least-square regression for modeling with acid-digestion solvent-extracted hydride generation atomic absorption spectrometry measurements. The data was standardized by applying standard normal variate and detrending algorithms and preprocessed with 2nd derivative.

B.3.7. Bioagents. Fish can contain parasites which range from plain ugly appearance to dangerous for human health. Some food-borne illnesses caused by microorganisms can be prevented by proper handling like cooking.

B.3.8. Spoilage. Fish is spoiled easily and the spoiled fish is usually unsuitable for human consumption. Lin et al. [202] studied the spoilage for rainbow trout. They used 600-1100 nm region which may be applicable to detect various fundamental molecular vibrations of several functional groups like $\mathrm{CH}, \mathrm{O}-\mathrm{H}, \mathrm{N}-\mathrm{H}$, and $\mathrm{C}=\mathrm{O}$. The absorption, reflectance, and transmittance of biochemical components help to determine the chemical composition and thus spoilage.

B.4. Class B, Type 009: Amphibians and Reptilians. The amphibians and reptilians group includes frogs, lizards, snakes, and turtles. This area seems to be lacking research papers.

B.5. Class B, Type 010: Invertebrate Animals. The invertebrate animals group consists of molluscs (including cephalopods) and other invertebrate animals.

B.5.1. Authenticity. Some edible invertebrate animals are more valuable and sought after than others. The processing of seafood causes appearance changes which make it very hard for a consumer to separate between authentic and adulterated products. This increases the risk of adulteration. Gayo and Hale [213] applied VIS and NIR spectra to find adulteration of crab meat. The crab meats (Atlantic blue and blue swimmer) were mixed with surimi-based adulterant in $10 \%$ increase. The adulterant increase caused decreasing water absorbance. They concluded that both PLC and principal component analysis can detect successfully adulteration. In another study, by Gayo et al. [214], VIS/NIR was applied to separate the Atlantic blue crabmeat adulterated with blue swimmer crabmeat (10\% increment). Adulteration of meat changed the water absorption bands which could be used for adulteration detection.

B.5.2. Content. Brown [215] applied VIS and NIR (350$2500 \mathrm{~nm}$ ) for homogenized oyster meat and analyzed the data quantitatively and qualitatively. The results for moisture $\left(r^{2}=\right.$ 0.92 , SEP $=0.53 \%$ wet weight $)$, protein $\left(r^{2}=0.97\right.$, SEP $=$ $0.18 \%$ wet weight), fat $\left(r^{2}=0.97, \mathrm{SEP}=0.11 \%\right.$ wet weight), and glycogen $\left(r^{2}=0.94, \mathrm{SEP}=0.24 \%\right.$ weight $)$ indicate that VIS/NIR is useful for oyster evaluations.

C.

\section{C.1. Class D, Type 12: Secondary Food Commodities of Plant Origin}

C.1.1. Content. Lebot et al. [216] applied NIR spectra (350$2500 \mathrm{~nm}$ ) for flours from tropical root and tuber crops (cassava, sweet potato, taro, and yam). They evaluated starch, total sugars, cellulose, total nitrogen, and ash (total minerals) contents of the flours. The prediction accuracy achieved over $85 \%$ confidence for starch, sugar, and nitrogen, while for ash (minerals) it was $71 \%$. The method was unsuitable for cellulose. The advantage of NIR is its cheapness.

Dacal-Nieto et al. [217] have recently used NIR multispectral imaging to detect the hollow heart of potato tubers. The camera used is sensitive from $900 \mathrm{~nm}$ to $1700 \mathrm{~nm}$ and used Specim Imspector N17E (Specim Oy, Oulu, Finland) spectrograph. Several wavelength selection methods were used, out of which the genetic algorithm was marginally the best, that is, gave the best classification accuracy in the classification step.

Green honeybush contains mangiferin and hesperidin which are bioactive components. Jourbert et al. [218] predicted content of these ingredients in dried plant material 
using diffuse NIR reflectance with results suitable for screening purposes.

Bellato et al. [219] studied wholegrains and flour of oats. The purpose was to determine $\beta$-glucan and protein content. They applied NIR reflectance for flour and grains and NIR transmittance for flours. The model for chemometric relationship was a partial robust $\mathrm{M}$-regression, a version of partial least squares. The models using reflectance values stood out best.

For example, Schimleck et al. [220] evaluated successfully air-dried leaves from Melaleuca cajuputi tree for their 1.8cineole (Eucalyptol) content and oil concentrations using NIR.

Evaluating roots provides an attractive possibility to select the individual containing the highest amount of ingredients or classify the roots in different groups according to some preset content classes. It is also possible to compare different root processing methods. Joubert et al. [221] studied Devil's claw root for evaluating iridoids (harpagoside and $8-\rho$ coumaroyl harpagide $(8 \rho \mathrm{CHG}))$ and moisture content from different drying conditions. The NIR study indicates that the harpagoside retention was lower in sun-dried samples than tunnel dried or freeze-dried samples. They concluded that the best retention was obtained from tunnel-drying at $50^{\circ} \mathrm{C}$. NIRS was very suitable for predicting moisture and suitable for semiquantitative classification using the iridoids.

Leaves of green tea were subjected to NIR reflectance measurement and PLS modeling to predict polyphenol and alkaloid compounds (Schulz et al. [222]). The prediction of parameters of green tea was very successful for gallic acid, epicatechin, epigallocatechin, epicatechin gallate, epigallocatechin gallate, caffeine, and theobromine, but a lower accuracy was obtained for total polyphenol content probably due to the colorimetric method (lack of specificity).

The dry matter of leaves can be evaluated very precisely (Schulz et al. [222]) for green tea $R^{2}=0.94$; $\mathrm{SD} / \mathrm{SECV}=$ 4.12. Furthermore, it is possible to discriminate tea leaves of different age by principal component analysis on the basis of the received NIR spectra.

Hernández-Hierro et al. [223] examined visible-NIR spectroscopy for freeze-dried broccoli. They concluded that it is potentially usable for screening of almost all individual glucosinolates and total glucosinolates.

C.1.2. Adulteration. Laasonen et al. [224] used PLS and pretreated NIR reflectance spectra to identify fast Echinacea purpurea dried and milled root from samples adulterated/substituted by other species (Echinacea angustifolia, Echinacea pallida, or Parthenium integrifolium). Minimum adulteration rate for detection was $10 \%$.

\section{C.2. Class D, Type 13: Derived Products of Plant Origin}

C.2.1. Content. Juices contain many important ingredients whose concentration needs to be evaluated. Li et al. [225] measured transmission spectra of orange juice dry extract in the range of $1100-2500 \mathrm{~nm}$. They used multivariate calibration to evaluate the amount of sugars (glucose, fructose, and sucrose) and acids (citric and malic acids). The reference values were obtained using enzymatic assays. The best model was obtained using partial least-square regression. Fruit juice from raw Japanese apricot which is also known as Japanese plum was also subjected to evaluation of citric and malic acid contents. Chen et al. [226] used NIR spectra of 1100-1850 nm and partial least-square regression for producing acceptable prediction results for the evaluation.

Sometimes the concentration of juice is important and one needs to get a high yield. For example, González-Sáiz et al. [227] applied successfully NIR and multivariate calibration for monitoring alcoholic fermentation of onion juice. The goal was the valorization of worthless onions.

Cen et al. [228] used VIS/NIR (325-1075 nm) for determining the soluble solids contents and $\mathrm{pH}$ in orange juice. The data was preprocessed with Wavelet packet transform, standard normal variate transformation (SNV), and SavitzkyGolay first-derivative transformation. Partial least-square (PLS) regression was applied and it produced best results with SNV.

We include in this juice group also cola beverages. For a cola beverage, important parameters are, for example, $\mathrm{pH}$. Liu and He [229] applied chemometrics to VIS/NIR spectra to get the soluble solid content and $\mathrm{pH}$ of cola beverage with excellent prediction precision. Least squares with support vector machine provided better results than partial least squares.

Different oils have also ingredients which need to be evaluated. $\mathrm{Ng}$ et al. [230] used NIR (1100-2500 nm) for the evaluation of degradation products (including total polar material and free fatty acids) of frying oils. According to their results, partial least-square regression is better in 700$1100 \mathrm{~nm}$ area than forward stepwise multiple linear regression, while in the whole range, they are equal. The best correlations were over 0.98 .

\section{C.3. Class D, Type 014: Manufactured Foods (Single Ingredient) of Plant Origin}

C.3.1. Content. Cozzolino et al. [231] did a review about nearinfrared spectroscopy applied to grapes and wine.

Chen and Lei [232] applied VIS and NIR spectra to obtain the amount of carbohydrate in soy milk powder. Their goal was to find a high speed method for this. They searched optimal wavelength band in spectra using simulated annealing and wavelet packet transform tree. After this, different partial least-square models were tested using 20 variables.

Dambergs et al. [233] determined the methanol content of wine-fortifying spirit. They developed partial least-square model for NIR spectra with results from gas chromatography used as a reference.

Sáiz-Abajo et al. [234] used NIR to classify the samples into red/white wine vinegar and alcohol vinegar samples. They used orthogonal signal correction (OSC) method to remove information related to tartaric acid. Sáiz-Abajo et al. [235] studied 14 parameters which are important for the quality of wine vinegar. 
Fan et al. [236] have recently used NIRS with several wavelength selection methods to predict the total acid of vinegar. Their main conclusion was that wavelength selection is essential for the creation of better regression models for acid prediction.

Bruun [237] has studied protein-lipid-carbohydrate interactions and their importance to the food quality.

Feng Liu et al. [238] have recently used VIS/NIR spectroscopy and least-square support vector machine (LS-SVM) for the soluble solid content (SSC) and $\mathrm{pH}$ determination of fruit vinegar. The results indicate that the method could be used in the online monitoring of vinegar fermentation.

C.3.2. Authenticity. Cozzoline et al. [239] used VIS and NIR spectra to classify Chardonnay and Riesling white wines according to their Australian varietal origins. Discriminant partial least-square (DPLS) regression was the most successful model tested; achieving 100\% correct labeling for Riesling. Later, Liu et al. [240] classified Tempranillo wines from Australia and Spain according to their geographical origins. They accompanied both VIS and NIR data (400-2500 nm) for multivariate analysis PCA, DPLS, PLS-DA, and LDA from which PLS-DA was the best with high correct classification rate.

Buratti et al. [241] have tested NIR and IR spectroscopy combined with electronic nose and tongue for the offline monitoring of wine fermentation. The results are promising for the development of an online fermentation monitoring method based on these techniques.

C.3.3. Age. Yu et al. [242] applied LS-support vector machine (SUM) to NIR spectra to determine age and oenological parameters of rice wine. The inputs to LS-SVM applied were scores of ten principal components (PCs) and radial basis functions. LS-SVM was a little better than PLS for alcohol content, titratable acidity, and $\mathrm{pH}$.

\section{C.4. Class D, Type 015: Manufactured Foods (Multi-Ingredient) of Plant Origin}

C.4.1. Content. Information about fat is often searched by consumer, for example, in cereals. However, the information is typically an estimate because the methods used like calorimetry destroy samples. Vines et al. [243] predicted the total amount of fat using near-infrared and modified partial least-square regression with good results when compared against reference values from the AOAC 996.01 method. Windham et al. [244] tested the effect of moisture to the calibration models and found that it has a significant effect. However, they developed a new partial least-square regression model to be robust enough to provide good prediction in a wide range of residual moistures. Kays et al. [245] used NIR reflectance (1100 to $2498 \mathrm{~nm}$ ) to determine the total dietary fiber in cereal and grain products. AOAC (991.43) enzymaticgravimetric method produced the reference samples.

Fernández Pierna et al. [64] have recently used NIR hyperspectral imaging and chemometrics for the detection of impurities in cereals. They used a whiskbroom system
MatrixNIR Chemical Imaging instrument (Malvern instruments, Analytical Imaging, Columbia, MD, USA)) with an InGaAs FPA along with two liquid crystal tuneable filters (LCTF) for wavelength selection. The results show potential for NIR imaging in impurity detection. However, the whiskbroom system might not be as good in this task as a pushbroom system that they used in another case study with sugar beets.

C.4.2. Total Fiber Amount. Kays et al. [246] evaluated the total fiber amount of cereals using NIR spectra. The samples with high sugar and crystalline sugar were selected because a unique spectrum of crystalline sugar affects NIR spectra. The developed partial least-square model predicted the content well. Kays et al. [247] extended the NIR model to cereals with high fat or sugar and fat. The extension was necessarily because high fat or sugar may differ substantially from spectral properties.

Kays and Barton II [248] used NIR reflectance (1104$2494 \mathrm{~nm}$ ) to determine the chemometric model for predicting gross energy and available energy of cereals. The reference values were obtained from bomb calorimetry. In another study, Kays and Barton II [249] determined accurately soluble and insoluble dietary fiber using NIR reflectance spectra (NIRSystems 6500 monochromator) and reference values from the AOAC Method 991.43. The modeling was done using modified PLS models.

Another aspect is how much energy comes from fat of ground cereals. Kays and Barton II [250] applied successfully near-infrared in the range of 1104-2494 nm to determine this using a version of PLS regression model. The sample reference was obtained using calorimetry. Archibald and Kays [251] analyzed whole intact breakfast cereals, snack foods, wholegrains, and milled products. They found that total dietary fiber could be evaluated from NIR reflectance spectra and moisture has not any effect on the results. Transmission and reflectance 700-1100 nm NIR spectra of cookies were measured by Ozanich et al. [252] to determine moisture and oil contents. Moisture content has highest correlation (and absorbance) with $965 \mathrm{~nm}$ wavelength (a combination band of $\mathrm{H}_{2} \mathrm{O}$ ) while oil content with $930 \mathrm{~nm}$ (a 3rd overtone $\mathrm{CH}$ stretch of methylene) in the normalized spectra.

C.4.3. Structural Properties. de Alencar Figueiredo et al. [253] studied a wide range of sorghum cores with high genetic diversity. They used NIR reflectance to determine amylase, protein, and lipid contents, endosperm texture, and hardness.

C.4.4. Handling/Fermentation. Bruun et al. [254] used NIR for analyzing gluten powder with different handling (heat, moisture). The NIR data was processed with secondderivative transformation and extended multiplicative signal correction. The moisture caused shifts and intensity changes in the protein bands. Bruun et al. [254] assumed this to be due to changes in water binding and microenvironments of the amino acid side chains. Heat caused an increase at $2209 \mathrm{~nm}$ and decrease at $2167-2182 \mathrm{~nm}$ which could be due to an $\alpha$ helix to $\beta$-sheet transformation. Next, in [255] different salts were added to the hydrated gluten. The same preprocessing 
was used and PCA was applied on this data. The results showed a correlation between spectra and salt type and concentration.

Sinelli et al. [256] used NIR (750-1100 nm) and MIR (4000-600 $\mathrm{cm}^{-1}$ ) with a fiberoptic surface interactance for dough proofing. Dough proofing is a phase during which the dough starts to ferment after the mixture of ingredients, it affects the quality of bread, and it was also noticed that NIR spectra changed.

\section{D.}

D.1. Class E, Type 016: Secondary Food Commodities of Animal Origin. Secondary food commodities of animal origin consist of dried meat and fish products and secondary milk products. We include here also products using dried meat and fish. An example of this is ham.

D.1.1. Appearance. García-Rey et al. [257] studied appearance (texture and color) of sliced samples from deboned and crosssectioned dry-cured in VIS/NIR 400-2200 nm with a fiberoptic probe. The classification accuracy for pastiness was $88.5 \%$ and $79.7 \%$ when compared against sensory evaluation. They classified into two classes: defect class and no-defect class.

D.2. Class E, Type 017: Derived Edible Products of Animal Origin. Derived edible products of the animal origin group include processed crustaceans and animals, milk, and derived fats.

D.3. Class E, Type 018: Manufactured Food (Single Ingredient) of Animal Origin. Manufactured food (single ingredient) of the animal origin group is the manufactured milk products using only single ingredient.

D.4. Class E, Type 019: Manufactured Food (Multi-Ingredient) of Animal Origin. Manufactured milk products using multiingredient belong to manufactured food (single ingredient) of the animal origin group. Here we consider dairy products like cheese or yogurts.

D.4.1. Appearance. Lucas et al. [258] applied VIS and NIR for estimating color parameters (brightness, redness, and yellowness) with good results.

D.4.2. Smell. NIR seems to be suitable. Çelik [259] used NIR to evaluate yogurts' aroma and its fermentation [260].

D.4.3. Taste. Taste depends on the goodness of the fermentation process. NIR can be combined with electric nose as a method for online fermentation monitoring and visualizing the state of the fermentation [260].

D.4.4. Content. The titratable acidity of the cultures for yogurt and sour milk can be predicted by forming a model using PLS with NIRS signals [260].
Lucas et al. [258] applied VIS/NIR (400-2500 nm) for 4 cheese varieties. They estimated the content of cheese for the following items: dry matter, fat, $\mathrm{pH}$, retinol, $\alpha$-tocopherol, $\beta$ carotene, xanthophylls, sodium chloride, calcium, potassium, magnesium, zinc, and total antioxidant capacity. The data was handled with modified partial least squares. The coefficient of determination and residual predictive deviation indicated that the spectra provided a good estimate for dry matter, fat, $\beta$-carotene, sodium chloride, calcium, and zinc in fresh cheeses while it was poor for the rest $(\mathrm{pH}$, retinol, $\alpha$ tocopherol, xanthophylls, potassium, magnesium, and total antioxidant capacity).

D.4.5. $p H . \mathrm{pH}$ of the dairy product is important. Navrátil et al. [260] predicted its value using NIR.

D.4.6. Origin. Cozzi et al. [261] developed a NIR- (1100$2500 \mathrm{~nm}$ ) based method using discriminant analysis to discriminate Asiago d'Allevo cheese from different production chains (alpine farms, mountain, and lowland factories). Alpine products were discriminable from factory products due to their different fatty acids profile and color. The results were confirmed by chemical data.

\section{Abbreviations}

$\begin{array}{ll}\text { ADF: } & \text { Acid detergent fiber } \\ \text { ADL: } & \text { Acid detergent lignin } \\ \text { AM: } & \text { Amylose content } \\ \text { AOAC: } & \text { Association of Official Agricultural } \\ & \text { Chemists } \\ \text { CH: } & \text { Carbon-hydrogen } \\ \text { CP: } & \text { Crude protein } \\ \text { DA: } & \text { Discriminant analysis } \\ \text { DM: } & \text { Dry matter } \\ \text { DPLS: } & \text { Discriminant partial least squares } \\ \text { EE: } & \text { Ether extract } \\ \text { ET: } & \text { Endosperm texture } \\ \text { FAO: } & \text { Food and Agriculture Organization } \\ \text { FPA: } & \text { Focal plane array } \\ \text { GA: } & \text { Genetic algorithms } \\ \text { GE: } & \text { Gross energy } \\ \text { GP: } & \text { Genetic programming } \\ \text { HCA: } & \text { Hierarchical cluster analysis } \\ \text { HD: } & \text { Hardness } \\ \text { HPLC: } & \text { High-performance liquid } \\ & \text { chromatography } \\ \text { IR: } & \text { Infrared } \\ \text { KDF: } & \text { Kernel Fisher discriminant } \\ \text { L*,a*, b* : Lab color space } \\ \text { LCTF: } & \text { Liquid crystal tuneable filter } \\ \text { LDA: } & \text { Linear discriminant analysis } \\ \text { LI: } & \text { Lipid content } \\ \text { LS: } & \text { Least squares } \\ \text { MCT: } & \text { Mercury-cadmium-telluride } \\ \text { MIR: } & \text { Mid-infrared } \\ \text { MORS: } & \text { Meullenet-Owens razor shear } \\ \text { mPLS: } & \text { Modified partial least squares } \\ & \end{array}$


MRE: Multiple regression equations

NDF: Neutral detergent fiber

NIR: Near-infrared

NIRS: Near-infrared spectroscopy

OSC: Orthogonal signal correction

PC: $\quad$ Principal components

PCA: Principal component analysis

pH: $\quad$ Potential hydrogen

PLS: $\quad$ Partial least squares

PLSDA: Partial least-squared discriminant analysis

PLSR: Partial least-square regression

PR: $\quad$ Protein content

$R^{2}$ : $\quad$ Coefficient of determination of a linear regression

RPFNN: Radical basis function neural network

SC: $\quad$ Sugar content

SMLR: Stepwise multiple linear regression

SEF: $\quad$ Sucrose ester of fatty acid

SPA: Successiveprojection algorithm

SSC: $\quad$ Soluble solid content

SVM: $\quad$ Support vector machines

SW-NIR: Short wavelength near-infrared

TA: $\quad$ Titratable acidity

UV: Ultraviolet

UVE: Uninformative variable elimination

VIP: $\quad$ Variable importance in projection

VIS: $\quad$ Visible wavelengths

VIS/NIR: Visual and near-infrared

WBSF: Warner-Bratzler shear force.

\section{Acknowledgments}

The authors want to acknowledge Tekes (the Finnish Funding Agency for Technology and Innovation) and industrial partners Riitan Herkku, Oy Ari Green Plant Ltd., Jepuan Peruna Oy, Etnovia Oy, and Specim, Spectral Imaging Ltd., for funding this research in a project called TarhaNIRSo (FruitForce) in Sapuska Research Program of Tekes. They also like to acknowledge Professor Paul Geladi for his many advices on NIRS applications.

\section{References}

[1] H. Huang, H. Yu, H. Xu, and Y. Ying, "Near infrared spectroscopy for on/in-line monitoring of quality in foods and beverages: a review," Journal of Food Engineering, vol. 87, no. 3, pp. 303-313, 2008.

[2] K. H. Norris and J. R. Hart, "Direct spectrophotometric determination of moisture content of grain and seeds," in Proceedings of the International Symposium on Humidity and Moisture, 1965.

[3] P. Williams, "Grains and seeds," in Near-Infrared Spectroscopy in Food Science and Technology, Y. Ozaki, W. F. McClure, and A. A. Christy, Eds., chapter 7.1, pp. 165-217, John Wiley \& Sons, 2007.

[4] B. G. Osborne, "Near-infrared spectroscopy in food analysis," in Encyclopedia of Analytical Chemistry, John Wiley \& Sons, 2006.

[5] J. Farkas and I. Dalmadi, "Near infrared and fluorescence spectroscopic methods and electronic nose technology for monitoring foods," Progress in Agricultural Engineering Sciences, vol. 5, no. 1, pp. 1-29, 2009.

[6] K. Kaffka, "How the NIR technology came to and spread in Europe for quality assessment and control in the food industry," Acta Alimentaria, vol. 37, no. 2, pp. 141-145, 2008.

[7] Y. Huang, T. M. Rogers, M. A. Wenz et al., "Detection of sodium chloride in cured salmon roe by SW-NIR spectroscopy," Journal of Agricultural and Food Chemistry, vol. 49, no. 9, pp. 4161-4167, 2001.

[8] P. Pallav, G. G. Diamond, D. A. Hutchins, R. J. Green, and T. H. Gan, "A near-infrared (NIR) technique for imaging food materials," Journal of Food Science, vol. 74, no. 1, pp. E23-E33, 2009.

[9] Y. Ozaki, W. F. McClure, and A. A. Christy, Eds., NearInfrared Spectroscopy in Food Science and Technology, WileyInterscience, 2006.

[10] L. A. Berrueta, R. M. Alonso-Salces, and K. Héberger, "Supervised pattern recognition in food analysis," Journal of Chromatography A, vol. 1158, no. 1-2, pp. 196-214, 2007.

[11] L. M. Reid, C. P. O’Donnell, and G. Downey, "Recent technological advances for the determination of food authenticity," Trends in Food Science and Technology, vol. 17, no. 7, pp. 344-353, 2006.

[12] H. Cen and Y. He, "Theory and application of near infrared reflectance spectroscopy in determination of food quality," Trends in Food Science and Technology, vol. 18, no. 2, pp. 72-83, 2007.

[13] C.-J. Du and D.-W. Sun, "Learning techniques used in computer vision for food quality evaluation: a review," Journal of Food Engineering, vol. 72, no. 1, pp. 39-55, 2006.

[14] M. Iwamoto, J. Uozumi, and K. Nishinari, "Preliminary investigation of the state of water in foods by near infrared spectroscopy," in NIR/NIT Conference, Budapest, Hungary, 1987.

[15] M. Iwamoto, S. Kawano, and H. Abe, "Water in foods. Analysis of hydrogen bonding related to water in foods," NIR News, vol. 6, no. 3, pp. 10-12, 1995.

[16] H. Maeda, Y. Ozaki, M. Tanaka, N. Hayashi, and T. Kojima, "Near infrared spectroscopy and chemometrics studies of temperature-dependent spectral variations of water: relationship between spectral changes and hydrogen bonds," Journal of Near Infrared Spectroscopy, vol. 3, pp. 191-201, 1995.

[17] H. Büning-Pfaue, "Analysis of water in food by near infrared spectroscopy," Food Chemistry, vol. 82, no. 1, pp. 107-115, 2003.

[18] P. Geladi and H. Grahn, Multivariate Image Analysis, John Wiley \& Sons, 1996.

[19] J. Workman Jr. and A. Springsteen, Applied Spectroscopy: A Compact Reference for Practitioners, Academic Press, 1998.

[20] J. Koljonen, T. E. M. Nordling, and J. T. Alander, "A review of genetic algorithms in near infrared spectroscopy and chemometrics: past and future," Journal of Near Infrared Spectroscopy, vol. 16, no. 3, pp. 189-197, 2008.

[21] D.-W. Sun, Modern Techniques for Food Authentication, Elsevier/Academic Press, 2008.

[22] J. Workman Jr. and L. Weyer, Practical Guide to Interpretive Near-Infrared Spectroscopy, CRC Press, Boca Raton, Fla, USA, 2008.

[23] J. R. Koza, "Genetic programming as a means for programming computers by natural selection," Statistics and Computing, vol. 4, no. 2, pp. 87-112, 1994.

[24] K. Norris and P. Williams, "Optimization of mathematical treatment of raw near-infrared signal in the measurement of 
protein in hard red spring wheat. I. Influence of particle size," Cereal Chemistry, vol. 61, pp. 158-165, 1983.

[25] R. Goodacre and D. B. Kell, "Evolutionary computing for the characterisation and qualification of microbial systems from hyperspectral data," in FT-IR Meeting in Berlin, 2000.

[26] P. Williams and D. Sobering, "Comparison of commercial near infrared transmittance and reflectance instruments for analysis of whole grains and seeds," Journal Near Infrared Spectroscopy, vol. 1, no. 1, pp. 25-32, 1993.

[27] P. Butz, C. Hofmann, and B. Tauscher, "Recent developments in noninvasive techniques for fresh fruit and vegetable internal quality analysis," Journal of Food Science, vol. 70, no. 9, pp. R131R141, 2005.

[28] B. M. Nicolaï, K. Beullens, E. Bobelyn et al., "Nondestructive measurement of fruit and vegetable quality by means of NIR spectroscopy: a review," Postharvest Biology and Technology, vol. 46, no. 2, pp. 99-118, 2007.

[29] C. M. Andersen, J. P. Wold, and S. B. Engelsen, "Autofluorescence spectroscopy in food analysis," in Handbook of Food Analysis Instruments, chapter 15, pp. 347-364, CRC Press, 2009.

[30] J. P. Wold and M. Mielnik, "Nondestructive assessment of lipid oxidation in minced poultry meat by autofluorescence spectroscopy," Journal of Food Science, vol. 65, no. 1, pp. 87-95, 2000.

[31] L. Nollet and F. Toldra, Handbook of Seafood and Seafood Products Analysis, CRC Press, Boca Raton, Fla, USA, 2010.

[32] H. B. Ding and R. J. Xu, "Near-infrared spectroscopic technique for detection of beef hamburger adulteration," Journal of Agricultural and Food Chemistry, vol. 48, no. 6, pp. 2193-2198, 2000.

[33] G. ElMasry, D.-W. Sun, and P. Allen, "Near-infrared hyperspectral imaging for predicting colour, $\mathrm{pH}$ and tenderness of fresh beef," Journal of Food Engineering, vol. 110, no. 1, pp. 127-140, 2012.

[34] Y. Liao, Y. Fan, and F. Cheng, "On-line prediction of $\mathrm{pH}$ values in fresh pork using visible/near-infrared spectroscopy with wavelet de-noising and variable selection methods," Journal of Food Engineering, vol. 109, no. 4, pp. 668-675, 2012.

[35] C. Collell, P. Gou, J. Arnau, and J. Comaposada, "Nondestructive estimation of moisture, water activity and $\mathrm{NaCl}$ at ham surface during resting and drying using NIR spectroscopy," Food Chemistry, vol. 129, no. 2, pp. 601-607, 2011.

[36] L. Dvash, O. Afik, S. Shafir et al., "Determination by nearinfrared spectroscopy of perseitol used as a marker for the botanical origin of avocado (Persea americana Mill.) honey," Journal of Agricultural and Food Chemistry, vol. 50, no. 19, pp. 5283-5287, 2002.

[37] G. Downey and J. D. Kelly, "Detection and quantification of apple adulteration in diluted and sulfited strawberry and raspberry purées using visible and near-infrared spectroscopy," Journal of Agricultural and Food Chemistry, vol. 52, no. 2, pp. 204-209, 2004.

[38] R. Fügel, R. Carle, and A. Schieber, "Quality and authenticity control of fruit purées, fruit preparations and jams-a review," Trends in Food Science \& Technology, vol. 16, no. 10, pp. 433441, 2005.

[39] P. Y. Qiu, H. B. Ding, Y. K. Tang, and R. J. Xu, “Determination of chemical composition of commercial honey by near-infrared spectroscopy," Journal of Agricultural and Food Chemistry, vol. 47, no. 7, pp. 2760-2765, 1999.

[40] J. Fontaine, J. Hörr, and B. Schirmer, "Near-infrared reflectance spectroscopy enables the fast and accurate prediction of the essential amino acid contents in soy, rapeseed meal, sunflower meal, peas, fishmeal, meat meal products, and poultry meal," Journal of Agricultural and Food Chemistry, vol. 49, no. 1, pp. 57-66, 2001.

[41] Y. Kim, M. Singh, and S. E. Kays, "Near-infrared spectroscopy for measurement of total dietary fiber in homogenized meals," Journal of Agricultural and Food Chemistry, vol. 54, no. 2, pp. 292-298, 2006.

[42] W. Zeng, H. Zhang, and T. Lee, "Direct determination of the starch content in gravy by near-infrared spectroscopy," Journal of Agricultural and Food Chemistry, vol. 44, no. 6, pp. 1460-1463, 1996.

[43] M. R. Ellekjaer, T. Naes, T. Isaksson, and R. Solheim, "Identification of sausages with fat-substitutes using near infrared spectroscopy," in Near Infrared Spectroscopy: Bridging the Gap Between Data Analysis and NIR Applications, pp. 320-326, Ellis Horwood, London, UK, 1992.

[44] A. J. Gaitán-Jurado, V. Ortiz-Somovilla, F. España-España, J. Pérez-Aparicio, and E. J. De Pedro-Sanz, "Quantitative analysis of pork dry-cured sausages to quality control by NIR spectroscopy," Meat Science, vol. 78, no. 4, pp. 391-399, 2008.

[45] V. Ortiz-Somovilla, F. España-España, A. J. Gaitán-Jurado, J. Pérez-Aparicio, and E. J. De Pedro-Sanz, "Proximate analysis of homogenized and minced mass of pork sausages by NIRS," Food Chemistry, vol. 101, no. 3, pp. 1031-1040, 2006.

[46] E. Mehinagic, G. Royer, D. Bertrand, R. Symoneaux, F. Laurens, and F. Jourjon, "Relationship between sensory analysis, penetrometry and visible-NIR spectroscopy of apples belonging to different cultivars," Food Quality and Preference, vol. 14, no. 5-6, pp. 473-484, 2003.

[47] Walsh, J. Guthrie, and J. Burney, "Application of commercially available, low-cost, miniaturised NIR spectrometers to the assessment of the sugar content of intact fruit," Australian Journal of Plant Physiology, vol. 27, no. 12, pp. 1175-1186, 2000.

[48] P. Carlini, R. Massantini, and F. Mencarelli, "Vis-NIR measurement of soluble solids in cherry and apricot by PLS regression and wavelength selection," Journal of Agricultural and Food Chemistry, vol. 48, no. 11, pp. 5236-5242, 2000.

[49] S. Tsuchikawa and T. Hamada, "Application of time-of-flight near infrared spectroscopy for detecting sugar and acid contents in apples," Journal of Agricultural and Food Chemistry, vol. 52, no. 9, pp. 2434-2439, 2004.

[50] R. J. Blakey, J. P. Bower, and I. Bertling, "Influence of water and ABA supply on the ripening pattern of avocado (Persea americana Mill.) fruit and the prediction of water content using Near Infrared Spectroscopy," Postharvest Biology and Technology, vol. 53, no. 1-2, pp. 72-76, 2009.

[51] L. León, A. Garrido-Varo, and G. Downey, "Parent and harvest year effects on near-infrared reflectance spectroscopic analysis of olive (Olea europaea L.) fruit traits," Journal of Agricultural and Food Chemistry, vol. 52, no. 16, pp. 4957-4962, 2004.

[52] S. Zhang, Y. Zhao, W. Guo et al., "Robust model of fresh jujube soluble solids content with near-infrared (NIR) spectroscopy," African Journal of Biotechnology, vol. 11, no. 32, pp. 8133-8140, 2012.

[53] A. Terdwongworakul, N. Nakawajana, S. Teerachaichayut, and A. Janhiran, "Determination of translucent content in mangosteen by means of near infrared transmittance," Journal of Food Engineering, vol. 109, no. 1, pp. 114-119, 2012.

[54] L. S. Magwaza, U. L. Opara, H. Nieuwoudt, P. J. Cronje, W. Saeys, and B. Nicolaï, "NIR spectroscopy applications for internal 
and external quality analysis of citrus fruit-a review," Food and Bioprocess Technology, vol. 5, no. 2, pp. 425-444, 2012.

[55] B. Shi, B. Ji, D. Zhu, Z. Tu, and Z. Qing, "Study on genetic algorithms-based NIR wavelength selection for determination of soluble solids content in fuji apples," Journal of Food Quality, vol. 31, no. 2, pp. 232-249, 2008.

[56] Y. Ying and Y. Liu, "Nondestructive measurement of internal quality in pear using genetic algorithms and FT-NIR spectroscopy," Journal of Food Engineering, vol. 84, no. 2, pp. 206213, 2008.

[57] A. Pissard, J. A. Fernández Pierna, V. Baeten et al., "Nondestructive measurement of vitamin $\mathrm{C}$, total polyphenol and sugar content in apples using near-infrared spectroscopy," Journal of the Science of Food and Agriculture, vol. 93, no. 2, pp. 238-244, 2013.

[58] M. Tanaka and T. Kojima, "Near-infrared monitoring of the growth period of Japanese pear fruit based on constituent sugar concentrations," Journal of Agricultural and Food Chemistry, vol. 44, no. 8, pp. 2272-2277, 1996.

[59] P. Sirisomboon, M. Tanaka, T. Kojima, and P. Williams, "Nondestructive estimation of maturity and textural properties on tomato "Momotaro" by nearinfrared spectroscopy," Journal of Food Engineering, vol. 112, no. 3, pp. 218-226, 2012.

[60] J. Xing, D. Guyer, D. Ariana, and R. Lu, "Determining optimal wavebands using genetic algorithm for detection of internal insect infestation in tart cherry," Sensing and Instrumentation for Food Quality and Safety, vol. 2, no. 3, pp. 161-167, 2008.

[61] M. Kim, A. Lefcourt, K. Chao, Y. Chen, I. Kim, and D. Chan, "Multispectral detection of fecal contamination on apples based on hyperspectral imagery: part I application of visible and nearinfrared reflectance imaging," Transactions of the ASABE, vol. 45, no. 6, pp. 2027-2037, 2002.

[62] M. Kim, A. Lefcourt, Y. Chen, I. Kim, D. Chan, and K. Chao, "Multispectral detection of fecal contamination on apples based on hyperspectral imagery: part II application of hyperspectral fluorescence imaging," Transactions of the American Society of Agricultural Engineers, vol. 45, no. 6, pp. 2039-2047, 2002.

[63] E. A. Veraverbeke, J. Lammertyn, B. M. Nicolaï, and J. Irudayaraj, "Spectroscopic evaluation of the surface quality of apple," Journal of Agricultural and Food Chemistry, vol. 53, no. 4, pp. 1046-1051, 2005.

[64] J. A. Fernández Pierna, P. Vermeulen, O. Amand, A. Tossens, P. Dardenne, and V. Baeten, "NIR hyperspectral imaging spectroscopy and chemometrics for the detection of undesirable substances in food and feed," Chemometrics and Intelligent Laboratory Systems, vol. 117, pp. 233-239, 2012.

[65] K. U. Flores Rojas, Determinación no destructiva de parámetros de calidad de frutas y hortalizas mediante espectroscopía de reflectancia en el infrarrojo cercano [doctoral thesis], Universidad de Córdoba, Córdoba, Spain, 2009.

[66] J. Sugiyama, "Visualization of sugar content in the flesh of a melon by near-infrared imaging," Journal of Agricultural and Food Chemistry, vol. 47, no. 7, pp. 2715-2718, 1999.

[67] M. Tsuta, J. Sugiyama, and Y. Sagara, "Near-infrared imaging spectroscopy based on sugar absorption band for melons," Journal of Agricultural and Food Chemistry, vol. 50, no. 1, pp. 48-52, 2002.

[68] A. M. K. Pedro and M. M. C. Ferreira, "Nondestructive determination of solids and carotenoids in tomato products by near-infrared spectroscopy and multivariate calibration," Analytical Chemistry, vol. 77, no. 8, pp. 2505-2511, 2005.
[69] F. Liu, Y. He, and G. Sun, "Determination of protein content of Auricularia auricula using near infrared spectroscopy combined with linear and nonlinear calibrations," Journal of Agricultural and Food Chemistry, vol. 57, no. 11, pp. 4520-4527, 2009.

[70] C. Van Dijk, M. Fischer, J. Holm, J. Beekhuizen, T. Tolle-Smits, and C. Boeriu, "Texture of cooked potatoes (Solanum tuberosum). 1. Relationships between dry matter content, sensoryperceived texture, and near-infrared spectroscopy," Journal of Agricultural and Food Chemistry, vol. 50, no. 18, pp. 5082-5088, 2002.

[71] A. Dacal-Nieto, E. Vázquez-Fernández, A. Formella, F. Martin, S. Torres-Guijarro, and H. González-Jorge, "A genetic algorithm approach for feature selection in potatoes classification by computer vision," in Proceedings of the 35th Annual Conference of the IEEE Industrial Electronics Society (IECON '09), pp. 19551960, November 2009.

[72] Y. Roggo, L. Duponchel, and J. Huvenne, "Quality evaluation of sugar beet (Beta vulgaris) by near-infrared spectroscopy," Journal of Agricultural and Food Chemistry, vol. 52, no. 5, pp. 1055-1061, 2004.

[73] S. R. Delwiche, L. O. Pordesimo, A. M. Scaboo, and V. R. Pantalone, "Measurement of inorganic phosphorus in soybeans with near-infrared spectroscopy," Journal of Agricultural and Food Chemistry, vol. 54, no. 19, pp. 6951-6956, 2006.

[74] I. V. Kovalenko, G. R. Rippke, and C. R. Hurburgh Jr., "Determination of amino acid composition of soybeans (Glycine max) by near-infrared spectroscopy," Journal of Agricultural and Food Chemistry, vol. 54, no. 10, pp. 3485-3491, 2006.

[75] D. L. Pazdernik, S. J. Plehn, J. L. Halgerson, and J. H. Orf, "Effect of temperature and genotype on the crude glycinin fraction (11s) of soybean and its analysis by near-infrared reflectance spectroscopy (near-IRS)," Journal of Agricultural and Food Chemistry, vol. 44, no. 8, pp. 2278-2281, 1996.

[76] D. L. Pazdernik, A. S. Killam, and J. H. Orf, "Analysis of amino and fatty acid composition in soybean seed, using near infrared reflectance spectroscopy," Agronomy Journal, vol. 89, no. 4, pp. 679-685, 1997.

[77] K. Hollung, M. Øverland, M. Hrustić et al., "Evaluation of nonstarch polysaccharides and oligosaccharide content of different soybean varieties (Glycine max) by near-infrared spectroscopy and proteomics," Journal of Agricultural and Food Chemistry, vol. 53, no. 23, pp. 9112-9121, 2005.

[78] D. T. Lamb and C. R. Hurburgh Jr., "Moisture determination in single soybean seeds by near-infrared transmittance," Transactions of the American Society of Agricultural Engineers, vol. 34, no. 5, pp. 2123-2129, 1991.

[79] J. O. Bennett, A. H. Krishnan, W. J. Wiebold, and H. B. Krishnan, "Positional effect on protein and oil content and composition of soybeans," Journal of Agricultural and Food Chemistry, vol. 51, no. 23, pp. 6882-6886, 2003.

[80] J. O. Bennett, O. Yu, L. G. Heatherly, and H. B. Krishnan, "Accumulation of genistein and daidzein, soybean isoflavones implicated in promoting human health, is significantly elevated by irrigation," Journal of Agricultural and Food Chemistry, vol. 52, no. 25, pp. 7574-7579, 2004.

[81] C. Esquerre, A. A. Gowen, C. P. O’donnell, and G. Downey, "Initial studies on the quantitation of bruise damage and freshness in mushrooms using visible-near-infrared spectroscopy," Journal of Agricultural and Food Chemistry, vol. 57, no. 5, pp. 1903-1907, 2009. 
[82] S. Li, X. Zhu, J. Zhang, G. Li, D. Su, and Y. Shan, "Authentication of pure camellia oil by using near infrared spectroscopy and pattern recognition techniques," Journal of Food Science, vol. 77, no. 4, pp. C374-C380, 2012.

[83] J. Siska and C. R. Hurburgh Jr., "Corn density measurement by near-infrared transmittance," Transactions of the American Society of Agricultural Engineers, vol. 38, no. 6, pp. 1821-1824, 1995.

[84] A. A. Gowen, C. P. O’Donnell, M. Taghizadeh, P. J. Cullen, J. M. Frias, and G. Downey, "Hyperspectral imaging combined with principal component analysis for bruise damage detection on white mushrooms (Agaricus bisporus)," Journal of Chemometrics, vol. 22, no. 3-4, pp. 259-267, 2008.

[85] T. C. Pearson and D. T. Wicklow, "Detection of corn kernels infected by fungi," Transactions of the ASABE, vol. 49, no. 4, pp. 1235-1245, 2006.

[86] S. H. Gordon, B. C. Wheeler, R. B. Schudy, D. T. Wicklow, and R. V. Greene, "Neural network pattern recognition of photoacoustic FTIR spectra and knowledge-based techniques for detection of mycotoxigenic fungi in food grains," Journal of Food Protection, vol. 61, no. 2, pp. 221-230, 1998.

[87] N. Berardo, V. Pisacane, P. Battilani, A. Scandolara, A. Pietri, and A. Marocco, "Rapid detection of kernel rots and mycotoxins in maize by near-infrared reflectance spectroscopy," Journal of Agricultural and Food Chemistry, vol. 53, no. 21, pp. 8128-8134, 2005.

[88] J. Jin, L. Tang, Z. Hruska, and H. Yao, "Classification of toxigenic and atoxigenic strains of Aspergillus flavus with hyperspectral imaging," Computers and Electronics in Agriculture, vol. 69, no. 2, pp. 158-164, 2009.

[89] F. E. Dowell, S. E. Ram, and L. M. Seitz, "Predicting scab, vomitoxin, and ergosterol in single wheat kernels using nearinfrared spectroscopy," Cereal Chemistry, vol. 76, no. 4, pp. 573$576,1999$.

[90] C. Miralbés, "Prediction chemical composition and alveograph parameters on wheat by near-infrared transmittance spectroscopy," Journal of Agricultural and Food Chemistry, vol. 51, no. 21, pp. 6335-6339, 2003.

[91] N. Yang and G. Ren, "Application of near-infrared reflectance spectroscopy to the evaluation of rutin and D-chiro-inositol contents in tartary buckwheat," Journal of Agricultural and Food Chemistry, vol. 56, no. 3, pp. 761-764, 2008.

[92] O. V. Brenna and N. Berardo, "Application of near-infrared reflectance spectroscopy (NIRS) to the evaluation of carotenoids content in maize," Journal of Agricultural and Food Chemistry, vol. 52, no. 18, pp. 5577-5582, 2004.

[93] S. Kawamura, M. Natsuga, and K. Itoh, "Determination of undried rough rice constituent content using near-infrared transmission spectroscopy," Transactions of the American Society of Agricultural Engineers, vol. 42, no. 3, pp. 813-818, 1999.

[94] C. Zhang, Y. Shen, J. Chen, P. Xiao, and J. Bao, "Nondestructive prediction of total phenolics, flavonoid contents, and antioxidant capacity of rice grain using near-infrared spectroscopy," Journal of Agricultural and Food Chemistry, vol. 56, no. 18, pp. 8268-8272, 2008.

[95] T. L. Stubbs, A. C. Kennedy, and A. Fortuna, "Using NIRS to predict fiber and nutrient content of Dryland cereal cultivars," Journal of Agricultural and Food Chemistry, vol. 58, no. 1, pp. 398-403, 2010.

[96] P. R. Wiley, G. J. Tanner, P. M. Chandler, and R. S. Anderssen, "Molecular classification of barley (Hordeum vulgare
L.) mutants using derivative NIR spectroscopy," Journal of Agricultural and Food Chemistry, vol. 57, no. 10, pp. 4042-4050, 2009.

[97] G. Fox and M. Manley, "Hardness methods for testing maize kernels," Journal of Agricultural and Food Chemistry, vol. 57, no. 13, pp. 5647-5657, 2009.

[98] M. Manley, P. Williams, D. Nilsson, and P. Geladi, "Near infrared hyperspectral imaging for the evaluation of endosperm texture in whole yellow maize (Zea maize L.) Kernels," Journal of Agricultural and Food Chemistry, vol. 57, no. 19, pp. 8761-8769, 2009.

[99] S. Kawamura, M. Natsuga, and K. Itoh, "Visual and nearinfrared reflectance spectroscopy for rice taste evaluation," Transactions of the American Society of Agricultural Engineers, vol. 40, no. 6, pp. 1755-1759, 1997.

[100] F. Davrieux, F. Allal, G. Piombo et al., "Near infrared spectroscopy for high-throughput characterization of shea tree (Vitellaria paradoxa) nut fat profiles," Journal of Agricultural and Food Chemistry, vol. 58, no. 13, pp. 7811-7819, 2010.

[101] R. Font, M. del Río, J. M. Fernández-Martínez, and A. de HaroBailón, "Use of near-infrared spectroscopy for screening the individual and total glucosinolate contents in indian mustard seed (Brassica juncea L. Czern. \& Coss.)," vol. 52, no. 11, pp. 3563-3569, 2004.

[102] R. Font, M. del Río, J. M. Fernández, and A. de Haro, "Acid detergent fiber analysis in oilseed brassicas by near-infrared spectroscopy," Journal of Agricultural and Food Chemistry, vol. 51, no. 10, pp. 2917-2922, 2003.

[103] S. Kim, H. Park, and G. Choung, "Nondestructive determination of oil content and fatty acid composition in perilla seeds by near-infrared spectroscopy," Journal of Agricultural and Food Chemistry, vol. 55, no. 5, pp. 1679-1685, 2007.

[104] G. Hacisalihoglu, B. Larbi, and Mark Settles, "Near-infrared reflectance spectroscopy predicts protein, starch, and seed weight in intact seeds of common bean (Phaseolus vulgaris L.)," Journal of Agricultural and Food Chemistry, vol. 58, no. 2, pp. 702-706, 2010.

[105] L. Wang, Q. Wang, H. Liu, L. Liu, and Y. Du, "Determining the contents of protein and amino acids in peanuts using nearinfrared reflectance spectroscopy," Journal of the Science of Food and Agriculture, vol. 93, no. 1, pp. 118-124, 2013.

[106] L. Yang and Q. Sun, "Recognition of the hardness of licorice seeds using a semi-supervised learning method and nearinfrared spectral data," Chemometrics and Intelligent Laboratory Systems, vol. 114, pp. 109-115, 2012.

[107] G. Downey, R. Briandet, R. H. Wilson, and E. K. Kemsley, "Near- and mid-infrared spectroscopies in food authentication: coffee varietal identification," Journal of Agricultural and Food Chemistry, vol. 45, no. 11, pp. 4357-4361, 1997.

[108] G. Downey, P. McIntyre, and A. N. Davies, "Detecting and quantifying sunflower oil adulteration in extra virgin olive oils from the Eastern Mediterranean by visible and near-infrared spectroscopy," Journal of Agricultural and Food Chemistry, vol. 50, no. 20, pp. 5520-5525, 2002.

[109] T. Woodcock, G. Downey, and C. P. O’Donnell, "Confirmation of declared provenance of European extra virgin olive oil samples by NIR spectroscopy," Journal of Agricultural and Food Chemistry, vol. 56, no. 23, pp. 11520-11525, 2008.

[110] L. D. Gautz, P. Kaufusi, M. C. Jackson, H. C. Bittenbender, and C. Tang, "Determination of kavalactones in dried kava (Piper methysticum) powder using near-infrared reflectance 
spectroscopy and partial least-squares regression," Journal of Agricultural and Food Chemistry, vol. 54, no. 17, pp. 6147-6152, 2006.

[111] A. Zalacain, S. A. Ordoudi, E. M. Díaz-Plaza et al., "Nearinfrared spectroscopy in saffron quality control: determination of chemical composition and geographical origin," Journal of Agricultural and Food Chemistry, vol. 53, no. 24, pp. 9337-9341, 2005.

[112] K. Tanaka, Y. Kuba, T. Sasaki, F. Hiwatashi, and K. Komatsu, "Quantitation of curcuminoids in curcuma rhizome by nearinfrared spectroscopic analysis," Journal of Agricultural and Food Chemistry, vol. 56, no. 19, pp. 8787-8792, 2008.

[113] G. Ren and F. Chen, "Simultaneous quantification of ginsenosides in American ginseng (Panax quinquefolium) root powder by visible/near-infrared reflectance spectroscopy," Journal of Agricultural and Food Chemistry, vol. 47, no. 7, pp. 2771-2775, 1999.

[114] S. Kim, H. Park, and G. Choung, "Nondestructive determination of lignans and lignan glycosides in sesame seeds by near infrared reflectance spectroscopy," Journal of Agricultural and Food Chemistry, vol. 54, no. 13, pp. 4544-4550, 2006.

[115] N. Xin, X. Gu, H. Wu, Y. Hu, and Z. Yang, "Discrimination of raw and processed Dipsacus asperoides by near infrared spectroscopy combined with least squares-support vector machine and random forests," Spectrochimica Acta-Part A, vol. 89, pp. 18-24, 2012.

[116] K. Horváth, Z. Seregély, É. Andrássy, I. Dalmadi, and J. Farkas, "A preliminary study using near infrared spectroscopy to evaluate freshness and detect spoilage in sliced pork meat," Acta Alimentaria, vol. 37, no. 1, pp. 93-102, 2008.

[117] D. I. Ellis, D. Broadhurst, D. B. Kell, J. J. Rowland, and R. Goodacre, "Rapid and quantitative detection of the microbial spoilage of meat by fourier transform infrared spectroscopy and machine learning," Applied and Environmental Microbiology, vol. 68, no. 6, pp. 2822-2828, 2002.

[118] W. R. Windham, D. P. Smith, B. Park, K. C. Lawrence, and P. W. Feldner, "Algorithm development with visible/near-infrared spectra for detection of poultry feces and ingesta," Transactions of the American Society of Agricultural Engineers, vol. 46, no. 6, pp. 1733-1738, 2003.

[119] H. L. A. Tarr, "Flavor of flesh foods," Advances in Chemistry, vol. 56, pp. 190-202, 1969.

[120] C. E. Byrne, G. Downey, D. J. Troy, and D. J. Buckley, "Nondestructive prediction of selected quality attributes of beef by near-infrared reflectance spectroscopy between 750 and 1098 nm," Meat Science, vol. 49, no. 4, pp. 399-409, 1998.

[121] S. Andrés, I. Murray, E. A. Navajas, A. V. Fisher, N. R. Lambe, and L. Bünger, "Prediction of sensory characteristics of lamb meat samples by near infrared reflectance spectroscopy," Meat Science, vol. 76, no. 3, pp. 509-516, 2007.

[122] M. Renerre and R. Labas, "Biochemical factors influencing metmyoglobin formation in beef muscles," Meat Science, vol. 19, no. 2, pp. 151-165, 1987.

[123] M. Renerre, "Factors involved in the discoloration of beef meat," International Journal of Food Science and Technology, vol. 25, no. 6, pp. 613-630, 1990.

[124] A. H. A. Van den Oord and J. J. Wesdorp, "Colour rating and pigment composition of beef: relation between colour measurement by reflectance spectrophotometry, subjective colour evaluation, and the relative concentration of oxymyoglobin and ferric myoglobin in chilled retail-packed beef," Journal of Food Technology, vol. 6, no. 1, pp. 15-20, 1971.
[125] B. Leroy, S. Lambotte, O. Dotreppe, H. Lecocq, L. Istasse, and A. Clinquart, "Prediction of technological and organoleptic properties of beef Longissimus thoracis from near-infrared reflectance and transmission spectra," Meat Science, vol. 66, no. 1, pp. 45-54, 2004.

[126] S. D. Shackelford, T. L. Wheeler, and M. Koohmaraie, "On-line classification of US Select beef carcasses for longissimus tenderness using visible and near-infrared reflectance spectroscopy," Meat Science, vol. 69, no. 3, pp. 409-415, 2005.

[127] D. Cozzolino, N. Barlocco, A. Vadell, F. Ballesteros, and G. Gallieta, "The use of visible and near-infrared reflectance spectroscopy to predict colour on both intact and homogenised pork muscle," LWT-Food Science and Technology, vol. 36, no. 2, pp. 195-202, 2003.

[128] S. Andrés, A. Silva, S. L. Soares-Pereira, C. Martins, A. M. Bruno-Soares, and L. Murray, "The use of visible and near infrared reflectance spectroscopy to predict beef M. longissimus thoracis et lumborum quality attributes," Meat Science, vol. 78, no. 3, pp. 217-224, 2008.

[129] J. D. Wood, M. Enser, A. V. Fisher et al., "Fat deposition, fatty acid composition and meat quality: a review," Meat Science, vol. 78, no. 4, pp. 343-358, 2008.

[130] N. Prieto, M. E. R. Dugan, O. López-Campos, T. A. McAllister, J. L. Aalhus, and B. Uttaro, "Near infrared reflectance spectroscopy predicts the content of polyunsaturated fatty acids and biohydrogenation products in the subcutaneous fat of beef cows fed flaxseed," Meat Science, vol. 90, no. 1, pp. 43-51, 2012.

[131] J. R. Anderson, C. Borggaard, A. J. Rasmussen, and L. P. Houmoller, "Optical measurements of $\mathrm{pH}$ in meat," Meat Science, vol. 53, no. 2, pp. 135-141, 1999.

[132] B. Savenije, G. H. Geesink, J. G. P. van der Palen, and G. Hemke, "Prediction of pork quality using visible near infrared reflectance spectroscopy," Meat Science, vol. 73, no. 1, pp. 181184, 2006.

[133] Y. Liao, Y. Fan, and F. Cheng, "On-line prediction of fresh pork quality using visible/near-infrared reflectance spectroscopy," Meat Science, vol. 86, no. 4, pp. 901-907, 2010.

[134] E. Tornberg, M. Wahlgren, J. Brøndum, and S. B. Engelsen, "Pre-rigor conditions in beef under varying temperature- and $\mathrm{pH}$-falls studied with rigometer, NMR and NIR," Food Chemistry, vol. 69, no. 4, pp. 407-418, 2000.

[135] D. E. Chan, P. N. Walker, and E. W. Mills, "Prediction of pork quality characteristics using visible and near-infrared spectroscopy," Transactions of the ASAE, vol. 45, no. 5, pp. 15191527, 2002.

[136] V. Sierra, N. Aldai, P. Castro, P. Osoro, A. Coto-Montes, and M. Oliván, "Prediction of the fatty acid composition of beef by near infrared transmittance spectroscopy," Meat Science, vol. 78, no. 3, pp. 248-255, 2008.

[137] M. Prevolnik, M. Candek-Potokar, D. Skorjanc et al., "Predicting intramuscular fat content in pork and beef by near infrared spectroscopy," Journal of Near Infrared Spectroscopy, vol. 13, no. 2, pp. 77-85, 2005.

[138] N. Barlocco, A. Vadell, F. Ballesteros, G. Galietta, and D. Cozzolino, "Predicting intramuscular fat, moisture and WarnerBratzler shear force in pork muscle using near infrared reflectance spectroscopy," Animal Science, vol. 82, no. 1, pp. 111116,2006

[139] J. Hong and K. Yasumoto, "Near-infrared spectroscopic analysis of heme and nonheme iron in raw meats," Journal of Food Composition and Analysis, vol. 9, no. 2, pp. 127-134, 1996. 
[140] N. Prieto, S. Andrés, F. J. Giráldez, A. R. Mantecón, and P. Lavín, "Potential use of near infrared reflectance spectroscopy (NIRS) for the estimation of chemical composition of oxen meat samples," Meat Science, vol. 74, no. 3, pp. 487-496, 2006.

[141] D. Pérez-Marín, E. De Pedro Sanz, J. E. Guerrero-Ginel, and A. Garrido-Varo, "A feasibility study on the use of near-infrared spectroscopy for prediction of the fatty acid profile in live Iberian pigs and carcasses," Meat Science, vol. 83, no. 4, pp. 627633, 2009.

[142] E. De Pedro, N. Núñez, J. García et al., "Implementing near infrared spectroscopy in the Iberian pig industry," OPtions Méditerranéennes, Series A, no. 76, pp. 225-227, 2007.

[143] J. García-Olmo, A. Garrido, and E. De Pedro, "Methodological aspects on near infrared analysis of Iberian pig fat using interactance-reflectance fiber optic mode," Journal of Near Infrared Spectroscopy, vol. 6, no. 1-4, pp. A307-A312, 1998.

[144] I. González-Martín, C. González-Pérez, J. Hernández-Méndez, and N. Álvarez-García, "Determination of fatty acids in the subcutaneous fat of Iberian breed swine by near infrared spectroscopy (NIRS) with a fibre-optic probe," Meat Science, vol. 65, no. 2, pp. 713-719, 2003.

[145] H. J. Swatland, On-Line Evaluation of Meat, Technomic Publishing, Lancaster, UK, 1995.

[146] D. Cozzolino, I. Murray, J. R. Scaife, and R. Paterson, "Study of dissected lamb muscles by visible and near infrared reflectance spectroscopy for composition assessment," Animal Science, vol. 70, no. 3, pp. 417-423, 2000.

[147] R. A. Lawri, Meat Science, Pergamon Press, Oxford, UK, 1985.

[148] M. Mitsumoto, S. Maeda, T. Mitsuhashi, and S. Ozawa, "Nearinfrared spectroscopy determination of physical and chemical characteristics in beef cuts," Journal of Food Science, vol. 56, no. 6, pp. 1493-1496, 1991.

[149] D. T. Delpy and M. Cope, "Quantification in tissue near-infrared spectroscopy," Philosophical Transactions of the Royal Society B, vol. 352, no. 1354, pp. 649-659, 1997.

[150] D. Cozzolino and I. Murray, "Effect of sample presentation and animal muscle species on the analysis of meat by near infrared reflectance spectroscopy," Journal of Near Infrared Spectroscopy, vol. 10, no. 1, pp. 37-44, 2002.

[151] I. Murray, "The NIR spectra of homologous series of organic compounds," in Proceedings of the International NIR/NIT Conference, Budapest, Hungary, 1986.

[152] G. Downey, J. McElhinney, and T. Fearn, "Species identification in selected raw homogenized meats by reflectance spectroscopy in the mid-infrared, near-infrared, and visible ranges," Applied Spectroscopy, vol. 54, no. 6, pp. 894-899, 2000.

[153] D. Lomiwes, M. M. Reis, E. Wiklund, O. A. Young, and M. North, "Near infrared spectroscopy as an on-line method to quantitatively determine glycogen and predict ultimate $\mathrm{pH}$ in pre rigor bovine M. longissimus dorsi," Meat Science, vol. 86, no. 4, pp. 999-1004, 2010.

[154] N. Prieto, S. Andrés, F. J. Giráldez, A. R. Mantecón, and P. Lavín, "Discrimination of adult steers (oxen) and young cattle ground meat samples by near infrared reflectance spectroscopy (NIRS)," Meat Science, vol. 79, no. 1, pp. 198-201, 2008.

[155] J. W. S. Yancey, J. K. Apple, J. F. Meullenet, and J. T. Sawyer, "Consumer responses for tenderness and overall impression can be predicted by visible and near-infrared spectroscopy, Meullenet-Owens razor shear, and Warner-Bratzler shear force," Meat Science, vol. 85, no. 3, pp. 487-492, 2010.
[156] B. Park, Y. R. Chen, W. R. Hruschka, S. D. Shackelford, and M. Koohmaraie, "Near-infrared reflectance analysis for predicting beef longissimus tenderness," Journal of Animal Science, vol. 76, no. 8, pp. 2115-2120, 1998.

[157] R. Rødbotten, Prediction of beef tenderness by NIR spectroscopy, and examination of the influence of ante- and post-mortem factors on tenderness [Ph.D. thesis], Agricultural University of Norway, Bergen, Norway, 2001.

[158] C. Venel, A. M. Mullen, G. Downey, and Troy, "Prediction of tenderness and other quality attributes of beef by near infrared reflectance spectroscopy between 750 and $1100 \mathrm{~nm}$; further studies," Journal of Near Infrared Spectroscopy, vol. 9, no. 3, pp. 185-198, 2001.

[159] N. Prieto, D. W. Ross, E. A. Navajas et al., "On-line application of visible and near infrared reflectance spectroscopy to predict chemical-physical and sensory characteristics of beef quality," Meat Science, vol. 83, no. 1, pp. 96-103, 2009.

[160] G. H. Geesink, F. H. Schreutelkamp, R. Frankhuizen et al., "Prediction of pork quality attributes from near infrared reflectance spectra," Meat Science, vol. 65, no. 1, pp. 661-668, 2003.

[161] R. J. Winger and C. J. Hagyard, "Juiciness-its importance and some contributing factors," in Quality Attributes and Their Measurement in Meat, Poultry and Fish Products, A. M. Pearson and T. R. Dutson, Eds., vol. 9 of Advances in Meat Research, chapter 4, pp. 94-124, Aspen Publisher, Frederick, Md, USA, 1994.

[162] K. I. Hildrum, B. N. Nilsen, M. Mielnik, and T. Næs, "Prediction of sensory characteristics of beef by near-infrared spectroscopy," Meat Science, vol. 38, no. 1, pp. 67-80, 1994.

[163] K. I. Hildrum, T. Isaksson, T. T. Naes, B. N. Nilsen, M. Rodbotten, and P. Lea, "Near infrared reflectance spectroscopy in the prediction of sensory properties of beef," Journal of Near Infrared Spectroscopy, vol. 3, no. 2, pp. 81-87, 1995.

[164] T. Næs and K. I. Hildrum, "Comparison of multivariate calibration and discriminant analysis in evaluating NIR spectroscopy for determination of meat tenderness," Applied Spectroscopy, vol. 51, no. 3, pp. 350-357, 1997.

[165] S. D. Shackelford, T. L. Wheeler, and M. Koohmaraie, "Development of optimal protocol for visible and near-infrared reflectance spectroscopic evaluation of meat quality," Meat Science, vol. 68, no. 3, pp. 371-381, 2004.

[166] D. Cozzolino, I. Murray, and R. Paterson, "Visible and near infrared reflectance spectroscopy for the determination of moisture, fat and protein in chicken breast and thigh muscle," Journal of Near Infrared Spectroscopy, vol. 4, no. 1-4, pp. 213223, 1996.

[167] D. Cozzolino, D. De Mattos, and D. Vaz Martins, "Visible/near infrared reflectance spectroscopy for predicting composition and tracing system of production of beef muscle," Animal Science, vol. 74, no. 3, pp. 477-484, 2002.

[168] P. H. M. Dian, D. Andueza, M. Jestin, I. N. Prado, and S. Prache, "Comparison of visible and near infrared reflectance spectroscopy to discriminate between pasture-fed and concentratefed lamb carcasses," Meat Science, vol. 80, no. 4, pp. 1157-1164, 2008.

[169] P. H. M. Dian, D. Andueza, C. M. P. Barbosa, S. Amoureux, M. Jestin, and P. C. F. Carvalho, "Methodological developments in the use of visible reflectance spectroscopy for discriminating pasture-fed from concentrate-fed lamb carcasses," Animal, vol. 1, no. 8, pp. 1198-1208, 2007.

[170] D. Cozzolino and I. Murray, "Identification of animal meat muscles by visible and near infrared reflectance spectroscopy," 
Lebensmittel-Wissenschaft und-Technologie, vol. 37, no. 4, pp. 447-452, 2004.

[171] H. B. Ding and R. J. Xu, "Differentiation of beef and kangaroo meat by visible/near-infrared reflectance spectroscopy," Journal of Food Science, vol. 64, no. 5, pp. 814-817, 1999.

[172] M. Prevolnik, M. Čandek-Potokar, M. Novič, and D. Škorjanc, "An attempt to predict pork drip loss from $\mathrm{pH}$ and colour measurements or near infrared spectra using artificial neural networks," Meat Science, vol. 83, no. 3, pp. 405-411, 2009.

[173] G. Downey and D. Beauchêne, "Discrimination between fresh and frozen-then-thawed beef $m$. longissimus dorsi by combined visible-near infrared reflectance spectroscopy: a feasibility study," Meat Science, vol. 45, no. 3, pp. 353-363, 1997.

[174] K. Thyholt and T. Isaksson, "Differentiation of frozen and unfrozen beef using near-infrared spectroscopy," Journal of the Science of Food and Agriculture, vol. 73, no. 4, pp. 525-532, 1997.

[175] N. S. Hobson, I. Tothill, and A. P. Turner, "Microbial detection," Biosensors and Bioelectronics, vol. 11, no. 5, pp. 455-477, 1996.

[176] M. Kawasaki, S. Kawamura, H. Nakatsuji, and M. Natsuga, "Online real-time monitoring of milk quality during milking by near infrared spectroscopy," in ASABE Meeting Presentation, 2005.

[177] H. M. Al-Qadiri, M. Lin, M. A. Al-Holy, A. G. Cavinato, and B. A. Rasco, "Monitoring quality loss of pasteurized skim milk using visible and short wavelength near-infrared spectroscopy and multivariate analysis," Journal of Dairy Science, vol. 91, no. 3, pp. 950-958, 2008.

[178] R. Karoui and J. De Baerdemaeker, "A review of the analytical methods coupled with chemometric tools for the determination of the quality and identity of dairy products," Food Chemistry, vol. 102, no. 3, pp. 621-640, 2007.

[179] M. Laporte and P. Paquin, "Near-infrared analysis of fat, protein, and casein in cow's milk," Journal of Agricultural and Food Chemistry, vol. 47, no. 7, pp. 2600-2605, 1999.

[180] S. Šašić and Y. Ozaki, "Short-wave near-infrared spectroscopy of biological fluids. 1. Quantitative analysis of fat, protein, and lactose in raw milk by partial least-squares regression and band assignment," Analytical Chemistry, vol. 73, no. 1, pp. 64-71, 2001.

[181] T. Sato, S. Kawano, and M. Iwamoto, "Detection of foreign fat adulteration of milk by near infrared spectroscopic method," Journal of Dairy Science, vol. 73, no. 12, pp. 3408-3413, 1990.

[182] Y. R. Chen, R. W. Huffman, B. Park, and M. Nguyen, "Transportable spectrophotometer system for on-line classification of poultry carcasses," Applied Spectroscopy, vol. 50, no. 7, pp. 910916, 1996.

[183] H. Chen and B. P. Marks, "Evaluating previous thermal treatment of chicken patties by visible/near-infrared spectroscopy," Journal of Food Science, vol. 62, no. 4, pp. 753-780, 1997.

[184] H. Chen and B. P. Marks, "Visible/near-infrared spectroscopy for physical characteristics of cooked chicken patties," Journal of Food Science, vol. 63, no. 2, pp. 279-282, 1998.

[185] Y. R. Chen, B. Park, R. W. Huffman, and M. Nguyen, "Classification of on-line poultry carcasses with backpropagation neural networks," Journal of Food Process Engineering, vol. 21, no. 1, pp. 33-48, 1998.

[186] J. McElhinney, G. Downey, and T. Fearn, "Chemometric processing of visible and near infrared reflectance spectra for species identification in selected raw homogenised meats," Journal of Near Infrared Spectroscopy, vol. 7, no. 3, pp. 145-154, 1999.
[187] H. Rannou and G. Downey, "Discrimination of raw pork, chicken and turkey meat by spectroscopy in the visible, nearand mid-infrared ranges," Analytical Communications, vol. 34, no. 12, pp. 401-404, 1997.

[188] B. Park, S. Yoon, W. R. Windham, K. C. Lawrence, M. S. Kim, and K. Chao, "Line-scan hyperspectral imaging for real-time in-line poultry fecal detection," Sensing and Instrumentation for Food Quality and Safety, vol. 5, no. 1, pp. 25-32, 2011.

[189] H. Ding, R.-J. Xu, and D. K. O. Chan, "Identification of broiler chicken meat using a visible/near-infrared spectroscopic technique," Journal of the Science of Food and Agriculture, vol. 79, no. 11, pp. 1382-1388, 1999.

[190] M. Lin, M. Al-Holy, M. Mousavi-Hesary, H. Al-Qadiri, A. G. Cavinato, and B. A. Rasco, "Rapid and quantitative detection of the microbial spoilage in chicken meat by diffuse reflectance spectroscopy (600-1100 nm)," Letters in Applied Microbiology, vol. 39, no. 2, pp. 148-155, 2004.

[191] Y. Liu and Y. Chen, “Two-dimensional correlation spectroscopy study of visible and near-infrared spectral variations of chicken meats in cold storage," Applied Spectroscopy, vol. 54, no. 10, pp. 1458-1470, 2000.

[192] Y. Liu, F. E. Barton II, B. G. Lyon, W. R. Windham, and C. E. Lyon, "Two-dimensional correlation analysis of visible/nearinfrared spectral intensity variations of chicken breasts with various chilled and frozen storages," Journal of Agricultural and Food Chemistry, vol. 52, no. 3, pp. 505-510, 2004.

[193] Y. Liu, Y. Chen, and Y. Ozaki, “Two-dimensional visible/nearinfrared correlation spectroscopy study of thermal treatment of chicken meats," Journal of Agricultural and Food Chemistry, vol. 48, no. 3, pp. 901-908, 2000.

[194] S. K. Stormo, A. H. Sivertsen, K. Heia, and D. Skipnes, "Endpoint temperature of heat-treated surimi can be measured by visible spectroscopy," Food Control, vol. 26, no. 1, pp. 92-97, 2012.

[195] S. H. Olsen, Quantification and characterisation of residual blood in fish muscle-impact of slaughtering methods [Ph.D. thesis], University of Tromsø UIT, Tromsø, Norway, 2011.

[196] S. H. Olsen, N. K. Sørensen, R. Larsen, E. O. Elvevoll, and H. Nilsen, "Impact of pre-slaughter stress on residual blood in fillet portions of farmed Atlantic cod (Gadus morhua)-measured chemically and by Visible and Near-infrared spectroscopy," Aquaculture, vol. 284, no. 1-4, pp. 90-97, 2008.

[197] D. Cozzolino, A. Chree, J. R. Scaife, and I. Murray, "Usefulness of Near-infrared reflectance (NIR) spectroscopy and chemometrics to discriminate fishmeal batches made with different fish species," Journal of Agricultural and Food Chemistry, vol. 53, no. 11, pp. 4459-4463, 2005.

[198] M. Uddin, E. Okazaki, S. Turza, Y. Yumiko, M. Tanaka, and Y. Fukuda, "Non-destructive visible/NIR spectroscopy for differentiation of fresh and frozen-thawed fish," Journal of Food Science, vol. 70, no. 8, pp. C506-C510, 2005.

[199] N. Bøknaes, K. N. Jensen, C. M. Andersen, and H. Martens, "Freshness assessment of thawed and chilled cod fillets packed in modified atmosphere using near-infrared spectroscopy," Lebensmittel-Wissenschaft und-Technologie, vol. 35, no. 7, pp. 628-634, 2002.

[200] H. Nilsen, M. Esaiassen, K. Heia, and F. Sigernes, "Visible/nearinfrared spectroscopy: a new tool for the evaluation of fish freshness?" Journal of Food Science, vol. 67, no. 5, pp. 1821-1826, 2002. 
[201] G. Olafsdottir, P. Nesvadba, C. Di Natale et al., "Multisensor for fish quality determination," Trends in Food Science and Technology, vol. 15, no. 2, pp. 86-93, 2004.

[202] M. Lin, M. Mousavi, M. Al-Holy, A. G. Cavinato, and B. A. Rasco, "Rapid near infrared spectroscopic method for the detection of spoilage in rainbow trout (Oncorhynchus mykiss) fillet," Journal of Food Science, vol. 71, no. 1, pp. S18-S23, 2006.

[203] H. Zhang and T. Lee, "Rapid near-infrared spectroscopic method for the determination of free fatty acid in fish and its application in fish quality assessment," Journal of Agricultural and Food Chemistry, vol. 45, no. 9, pp. 3515-3521, 1997.

[204] B. Gjerde and H. Martens, "Predicting carcass composition of rainbow trout by near-infrared reflectance spectroscopy," Journal of Animal Breeding and Genetics, vol. 104, pp. 137-148, 1987.

[205] J. Shimamoto, K. Hasegawa, S. Hattori, Y. Hattori, and T. Mizuno, "Non-destructive determination of the fat content in glazed bigeye tuna by portable near infrared spectrophotometer," Fisheries Science, vol. 69, no. 6, pp. 1247-1256, 2003.

[206] J. Shimamoto, K. Hasegawa, K. Ide, and S. Kawano, "Nondestractive determination of the fat content in raw and frozen horse mackerel by near infrared spectroscopy," Nippon Suisan Gakkaishi, vol. 67, no. 4, pp. 717-722, 2001.

[207] S. Yamauchi, T. Sawada, and S. Kawano, "Nondestructive determination of fat content in frozen skipjack by near infrared (NIR) spectroscopy with fiber optics in interactance mode," Nippon Suisan Gakkaishi, vol. 65, no. 4, pp. 747-752, 1999.

[208] J. Shimamoto, S. Hiratsuka, K. Hasegawa, M. Sato, and S. Kawano, "Rapid non-destructive determination of fat content in frozen skipjack using a portable near infrared spectrophotometer," Fisheries Science, vol. 69, no. 4, pp. 856-860, 2003.

[209] J. A. Mathias, P. C. Williams, and D. C. Sobering, "The determination of lipid and protein in freshwater fish using nearinfrared reflectance spectroscopy," Aquaculture, vol. 61, no. 3-4, pp. 303-311, 1987.

[210] M. H. Lee, A. G. Cavinato, D. M. Mayes, and B. A. Rasco, "Noninvasive short-wavelength near-infrared spectroscopic method to estimate the crude lipid content in the muscle of intact rainbow trout," Journal of Agricultural and Food Chemistry, vol. 40, no. 11, pp. 2176-2180, 1992.

[211] M. Lin, A. G. Cavinato, D. M. Mayes et al., "Bruise detection in Pacific pink salmon (Oncorhynchus gorbuscha) by visible and short-wavelength near-infrared (SW-NIR) spectroscopy (600$1100 \mathrm{~nm}$ )," Journal of Agricultural and Food Chemistry, vol. 51, no. 22, pp. 6404-6408, 2003.

[212] R. Font, M. Del Río-Celestino, D. Vélez, A. De Haro-Bailón, and R. Montoro, "Visible and near-infrared spectroscopy as a technique for screening the inorganic arsenic content in the red crayfish (Procambarus clarkii Girard)," Analytical Chemistry, vol. 76, no. 14, pp. 3893-3898, 2004.

[213] J. Gayo and S. A. Hale, "Detection and quantification of species authenticity and adulteration in crabmeat using visible and near-infrared spectroscopy," Journal of Agricultural and Food Chemistry, vol. 55, no. 3, pp. 585-592, 2007.

[214] J. Gayo, S. A. Hale, and S. M. Blanchard, "Quantitative analysis and detection of adulteration in crab meat using visible and near-infrared spectroscopy," Journal of Agricultural and Food Chemistry, vol. 54, no. 4, pp. 1130-1136, 2006.

[215] M. R. Brown, "Rapid compositional analysis of oysters using visible-near infrared reflectance spectroscopy," Aquaculture, vol. 317, no. 1-4, pp. 233-239, 2011.
[216] V. Lebot, A. Champagne, R. Malapa, and D. Shiley, "NIR determination of major constituents in tropical root and tuber crop flours," Journal of Agricultural and Food Chemistry, vol. 57, no. 22, pp. 10539-10547, 2009.

[217] A. Dacal-Nieto, A. Formella, P. Carrión, E. Vazquez-Fernandez, and M. Fernández-Delgado, "Non-destructive detection of hollow heart in potatoes using hyperspectral imaging," in Computer Analysis of Images and Patterns: 14th International Conference (CAIP '11), P. Real, D. Díaz-Pernil, H. Molina-Abril, A. Berciano, and W. Kropatsch, Eds., vol. 6855 of Lecture Notes in Computer Science, pp. 180-187.

[218] E. Joubert, M. Manley, and M. Botha, "Use of NIRS for quantification of mangiferin and hesperidin contents of dried green honeybush (Cyclopia genistoides) plant material," Journal of Agricultural and Food Chemistry, vol. 54, no. 15, pp. 52795283, 2006.

[219] S. Bellato, V. Del Frate, R. Redaelli et al., "Use of near infrared reflectance and transmittance coupled to robust calibration for the evaluation of nutritional value in naked oats," Journal of Agricultural and Food Chemistry, vol. 59, no. 9, pp. 4349-4360, 2011.

[220] L. R. Schimleck, J. C. Doran, and A. Rimbawanto, "Near infrared spectroscopy for cost effective screening of foliar oil characteristics in a Melaleuca cajuputi breeding population," Journal of Agricultural and Food Chemistry, vol. 51, no. 9, pp. 2433-2437, 2003.

[221] E. Joubert, M. Manley, B. R. Gray, and H. Schulz, "Rapid measurement and evaluation of the effect of drying conditions on harpagoside content in Harpagophytum procumbens (devil's claw) root," Journal of Agricultural and Food Chemistry, vol. 53, no. 9, pp. 3493-3502, 2005.

[222] H. Schulz, U. H. Engelhardt, A. Wegent, H. Drews, and S. Lapczynski, "Application of near-infrared reflectance spectroscopy to the simultaneous prediction of alkaloids and phenolic substances in green tea leaves," Journal of Agricultural and Food Chemistry, vol. 47, no. 12, pp. 5064-5067, 1999.

[223] J. M. Hernández-Hierro, J. Valverde, S. Villacreces et al., "Feasibility study on the use of visible-near-infrared spectroscopy for the screening of individual and total glucosinolate contents in broccoli," Journal of Agricultural and Food Chemistry, vol. 60, no. 30, pp. 7352-7358, 2012.

[224] M. Laasonen, T. Harmia-Pulkkinen, C. L. Simard, E. Michiels, M. Räsänen, and H. Vuorela, "Fast identification of Echinacea purpurea dried roots using near-infrared spectroscopy," Analytical Chemistry, vol. 74, no. 11, pp. 2493-2499, 2002.

[225] W. Li, P. Goovaerts, and M. Meurens, "Quantitative analysis of individual sugars and acids in orange juices by near-infrared spectroscopy of dry extract," Journal of Agricultural and Food Chemistry, vol. 44, no. 8, pp. 2252-2259, 1996.

[226] Y. C. Chen, H. Zhang, and R. Matsunaga, "Rapid determination of the main organic acid composition of raw Japanese apricot fruit juices using near-infrared spectroscopy," Journal of Agricultural and Food Chemistry, vol. 54, no. 26, pp. 9652-9657, 2006.

[227] J. M. González-Sáiz, C. Pizarro, I. Esteban-Díez et al., "Monitoring of alcoholic fermentation of onion juice by NIR spectroscopy: valorization of worthless onions," Journal of Agricultural and Food Chemistry, vol. 55, no. 8, pp. 2930-2936, 2007.

[228] H. Cen, Y. He, and M. Huang, "Measurement of soluble solids contents and $\mathrm{pH}$ in orange juice using chemometrics and Vis-NIRS," Journal of Agricultural and Food Chemistry, vol. 54, no. 20, pp. 7437-7443, 2006. 
[229] F. Liu and Y. He, "Use of visible and near infrared spectroscopy and least squares-support vector machine to determine soluble solids content and $\mathrm{pH}$ of cola beverage," Journal of Agricultural and Food Chemistry, vol. 55, no. 22, pp. 8883-8888, 2007.

[230] C. L. Ng, R. L. Wehling, and S. L. Cuppett, "Method for determining frying oil degradation by near-infrared spectroscopy," Journal of Agricultural and Food Chemistry, vol. 55, no. 3, pp. 593-597, 2007.

[231] D. Cozzolino, R. G. Dambergs, L. Janik, W. U. Cynkar, and M. Gishen, "Analysis of grapes and wine by near infrared spectroscopy," Journal of Near Infrared Spectroscopy, vol. 14, no. 5, pp. 279-289, 2006.

[232] X. Chen and X. Lei, "Application of a hybrid variable selection method for determination of carbohydrate content in soy milk powder using visible and near infrared spectroscopy," Journal of Agricultural and Food Chemistry, vol. 57, no. 2, pp. 334-340, 2009.

[233] R. G. Dambergs, A. Kambouris, L. Francis, and M. Gishen, "Rapid analysis of methanol in grape-derived distillation products using near-infrared transmission spectroscopy," Journal of Agricultural and Food Chemistry, vol. 50, no. 11, pp. 3079-3084, 2002.

[234] M.-J. Sáiz-Abajo, J.-M. González-Sáiz, and C. Pizarro, “Classification of wine and alcohol vinegar samples based on nearinfrared spectroscopy. Feasibility study on the detection of adulterated vinegar samples," Journal of Agricultural and Food Chemistry, vol. 52, no. 25, pp. 7711-7719, 2004.

[235] M. J. Sáiz-Abajo, J. M. González-Sáiz, and C. Pizarro, "Prediction of organic acids and other quality parameters of wine vinegar by near-infrared spectroscopy. A feasibility study," Food Chemistry, vol. 99, no. 3, pp. 615-621, 2006.

[236] W. Fan, Y. Shan, G. Li, H. Lv, H. Li, and Y. Liang, "Application of competitive adaptive reweighted sampling method to determine effective wavelengths for prediction of total acid of vinegar," Food Analytical Methods, vol. 5, no. 3, pp. 585-590, 2012.

[237] S. W. Bruun, Protein-lipid-carbohydrate interactions and importance to food quality-spectroscopic detection of macromolecular interactions [Ph.D. thesis], Technical University of Denmark, Lyngby, Denmark, 2006.

[238] F. Liu, W. Kong, and Y. He, "Quality determination of fruit vinegars using visible/near infrared spectroscopy and least squares-support vector machine," African Journal of Agricultural Research, vol. 7, no. 15, pp. 2395-2404, 2012.

[239] D. Cozzolino, H. E. Smyth, and M. Gishen, "Feasibility study on the use of visible and near-infrared spectroscopy together with chemometrics to discriminate between commercial white wines of different varietal origins," Journal of Agricultural and Food Chemistry, vol. 51, no. 26, pp. 7703-7708, 2003.

[240] L. Liu, D. Cozzolino, W. U. Cynkar, M. Gishen, and C. B. Colby, "Geographic classification of Spanish and Australian tempranillo red wines by visible and near-infrared spectroscopy combined with multivariate Analysis," Journal of Agricultural and Food Chemistry, vol. 54, no. 18, pp. 6754-6759, 2006.

[241] S. Buratti, D. Ballabio, G. Giovanelli et al., "Monitoring of alcoholic fermentation using near infrared and mid infrared spectroscopies combined with electronic nose and electronic tongue," Analytica Chimica Acta, vol. 697, no. 1-2, pp. 67-74, 2011.

[242] H. Yu, H. Lin, H. Xu, Y. Ying, B. Li, and X. Pan, "Prediction of enological parameters and discrimination of rice wine age using least-squares support vector machines and near infrared spectroscopy," Journal of Agricultural and Food Chemistry, vol. 56, no. 2, pp. 307-313, 2008.

[243] L. L. Vines, S. E. Kays, and P. E. Koehler, "Near-infrared reflectance model for the rapid prediction of total fat in cereal foods," Journal of Agricultural and Food Chemistry, vol. 53, no. 5, pp. 1550-1555, 2005.

[244] Windham, S. E. Kays, and F. E. Barton II, "Effect of cereal product residual moisture content on total dietary fiber determined by near-infrared reflectance spectroscopy," Journal of Agricultural and Food Chemistry, vol. 45, no. 1, pp. 140-144, 1997.

[245] S. E. Kays, Windham, and F. E. Barton II, "Prediction of total dietary fiber in cereal products using near-infrared reflectance spectroscopy," Journal of Agricultural and Food Chemistry, vol. 44, no. 8, pp. 2266-2271, 1996.

[246] S. E. Kays, F. E. Barton II, W. R. Windham, and D. S. Himmelsbach, "Prediction of total dietary fiber by near-infrared reflectance spectroscopy in cereal products containing high sugar and crystalline sugar," Journal of Agricultural and Food Chemistry, vol. 45, no. 10, pp. 3944-3951, 1997.

[247] S. E. Kays, Windham, and F. E. Barton II, "Prediction of total dietary fiber by near-infrared reflectance spectroscopy in high-fat- and high-sugar-containing cereal products," Journal of Agricultural and Food Chemistry, vol. 46, no. 3, pp. 854-861, 1998.

[248] S. E. Kays and F. E. Barton II, "Rapid prediction of gross energy, and utilizable energy in cereal food products using nearinfrared reflectance spectroscopy," Journal of Agricultural and Food Chemistry, vol. 50, no. 5, pp. 1284-1289, 2002.

[249] S. E. Kays and F. E. Barton II, "Near-infrared analysis of soluble and insoluble dietary fiber fractions of cereal food products," Journal of Agricultural and Food Chemistry, vol. 50, no. 10, pp. 3024-3029, 2002.

[250] S. E. Kays and F. E. Barton II, "Energy from fat determined by near-infrared reflectance spectroscopy," Journal of Agricultural and Food Chemistry, vol. 52, no. 6, pp. 1669-1674, 2004.

[251] D. D. Archibald and S. E. Kays, "Determination of total dietary fiber of intact cereal food products by near-infrared reflectance," Journal of Agricultural and Food Chemistry, vol. 48, no. 10, pp. 4477-4486, 2000.

[252] R. M. Ozanich, M. L. Schrattenholzer, and J. B. Callis, "Noninvasive determination of moisture and oil content of wheat-flour cookies-near-infrared spectroscopy in the wavelength range 700-1100 nm," in Biosensor Design and Application, vol. 511 of ACS Symposium Series, chapter 12, pp. 137-164, 1992.

[253] L. F. de Alencar Figueiredo, F. Davrieux, G. Fliedel et al., "Development of NIRS equations for food grain quality traits through exploitation of a core collection of cultivated sorghum," Journal of Agricultural and Food Chemistry, vol. 54, no. 22, pp. 8501-8509, 2006.

[254] S. W. Bruun, I. Søndergaard, and S. Jacobsen, "Analysis of protein structures and interactions in complex food by nearinfrared spectroscopy. 1. Gluten powder," Journal of Agricultural and Food Chemistry, vol. 55, no. 18, pp. 7234-7243, 2007.

[255] S. W. Bruun, I. Søndergaard, and S. Jacobsen, "Analysis of protein structures and interactions in complex food by nearinfrared spectroscopy. 2. Hydrated gluten," Journal of Agricultural and Food Chemistry, vol. 55, no. 18, pp. 7244-7251, 2007.

[256] N. Sinelli, E. Casiraghi, and G. Downey, "Studies on proofing of yeasted bread dough using near- and mid-infrared spectroscopy," Journal of Agricultural and Food Chemistry, vol. 56, no. 3, pp. 922-931, 2008. 
[257] R. M. García-Rey, J. García-Olmo, E. De Pedro, R. Quiles-Zafra, and M. D. Luque de Castro, "Prediction of texture and colour of dry-cured ham by visible and near infrared spectroscopy using a fiber optic probe," Meat Science, vol. 70, no. 2, pp. 357-363, 2005.

[258] A. Lucas, D. Andueza, E. Rock, and B. Martin, "Prediction of dry matter, fat, $\mathrm{pH}$, vitamins, minerals, carotenoids, total antioxidant capacity, and color in fresh and freeze-dried cheeses by visible-near-infrared reflectance spectroscopy," Journal of Agricultural and Food Chemistry, vol. 56, no. 16, pp. 6801-6808, 2008.

[259] E. S. Çelik, Determination of aroma compounds and exopolysaccharides formation by lactic acid bacteria isolated from traditional yogurts [M.S. thesis], İzmir Institute of Technology, İzmir, Turkey, 2007.

[260] M. Navrátil, C. Cimander, and C. Mandenius, "On-line multisensor monitoring of yogurt and filmjölk fermentations on production scale," Journal of Agricultural and Food Chemistry, vol. 52, no. 3, pp. 415-420, 2004.

[261] G. Cozzi, J. Ferlito, G. Pasini, B. Contiero, and F. Gottardo, "Application of near-infrared spectroscopy as an alternative to chemical and color analysis to discriminate the production chains of Asiago d'Allevo cheese," Journal of Agricultural and Food Chemistry, vol. 57, no. 24, pp. 11449-11454, 2009.

[262] J. Blasco, N. Aleixos, J. Gómez, and E. Moltó, "Citrus sorting by identification of the most common defects using multispectral computer vision," Journal of Food Engineering, vol. 83, no. 3, pp. 384-393, 2007.

[263] P. M. Mehl, K. Chao, M. Kim, and Y. R. Chen, "Detection of defects on selected apple cultivars using hyperspectral and multispectral image analysis," Applied Engineering in Agriculture, vol. 18, no. 2, pp. 219-226, 2002.

[264] I. S. Arvanitoyannis and M. Van Houwelingen-Koukaliaroglou, "Implementation of chemometrics for quality control and authentication of meat and meat products," Critical Reviews in Food Science and Nutrition, vol. 43, no. 2, pp. 173-218, 2003.

[265] T. Woodcock, C. C. Fagan, C. P. O’Donnell, and G. Downey, "Application of near and mid-infrared spectroscopy to determine cheese quality and authenticity," Food and Bioprocess Technology, vol. 1, no. 2, pp. 117-129, 2008. 

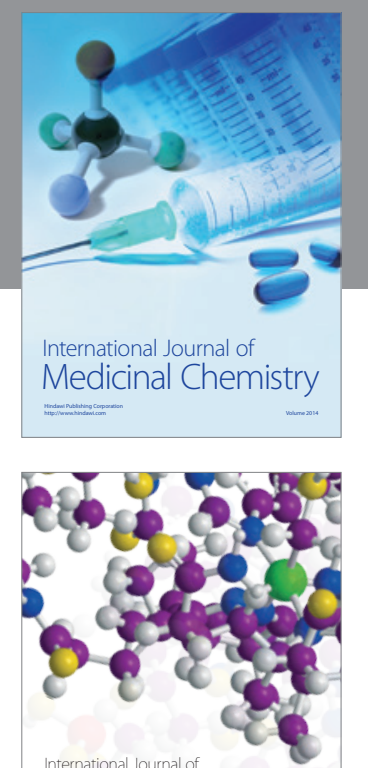

\section{Carbohydrate} Chemistry

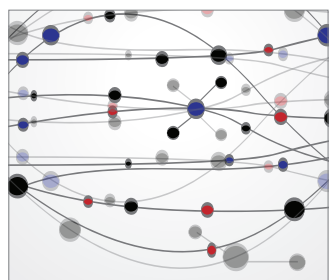

The Scientific World Journal
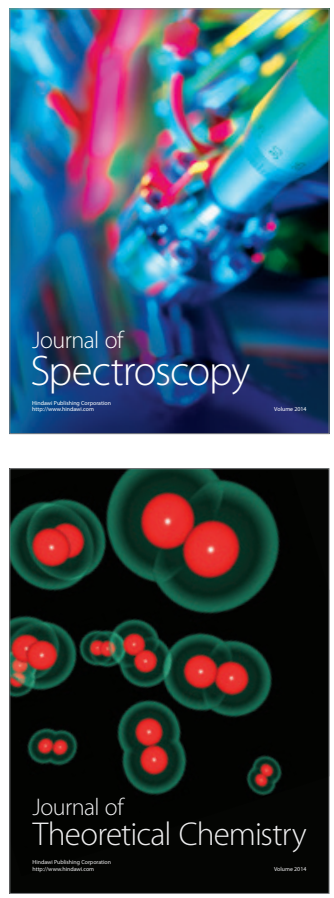
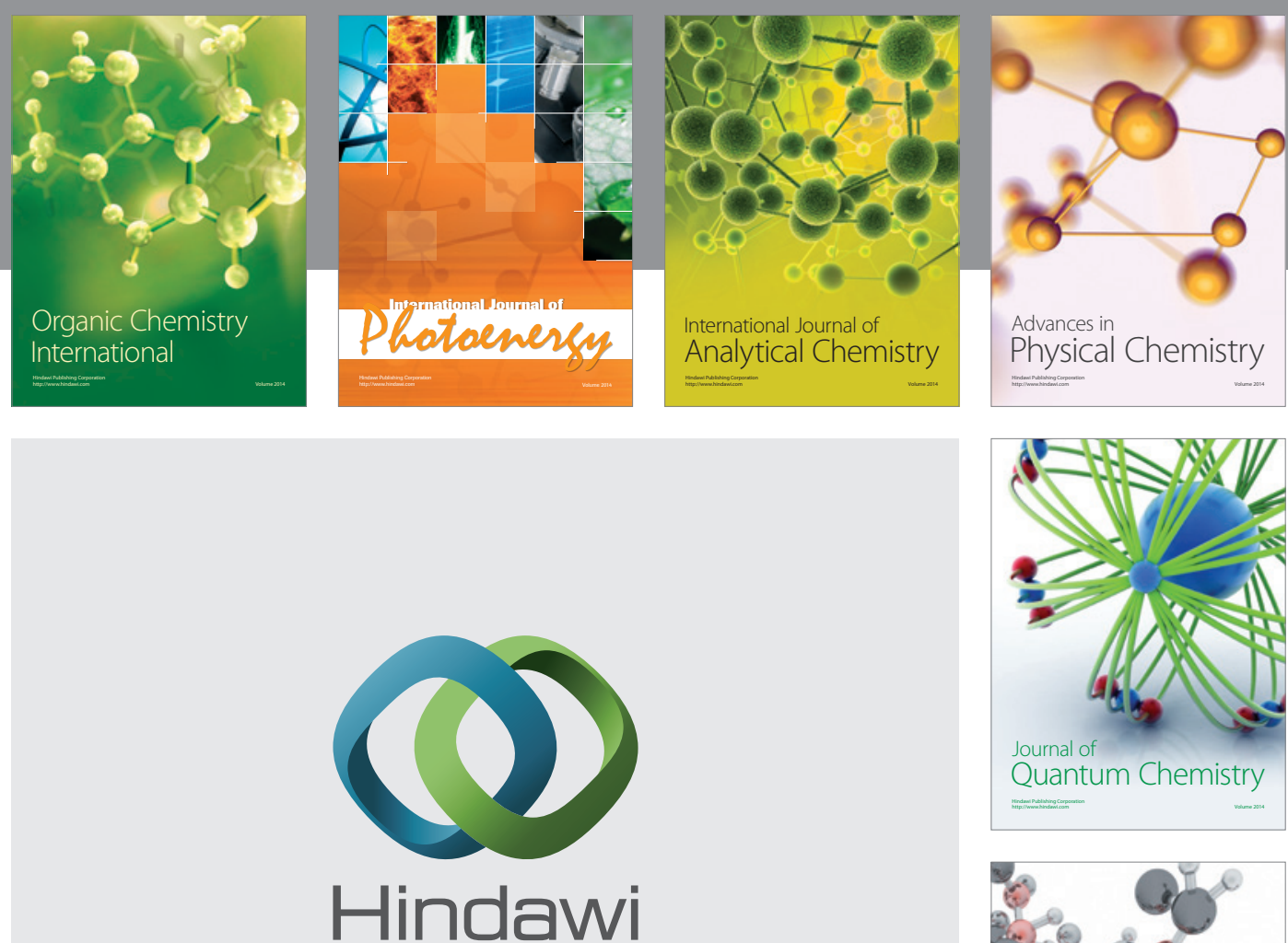

Submit your manuscripts at

http://www.hindawi.com

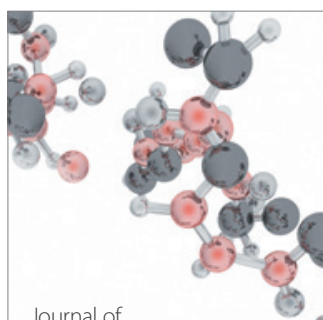

Analytical Methods

in Chemistry

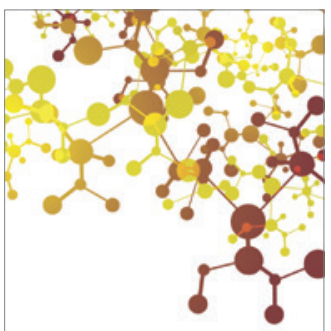

Journal of

Applied Chemistry

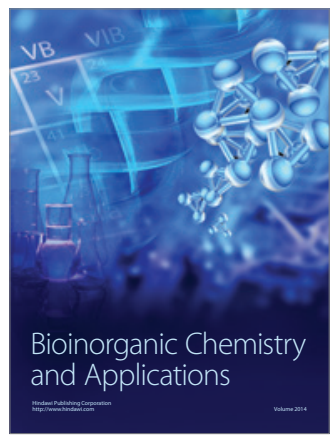

Inorganic Chemistry
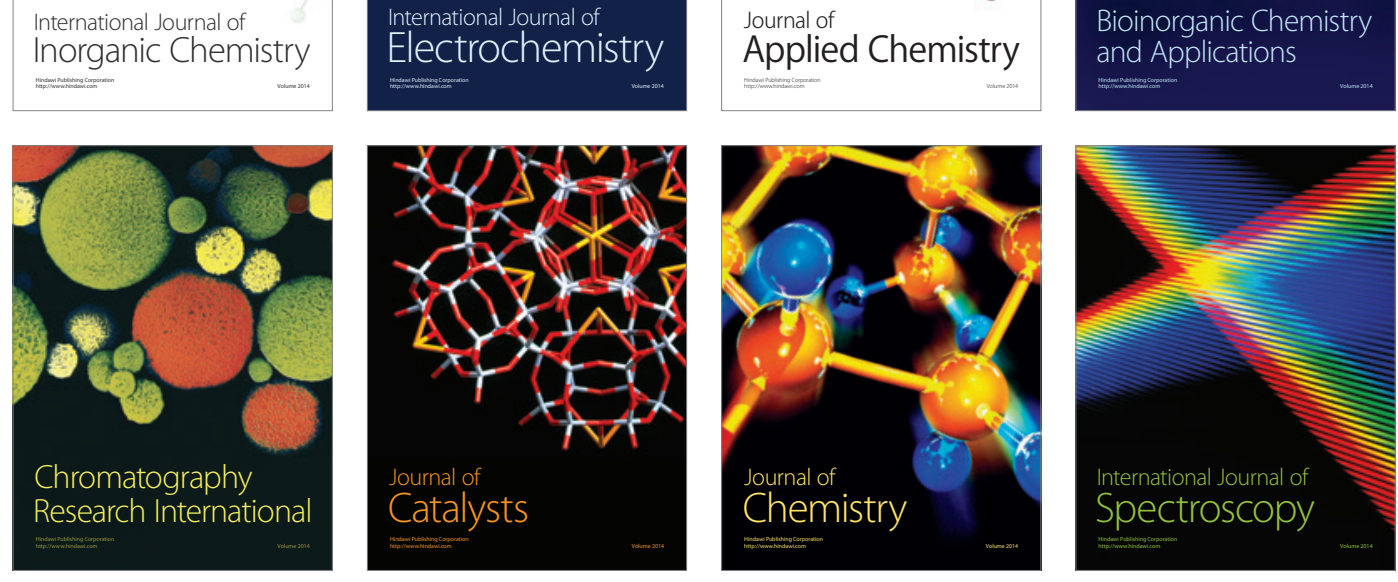